Review

\title{
Self-Assembled Organic Materials for Photovoltaic Application
}

\author{
Tanwistha Ghosh 1,2, Jayanthy S. Panicker ${ }^{1,2}$ and Vijayakumar C. Nair 1,2,* \\ 1 Photosciences and Photonics Section, Council of Scientific and Industrial Research-National Institute for \\ Interdisciplinary Science and Technology (CSIR-NIIST), Trivandrum 695019, India; \\ tanwistha.myrtus@gmail.com (T.G.); jayanthykuttickal@gmail.com (J.S.P.) \\ 2 Academy of Scientific and Innovative Research (AcSIR), New Delhi 110001, India \\ * Correspondence: cvijayakumar@niist.res.in; Tel.: +91-471-251-5484
}

Academic Editors: Laure Biniek and Christian B. Nielsen

Received: 23 January 2017; Accepted: 15 March 2017; Published: 21 March 2017

\begin{abstract}
Organic photovoltaic cells based on bulk-heterojunction architecture have been a topic of intense research for the past two decades. Recent reports on power conversion efficiency surpassing $10 \%$ suggest these devices are a viable low-cost choice for a range of applications where conventional silicon solar cells are not suitable. Further improvements in efficiency could be achieved with the enhanced interaction between the donor and acceptor components. Effective utilization of supramolecular interactions to tailor and manipulate the communication between the components in the blend is a good strategy towards this end. Literature reports suggest that the long-term stability of organic solar cells, a major hurdle for commercial applications, can also be partially addressed by generating stable supramolecular nanostructures. In this review, we have made an attempt to summarize advances in small molecule, oligomer and polymer based systems, wherein supramolecular interactions such as hydrogen-bonding, pi-pi stacking, and dipole-dipole are explored for realizing stable and efficient bulk-heterojunction solar cells.
\end{abstract}

Keywords: self-assembly; organic photovoltaic cells; bulk-heterojunction; donor-acceptor systems; oligomers; polymers

\section{Introduction}

Solar radiation is a prime source of energy and its abundant availability on Earth's surface makes it a perfect candidate for clean and renewable sources of electricity [1-3]. Development in the field of solar energy harvesting will help to reduce the world's dependence on exhaustible, expensive and polluting sources of energy, thereby help countries tackle their manifold energy challenges. Scientists are therefore putting enormous efforts in the field of photovoltaic technology as it can serve as the most high-potential prospect for harnessing solar energy. Silicon solar cells, the first generation solar technology, can convert $25 \%$ of the energy in sunlight to electricity and the second generation cells composed of amorphous silicon, cadmium telluride (CdTe) and copper indium gallium selenide (CIGS) shows typical performance in the range of $\sim 22 \%$ [4-6]. Though both these photovoltaic technologies have good performance and stability, they need highly expensive clean-room technology and require a lot of energy in production [7]. To address these problems, scientists have done intense research in the field of third generation photovoltaics, particularly organic solar cells (OSC) as it has the potential to serve as an alternative to silicon-based cells in terms of cost effectiveness, light weightiness, roll-to-roll fabrication, mechanical flexibility in addition to the use of low-cost solution processing techniques for large area fabrication [8-13]. Most of the current research is focusing toward the development of novel materials with improved efficiencies through molecular engineering [14-18]. Recent reports suggest 
that OSCs have entered the phase of commercialization, although improvements in efficiency and stability are still desirable [19-21].

Organic solar cells consist of organic semiconductors such as small molecules, oligomers and polymers as active photoabsorption layer. The incorporation of both donor and acceptor type semiconductors in the photoabsorption layer is the most common strategy, as it can split excitons more efficiently than single layer photovoltaic cells. This idea started with the phenomenal work by Tang in 1986, where he demonstrated efficient charge separation at the donor-acceptor interface (bilayer architecture), yielding a power conversion efficiency (PCE) of 1\% [22]. It is a well-known fact that the charge carrier recombination has an adverse effect on the efficiency of OSCs. For efficient photoabsorption in a bilayer solar cell, the layers are required to have a thickness of at least $100 \mathrm{~nm}$ but the excitons may not be able to travel more than 10-20 nm before recombination [23]. As a result, most of the excitons generated in bilayer devices do not reach the interface and contribute to the charge carrier generation. Therefore, the PCEs of the bilayer solar cells usually lie in the range of $1.0 \%-1.5 \%[24,25]$ and approach a maximum of $2 \%-5 \%$ in exceptional cases [26-30]. Intermixing of donor and acceptor was proposed as a plausible solution to solve this problem as the thickness of the light absorbing material can be $100 \mathrm{~nm}$ or above but the creation of nanodomains of the order of 10-20 nm facilitates efficient dissociation of the generated excitons to charge carriers (holes and electrons). These charges can travel to the respective electrodes (holes to the anode and electrons to the cathode) through the interpenetrating donor/acceptor network with minimum recombination. This active layer architecture is known as bulk-heterojunction (BHJ), which is schematically shown in Figure 1a. The first prototype of this kind was realized and experimentally verified by Heeger and co-workers in 1992 [31]. The donors used in BHJ solar cells are normally pi-conjugated small molecules, oligomers or polymers and commonly used acceptors are soluble derivatives of fullerene such as phenyl-C61-butyric acid methyl ester ( $\mathrm{PC}_{61} \mathrm{BM}$; Figure $\left.1 \mathrm{~b}\right)$ and phenyl-C71-butyric acid methyl ester ( $\mathrm{PC}_{71} \mathrm{BM}$; Figure 1c). The major requirement of the donor is to have an optical band gap in the visible range of the solar spectrum. Light falling on the active layer is therefore efficiently absorbed by the donor and leads to the generation of highly energetic excitons (ca. $100 \mathrm{MeV}$ ). For the efficient diffusion and dissociation of excitons and the transport of charge carriers, the active layer should have a bicontinuous interpenetrating network of donors and acceptors with a minimum number of defect sites. Rational use of supramolecular interactions is considered as an ideal strategy towards this direction.

(a)

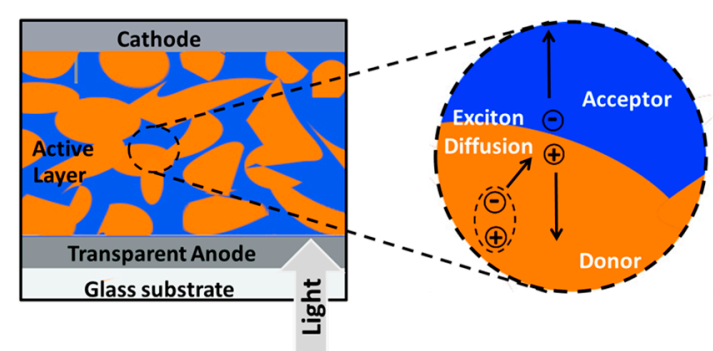

(b)

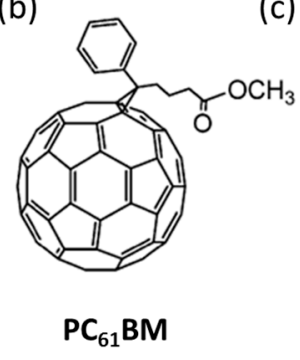

(c)

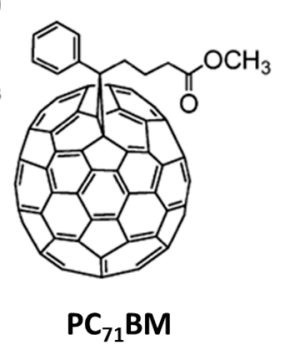

Figure 1. (a) Simplified schematic representation describing the main processes in a bulk-heterojunction solar cell device. The light absorption by the active layer (predominantly donor) generates excitons, which diffuses towards the donor-acceptor interface where they separate into free charge carriers (holes and electrons). Holes move towards anode and electrons move to the cathode. Chemical structures of fullerene-based acceptors (b) $\mathrm{PC}_{61} \mathrm{BM}$ and (c) $\mathrm{PC}_{71} \mathrm{BM}$.

\subsection{Supramolecular Interactions and Self-Assembly}

Supramolecular chemistry, which deals with non-covalent interactions, is one of the frontier fields of chemistry in the 21st century. This area, initially developed by Jean-Marie Lehn, Donald Cram 
and Charles Pedersen, is defined as the "chemistry of molecular assemblies and of the intermolecular interactions" [32]. Contrary to covalent interactions, the sharing of electrons does not take place in supramolecular, but rather involves an electrostatic interaction between molecules or within a molecule. The process by which molecules adopt a defined or ordered arrangement using various non-covalent interactions without the influence from an outside source is called self-assembly. In this process, small components (individual building blocks) join together spontaneously and form large and complex supramolecular assemblies. Major non-covalent forces involved are hydrogen bonding, ion-ion, ion-dipole, dipole-dipole, pi-pi stacking, cation-pi, anion-pi, van der Waals and hydrophobic interactions [33].

\subsubsection{Hydrogen Bonding}

Hydrogen bonding (H-bonding), a weak intermolecular interaction $(4-60 \mathrm{~kJ} / \mathrm{mol})$, was first noted by Nernst in 1892, is an attractive force between the hydrogen attached to an electronegative atom of one molecule and an electron lone pair on another electronegative atom of a different molecule [34]. Such an interaction was little known at that time but later in 1935 its actual mechanism was extricated and the term "hydrogen bond" was proposed by two scientists, Bernal and Huggins. The best use of H-bonding in nature includes the folding of the protein and double helical structure of DNA. Since then, H-bonding interactions have continued to fascinate chemists, biologists, material scientists and theoreticians across the globe.

Hydrogen-bonding is directional in nature and hence the hydrogen-bond donor, the hydrogen atom and the hydrogen-bond acceptor should lie in the same line for obtaining strong bonds. However, the stability of single bonded hydrogen bonding sites limits their direct usage in the non-covalent synthesis of well-defined assemblies. Therefore, different strategies have been adopted to increase the strength, which include the use multiple H-bonding motifs. The stability of multiple H-bonded motifs was studied by Jorgensen and co-workers. The "Jorgensen model" states that the total hydrogen bond should be more stable when all the protons of the H-bond donor-acceptor pairs are arranged in the same direction. On the other hand, the H-bond should be less stable when the protons are arranged alternatively $[35,36]$.

\subsubsection{Ion-Ion Interactions}

As the name suggests, the ion-ion interactions occur between charged atoms or molecules. The strength of ionic bonding is comparable to that of covalent bonds with bond energy approximately $100-350 \mathrm{~kJ} / \mathrm{mol}$. These bonds are harder to break and therefore it is the strongest bond among all supramolecular interactions. However, this interaction can be easily broken with the addition of water or any other polar solvent. The best example of a supramolecular compound with ion-ion interaction is sodium chloride $(\mathrm{NaCl})$. The energy required to break the bond in $\mathrm{NaCl}$ is $188 \mathrm{kcal} / \mathrm{mol}$ as a result of which it has a boiling point of $1413^{\circ} \mathrm{C}$.

\subsubsection{Ion-Dipole Interactions}

Here, the bonding is between an ion and a molecule with a permanent or induced dipole moment, and the energy typically lies between 50 and $200 \mathrm{~kJ} / \mathrm{mol}$. This kind of bonding is observed both in solids as well as in solutions. The interaction between an electrophilic interior of a crown ether and a cation is a typical example of this kind. Co-ordinate bonds are included in this category as these interactions are between nonpolarisable metal cations and hard bases. Two main types of ion-dipole interactions are orientation interaction (ion-permanent dipole) and induction interaction (ion-induced dipole).

\subsubsection{Dipole-Dipole Interactions}

The attraction between the positive and negative ends of two neighboring molecules is termed as dipole-dipole interaction. It mostly involves molecules having a permanent dipole moment. 
These electrostatic interactions induce alignment of the molecules to increase the attraction between assemblies and are considered as a type of van der Waals forces. The dipoles are normally associated with electronegative atoms, such as oxygen, nitrogen, sulfur, and fluorine. The strength of the dipole-dipole interaction depends on (a) magnitude of the interacting dipoles; (b) distance between the centers of the two interacting dipoles; (c) the angle of orientation of two parallel dipoles and (d) the overlap integral between energy states which indirectly satisfies the conservation of momentum and energy. The Debye force or the permanent-induced dipoles interaction is another type interaction comes under the same category, which involves an interaction between molecules with a permanent dipole to another molecule with no permanent dipole. London dispersion forces, the weakest type of non-covalent interaction, are most commonly known as "induced-induced dipoles interaction" and present between all molecules.

\subsubsection{Pi-Pi Stacking Interactions}

The interaction that is frequently observed for stabilizing non-covalent interactions between parallel aromatic rings is "pi-pi stacking". The concept of pi-pi stacking of organic semiconducting materials was first established by Sanders and Hunter in the early 1990s [37]. They have reported the formation of a partial negative quadruple moment above the aromatic planes and a partial positive charge around the periphery due to the pi-electron cloud density on the aromatic rings. They have used a simple mathematical model to qualitatively determine the effect of substituents. According to their model, parallel displaced and sandwich conformations are favored for aromatic rings containing electron-withdrawing groups as they reduce the negative quadruple moment. On the other hand, a T-shaped configuration is preferred for aromatic molecules with electron donating groups. Such an interaction helps to reduce the steric hindrance caused by non-conjugated side chains.

\subsubsection{Cation-Pi Interactions}

Ferrocene and Zeise's salt are typical examples of cation-pi interaction, where transition metal cations such as $\mathrm{Fe}^{2+}$ and $\mathrm{Pt}^{2+}$ form complexes with olefinic and aromatic hydrocarbon. In general, it is a kind of non-covalent bonding between a cation and a quadrupole (pi-system), where the negatively charged region of aromatic ring quadrupole interact favorably with positively charged species (cation). The interaction of alkaline and alkaline earth metal cations with carbon-carbon double bond is one of the most studied cation-pi interaction. Dougherty and co-workers reported an electrostatic model based on differences in electrostatic attraction for describing the trends in binding energy. It was understood that interaction energies of cation-pi pairs correlate well with electrostatic potential above the pi-face of arenes.

\subsubsection{Anion-Pi Interactions}

As the name suggest, it is an attraction between an anion and pi-electron density. Intuitively, it should be repulsive. However, a small charge difference occurs between a neutral aromatic ring and an anion, and in principle, an electrostatic attraction exists between them. This interaction is a reason for the self-assembly reactions of pi-acidic aromatic rings with $\mathrm{Ag}$ (I) complexes. In 2004, the first anion-pi interaction was reported in the crystal structure of carousel copper(II)-triazine complex [38]. Though this kind of interaction is depicted in the solid state, there is evidence that the interaction is present in solution also.

\subsubsection{Van Der Waals Forces}

Van der Waals interaction, named after Dutch physicist, Johannes Diderik van der Waals, is a very weak, short-range electrostatic attraction independent of temperature arises from the polarization of electron cloud by the propinquity of an adjacent nucleus. Due to its non-directional characteristic, the scope of designing specific hosts utilizing van der Waals interaction is limited for the 
selective complexation of a particular guest. The geckos stick on to the wall is an example of van der Waals forces from nature.

\subsubsection{Hydrophobic Interactions}

Hydrophobic interactions mainly occur between non-polar molecules or more specifically hydrocarbons in an aqueous environment. Water is comprised of a three-dimensional network of hydrogen bonds $(\sim 5 \mathrm{kcal} / \mathrm{mol})$ which are dynamic in nature. When non-polar molecules come in the vicinity of hydrophobic surfaces, water molecules will drive them to aggregate. This process can significantly decrease the energetically unfavorable interface. Such hydrophobic interactions are omnipresent in biological systems and are responsible for key natural processes such as protein folding, membrane formation, etc.

It is a well-known fact that the morphology of active layers plays a crucial role in the power conversion efficiency of $\mathrm{BHJ}$ based organic solar cells [39,40]. It influences almost all aspects of the device like charge carrier generation, recombination, mobility and collection efficiency. Therefore, enabling a control over morphology will help in unlocking the vast potential of OSCs into viable technologies. Scientists have made attempts to incorporate the above mentioned supramolecular interactions into organic molecules for solar cell applications to achieve control on morphology via optimized nanodomains resulting in precise bicontinuous donor-acceptor networks and improved stability. The most commonly employed interactions in a solar cell so far are hydrogen bonding, pi-pi stacking, and dipole-dipole. In the following sections, we will discuss those works which have highlighted the self-assembly of donors and/or acceptors using non-covalent forces for solar cell applications. A number of reviews are available in literature discussing various aspects of supramolecular systems for solar cell application [41-44]. Most of the reviews highlight the design principles and strategies for morphology control using supramolecular interactions to get improved efficiency and stability. The present review provides a comprehensive summary of BHJ based solar cell devices consisting of self-assembled supramolecular systems (small molecules, oligomers and polymers). This review is structured around the various intermolecular forces and their effect on device performance. However, we will not be discussing papers on regular pi-conjugated systems used in bulk-heterojunction solar cells having obvious pi-pi stacking interactions. We have taken into account of those works where self-assembly is induced via special molecular design such as the introduction of hydrogen bonding groups, large pi-chromophores, dipolar moieties, etc.

\section{Small Molecules and Oligomers}

Small molecules and oligomers have earned intense scientific interest when compared to that of polymers for solar cell applications over the last few years due to their ease of preparation in high purity, no batch-to-batch variation and well-defined structure [45,46]. Recent reports suggest that the power conversion efficiency has reached above $10 \%$ by adopting $\mathrm{BHJ}$ architecture [47]. Important papers describing the self-assembly of the components of the active layer of a bulk-heterojunction organic solar cell through non-covalent interactions is discussed below.

Early in 2001, Janssen, Meijer and co-workers for the first time synthesized and studied the electronic properties of a hydrogen-bonded pi-conjugated supramolecular system consisting of bifunctional ureido-pyrimidinone appended with oligo( $p$-phenylenevinylene) chromophores (1) as shown in Figure 2 [48]. The authors have also investigated the photovoltaic properties of the self-assembled molecules by mixing with $\mathrm{PC}_{61} \mathrm{BM}$ as an electron acceptor. Spin-coated blend films of $1 / \mathrm{PC}_{61} \mathrm{BM}$ (1:2.8 by weight) showed complete quenching of the phenylenevinylene fluorescence. Fabricated devices with architecture, ITO/PEDOT:PSS/1:PC ${ }_{61} \mathrm{BM} / \mathrm{Al}$, yielded short circuit current of $0.32 \mathrm{~mA} \cdot \mathrm{cm}^{-2}$, open circuit voltage of $0.82 \mathrm{~V}$ and fill factor of 0.39 . The values of short circuit current and open circuit voltage are favorable and comparable to previous reports on solar cells based on pi-conjugated systems in combination with fullerene. This work illustrated that supramolecular 
systems could act as promising materials for photovoltaic devices. This work has also opened up multiple opportunities to the usage of supramolecular architectures in optoelectronic devices.

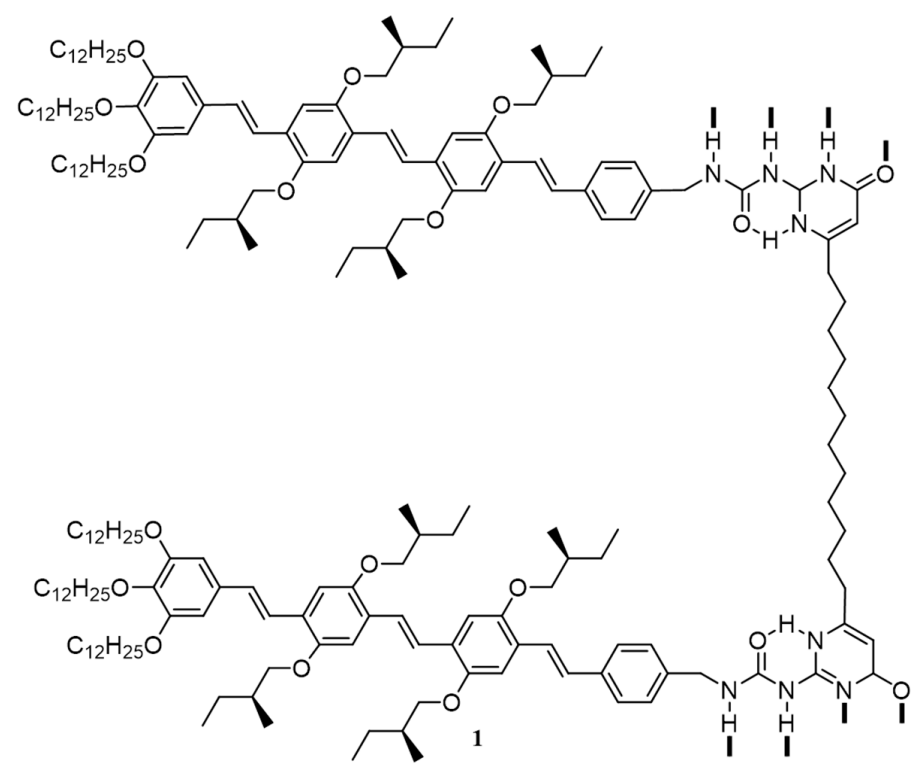

Figure 2. Chemical structure of the bifunctional ureido-pyrimidinone appended with oligo( $p$-phenylenevinylene) chromophores (1) synthesized by Janssen and Meijer et al. [48].

The incorporation of non-self-complementary hydrogen bonding motifs present in melamine/barbituric acid moieties is found to be an excellent tool to control the geometries of electron donors and acceptors. In 2005, Bassani and co-workers had for the first time incorporated molecular recognition motifs based on these moieties into thiophene oligomers using Schiff base formation or the Knoevenagel condensation reactions [49]. They synthesized two oligomers with central ethylenedioxythiophene (EDOT) core and 2,4,5,6-tetraaminopyrimidine (2) or complementary barbituric acid (3) at the ends as shown in Figure 3a. With respect to the parent oligomer (pentathiophene), $\mathbf{2}$ and $\mathbf{3}$ showed better solubility and lower oxidation potential due to the presence of central EDOT unit. Photovoltaic devices were fabricated using 2 as a donor and a complementary fullerene-substituted barbituric acid derivative (4) as an acceptor. The performance of the devices was evaluated in terms of open-circuit voltage conversion efficiency, $\Phi\left(V_{\mathrm{OC}}\right)$, and short-circuit quantum conversion efficiency, $\Phi\left(I_{S C}\right)$. Initially, the oligomer 2 alone was tested for a photovoltaic response and the obtained values of $\Phi\left(V_{\mathrm{OC}}\right)$ and $\Phi\left(I_{\mathrm{SC}}\right)$ were 0.14 and 0.05 , respectively. Atomic force microscopy (AFM) image of the self-assembled film is shown in Figure $3 \mathrm{~b}$. The $I / V$ curve of photocurrent generated vs. applied potential was plotted as given in Figure 3c. Devices were fabricated under identical conditions using 2 ( 1 equiv.) in combination with two equiv. of either pristine $\mathrm{C}_{60}$ or 4 . With reference to oligomer alone, two-fold increments in photocurrent were observed for the combination of $2 / \mathrm{C}_{60}$ and five-fold increment for the combination of $2 / 4$. The better performance of $2 / 4$ device could be attributed to the complementary $\mathrm{H}$-bonding between the active components that granted extended organized domains, which helped in the charge separation and transport.

Use of electron deficient, self-complementary hydrogen-bonding units incorporated as an acceptor in "push-pull" p-type small molecules were proposed as another method to enhance the efficiency of photovoltaic devices. Kumar and co-workers have reported a comparison study of two such donor-acceptor small molecules, 5 [50] and 6 (without and with self-complementary hydrogen-bonding units), as given in Figure 4a [51]. Both molecules possess cyanopyridone moiety as the acceptor motif, where the nitrogen is alkylated with a 2-ethylhexyl substituent in 5, which masks the possibility of self-assembly while it is free or unmasked in the case of 6 . The formation of interconnected nanostructures of 6 was confirmed by AFM and ${ }^{1} \mathrm{H}$ NMR analysis. AFM images of films prepared 
from 1 and $10 \mathrm{mg} / \mathrm{mL}$ chloroform solutions of $\mathbf{6}$ (Figure $4 \mathrm{~b}, \mathrm{c}$ ) revealed the formation of interconnected fibrous nanostructures of $\sim 85-110 \mathrm{~nm}$ in width. The UV-visible absorption spectra of a thin film of 6 show blue-shift of the absorption peak $(30 \mathrm{~nm})$ in comparison with the solution state indicated the formation of $\mathrm{H}$-aggregates. Upon fabrication of $\mathrm{BHJ}$ cells using 1:1 mixture of donor and acceptor $\left(\mathrm{PC}_{61} \mathrm{BM}\right), 6$ gave an efficiency of $2.40 \%$ at a concentration of $10 \mathrm{mg} / \mathrm{mL}$, whereas, 5 yielded an efficiency of $2.25 \%$ at a higher concentration of $20 \mathrm{mg} / \mathrm{mL}$. It was assumed that the hole percolation to the electrodes facilitated by the one-dimensional chains of $\mathbf{6}$ formed through hydrogen bonding created networks, resulting in an increase in PCE.

An example to explain the ability of an amide group to provide hydrogen-bonding and a second driving force for self-assembly beyond pi-pi stacking was emphasized by the research group of Stupp in 2015 [52]. They have synthesized symmetric $(\mathbf{7}, \mathbf{8})$ and asymmetric $(\mathbf{9}, \mathbf{1 0})$ donor molecules (Figure 5a) to study the effect of $\mathrm{H}$-bonding on the active layer morphology. Devices from 7 to 8 were fabricated from chlorobenzene $(\mathrm{CB})$ using $\mathrm{PC}_{71} \mathrm{BM}$ as the acceptor with a blend ratio of 1:1. A poor efficiency value of $1 \%$ was observed for both molecules due to the formation of large aggregates $(\sim 100 \mathrm{~nm})$, which limited the exciton diffusion to the interphase. Interestingly, devices made from asymmetric derivatives were better than the symmetric counterparts; PCE of $\mathbf{9}$ and $\mathbf{1 0}$ were 3.65 and $1.45 \%$, respectively. In addition, the effect of solvent additives such as 1,8-diiodooctane (DIO) and nitrobenzene (NB) on device performance was also studied. The NB addition to 9 gave the best PCE of $4.57 \%$. The performance enhancement upon addition of NB was due to the formation of more interconnected domains, as evident from the transmission electron microscopy (TEM) image (Figure 5b), which resulted in the decrease of shunt resistance and an increase of hole mobility. The pi-pi stacking played no role in $\mathbf{9}$ as confirmed from two-dimensional grazing incidence $\mathrm{X}$-ray diffraction (2D-GIXRD) (Figure 5c) and hence, hydrogen bonding was solely responsible for the improvement in PCE.

(a)
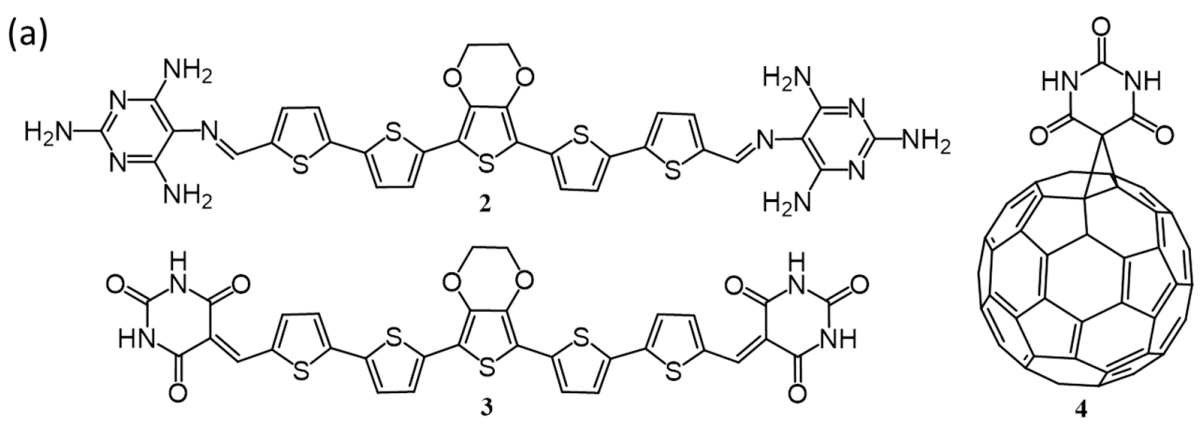

(b)

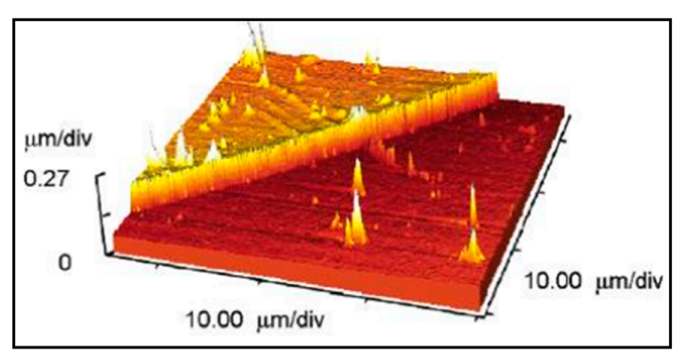

(c)

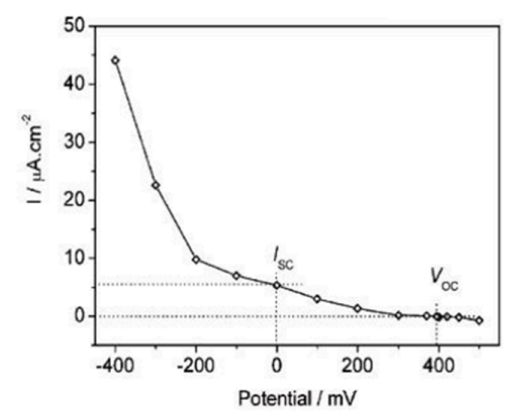

Figure 3. (a) Chemical structures of oligomers (2 and 3) and a complementary fullerene-substituted barbituric acid derivative (4) synthesized by Bassani et al. [49]. (b) Atomic force microscopy (AFM) image of the film of $\mathbf{2}$ prepared from DMSO. (c) $I / V$ curve obtained from a drop-cast film of 2 on Au. Adapted with permission from Ref. [49] Copyright 2005 American Chemical Society. 
(a)
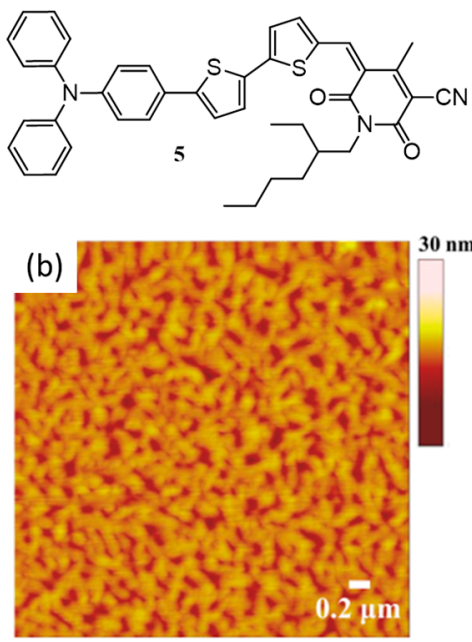
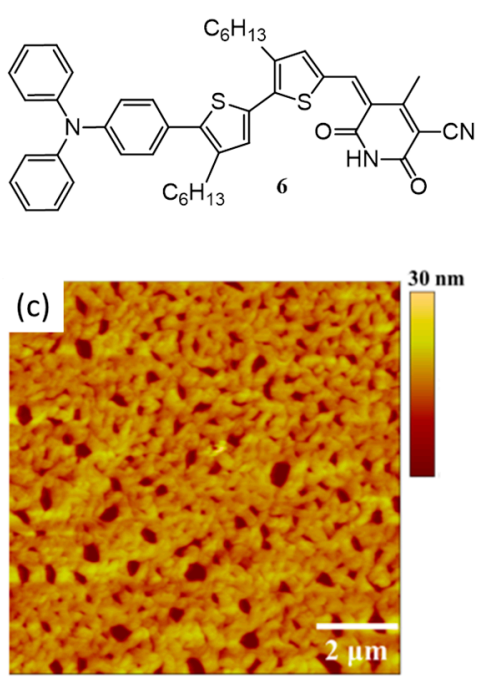

Figure 4. (a) Chemical structures of 5 and $\mathbf{6}$ synthesized by Kumar et al. [51]. AFM height image of observed nanostructures of films drop-cast from (b) $1 \mathrm{mg} / \mathrm{mL}$ and (c) $10 \mathrm{mg} / \mathrm{mL}$ chloroform solution of 6. Adapted from Ref. [51] which is an Open Access article under the terms of the Creative Commons Attribution License (http:/ / creativecommons.org/licenses/by/2.0).

(a)

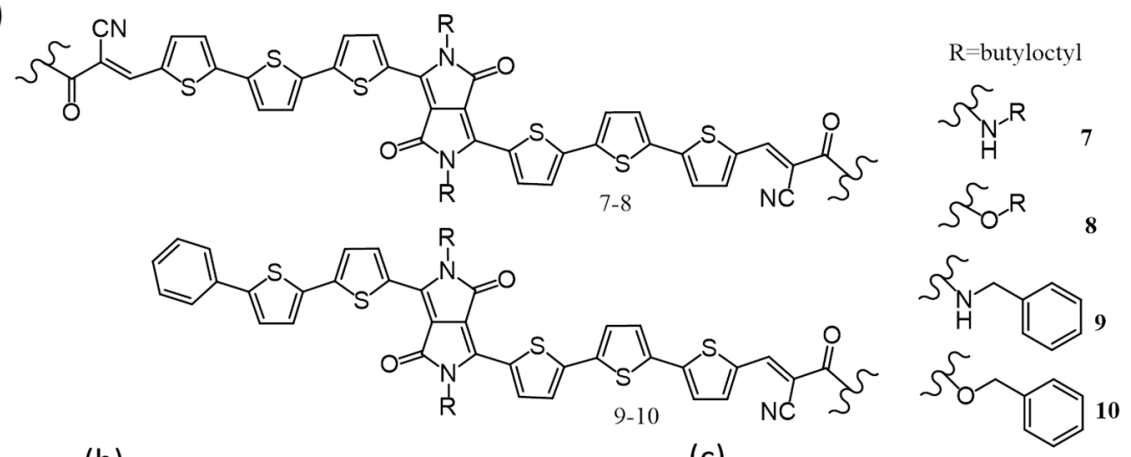

(b)

(c)
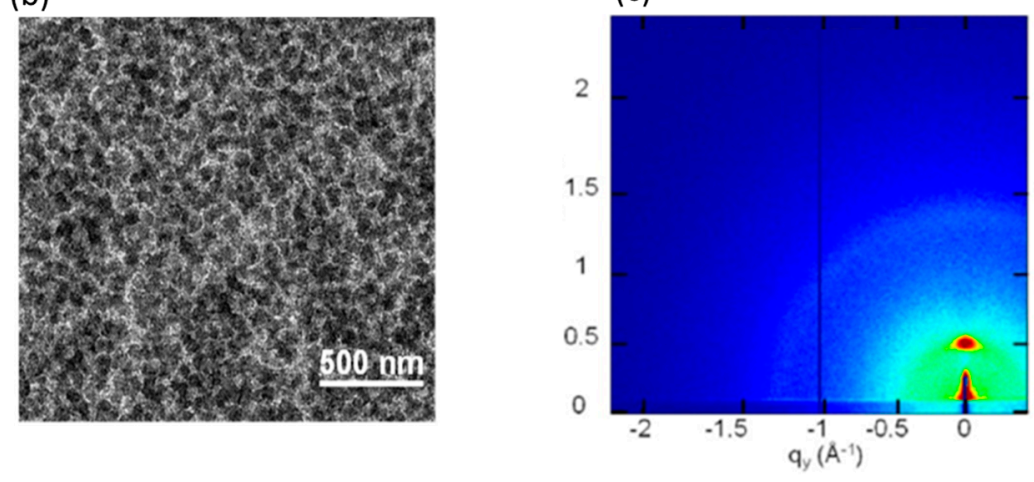

Figure 5. (a) Chemical structures of 7-10 synthesized by Stupp et al. [52]. (b) Transmission electron microscopy (TEM) image of $\mathbf{9} / \mathrm{PC}_{71} \mathrm{BM}$ and (c) two-dimensional grazing incidence $\mathrm{X}$-ray diffraction (2D-GIXRD) of 9 drop-cast from a mixture of CB and NB. Adapted with permission from Ref. [52] Copyright 2015 American Chemical Society.

It was well established that $\mathrm{H}$-bond assisted self-assembly of barbiturate-conjugated pi-systems has the ability to form supramolecular rosettes, which on further stacking form highly ordered nanorods. Utilizing this idea, Yagai et al. in 2014, reported the self-organization and photovoltaic properties of barbiturate-conjugated thienyl-[oligo(hexylthiophene)]s derivatives 
(11-13; Figure 6a) [53]. The STM images of the molecules at the liquid-solid interface of 1-phenyloctane and highly oriented pyrolytic graphite (HOPG) revealed well-resolved two-dimensionally organized rosettes consist of six units aggregated by multiple H-bonds (STM image of $\mathbf{1 3}$ is shown in Figure 6b). The rosettes on further self-assembly through pi-pi stacking results in highly ordered nanorods. As cast $\mathrm{BHJ}$ films consist of the nanorods and $\mathrm{PC}_{61} \mathrm{BM}$ showed PCE of $1.38 \%, 0.97 \%$ and $1.49 \%$ for 11, 12 and 13, respectively. Interestingly, the devices of 12 showed a remarkable improvement of the photovoltaic performance upon increasing the annealing temperature from 50 to $80{ }^{\circ} \mathrm{C}$ (PCE from $0.83 \%$ to $2.1 \%$ ) due to the betterment in the film morphology (Figure $6 \mathrm{~d}$ ) when compared to that of $\mathbf{1 1}$ and 13 (Figure 6c,e, respectively). Further improvement in PCE of $\mathbf{1 2}$ (3.01\%) was achieved by using $\mathrm{PC}_{71} \mathrm{BM}$. To confirm that the design was appropriate, the authors made derivatives with a non-hydrogen bonded reference molecule (14) and derivatives possess long aliphatic chains $(\mathbf{1 5}, \mathbf{1 6})$. The performances of these molecules were far less than that of the other three derivatives.

(a)

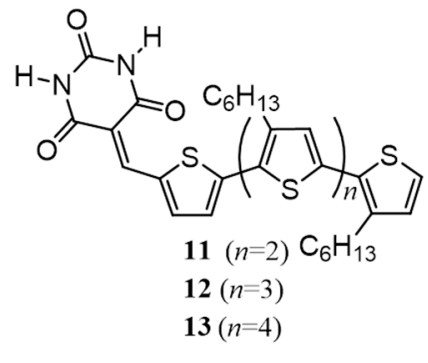<smiles>C=CC(C)(C)C1CC1</smiles>

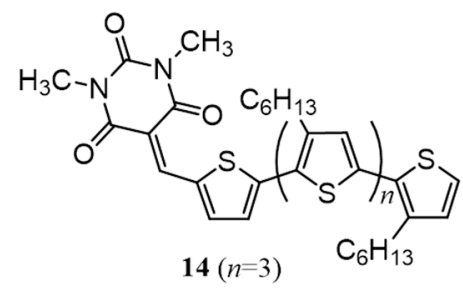

\section{(b)}

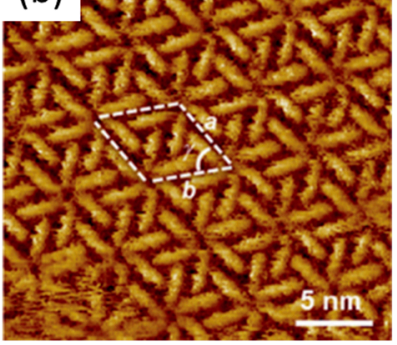

(c)

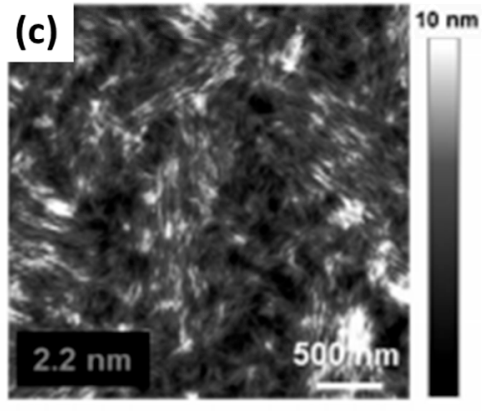

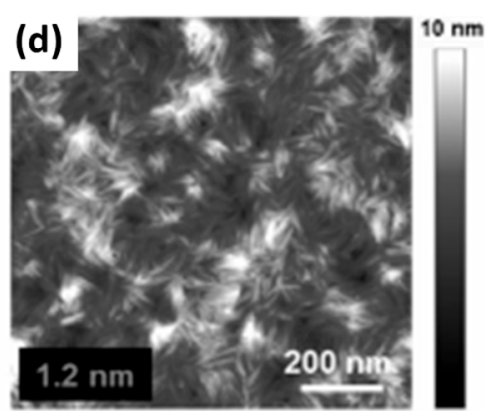

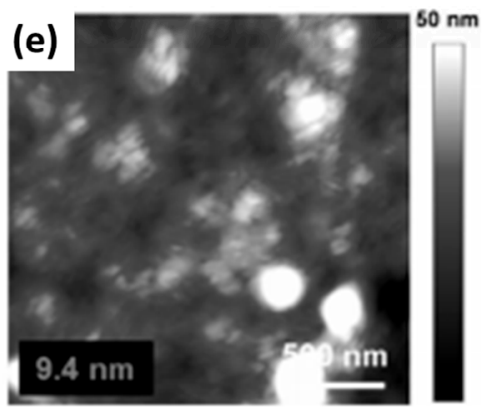

Figure 6. (a) Chemical structure of barbiturate-conjugated thienyl-[oligo(hexylthiophene)]s (11-16) synthesized by Yagai et al. [53]. (b) STM image of 13 on the 1-phenyloctane-highly oriented pyrolytic graphite (HOPG) interface. AFM topography images of the 1:1 $(w / w)$ blend films of (c) $11 / \mathrm{PC}_{61} \mathrm{BM}$; (d) $12 / \mathrm{PC}_{61} \mathrm{BM}$ and (e) $13 / \mathrm{PC}_{61} \mathrm{BM}$ after annealing at $80{ }^{\circ} \mathrm{C}$. The values at the bottom-left corner are root-mean-square (RMS) roughness. Adapted with permission from Ref. [53] Copyright 2014 WILEY-VCH Verlag GmbH \& Co., KGaA.

The same group has reported functionalization of the best performing molecule (12) by BDT (benzo[1,2-b:4,5- $b^{\prime}$ ]dithiophene) unit (17; Figure 7a) for further improving the photovoltaic device performance [54]. Upon fabrication of $\mathrm{BHJ}$ solar cells using a blend of $\mathbf{1 7}$ as donor and $\mathrm{PC}_{61} \mathrm{BM}$ as an acceptor (1:1) yielded a PCE of $2.98 \%$ without any thermal treatment. The thermal treatment decreases the PCE in the case of 17, while it improves in the case of 12. Hence, it was clear that an optimum phase-separated morphology for $\mathbf{1 7}$ was already achieved through solution processing, as supported 
by powder X-ray diffraction (PXRD) pattern which showed a one-dimensional columnar architecture via the formation of hydrogen bonded rosettes in the presence of $\mathrm{PC}_{61} \mathrm{BM}$ (Figure $7 \mathrm{~b}$ ).

(a)

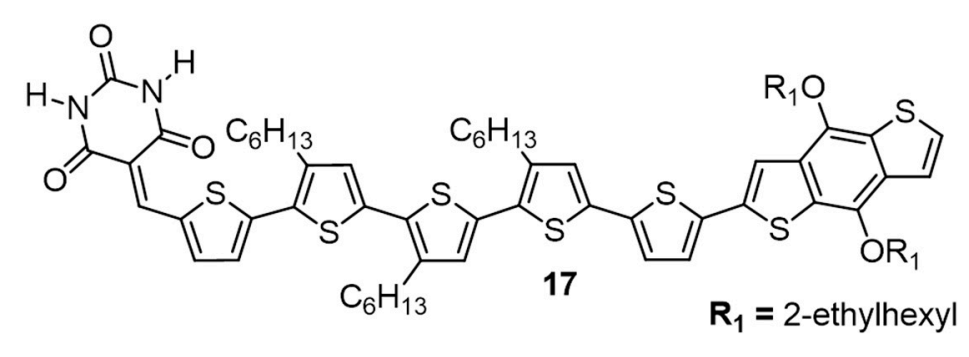

(b)

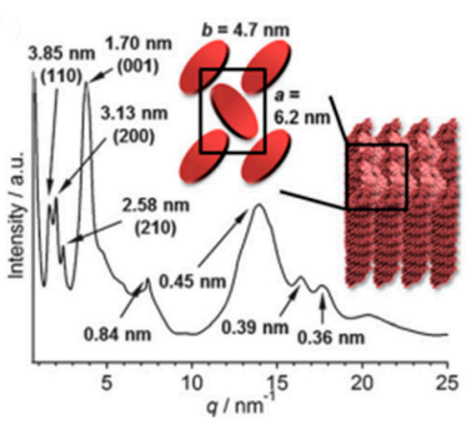

Figure 7. (a) Chemical structure of 17 synthesized by Yagai et al. [54]. (b) PXRD patterns of bulk samples of $17 / \mathrm{PC}_{61} \mathrm{BM}$ at $25^{\circ} \mathrm{C}$. Adapted with permission from Ref. [54] Copyright 2016 The Royal Society of Chemistry.

As described in the above reports, hydrogen bonding can be effectively used for improving the photocurrent efficiency of organic molecules. However, it can also be detrimental, as observed in several cases. Aggressive hydrogen bonding results in the formation of macro domains, which hinders the charge transport in the molecule leading to poor efficiency. A few such examples are discussed in the following section.

In order to improve the phase separation of fullerene acceptor with a polymeric donor such as poly(3-hexylthiophene) or P3HT (18), Li et al. have designed and synthesized $\mathrm{PC}_{61} \mathrm{BM}$ analogues containing hydrogen bonding amide groups (19-21; Figure 8a) [55]. All the three derivatives were functionalized with amide group in the place of ester group of $\mathrm{PC}_{61} \mathrm{BM}$, while in the case of 21 there is an additional methoxy group. Devices were made with 18/fullerene derivative (1:4 w/w), and among the three, 21 gave an efficiency of $0.45 \%$, while the reference $\mathrm{PC}_{61} \mathrm{BM}$ gave an efficiency of $0.42 \%$. It was concluded that both fullerene derivatives have similar phase segregation scale. But upon annealing, amide fullerenes gave PCE almost zero, while $\mathrm{PC}_{61} \mathrm{BM}$ achieved an efficiency of $1.55 \%$. As annealing was ineffective to amide fullerenes, the authors added $2.5 \%$ of 1,12 -diiodododecane to the mixed solution of $\mathbf{1 8}$ /fullerenes. However, the efficiency of devices made from amide fullerene derivatives did not improve, while the performance of $\mathrm{PC}_{61} \mathrm{BM}$ based devices enhanced to $1.77 \%$ under similar conditions. AFM images of the active layer confirmed that 1,12-diiodododecane could not prevent the unfavorable aggregation nature of amide methanofullerene derivatives resulting in large phase separation (Figure 8b,c).

The effect of self-assembly induced by the cooperative hydrogen bonding and pi-pi stacking on the photophysical properties and the film morphology of an oligothiophene derivative (22; Figure 9a) was studied by Satish Patil et al. in 2011 [56]. The oligomer had a donor-acceptor-donor (D-A-D) structure with pyran-barbituric acid as the central core. H-bonding and pi-pi stacking interactions were induced by barbituric acid moiety and oligothiophene units, respectively. Due to the cooperative effect, the oligomer was able to form nanoribbons (Figure 9b) in the presence as well as in the absence of $\mathrm{PC}_{61} \mathrm{BM}$ as observed from AFM (Figure 9c,d, respectively). The authors have also made a non-hydrogen bonding model compound which did not form nanoribbons. The hole mobility of 22 was found to be $\sim 7 \times 10^{-7} \mathrm{~cm}^{2} \cdot \mathrm{V}^{-1} \cdot \mathrm{s}^{-1}$, measured using an organic field effect transistor (OFET) device architecture. The blend film of 22 with $\mathrm{PC}_{61} \mathrm{BM}$ (1:1 ratio) showed a maximum photovoltaic efficiency of $0.18 \%$. 


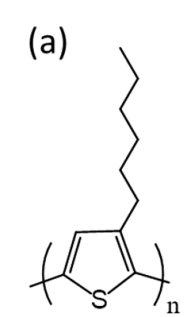

18

(b)

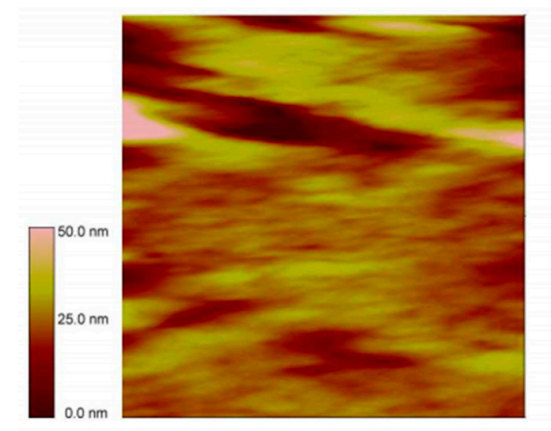

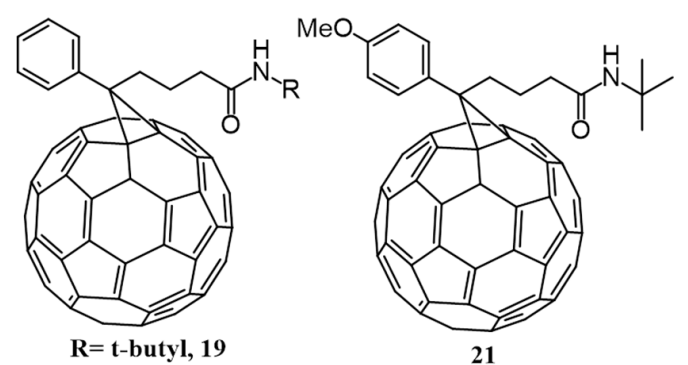

(c)

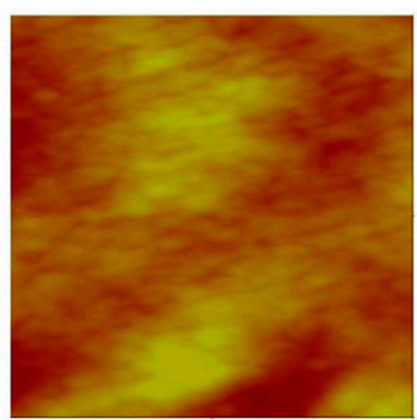

Figure 8. (a) Chemical structure of P3HT (18) and fullerene derivatives (19-21) synthesized by Li et al. [55]. AFM height images of cells fabricated from $o$-dichlorobenzene solution with the ratio of 1:4 of (b) 18/20 (c) 18/21 with 2.5\% 1,12-diiodododecane by weight. Adapted with permission from Ref. [55] Copyright 2009 American Chemical Society.

(a)

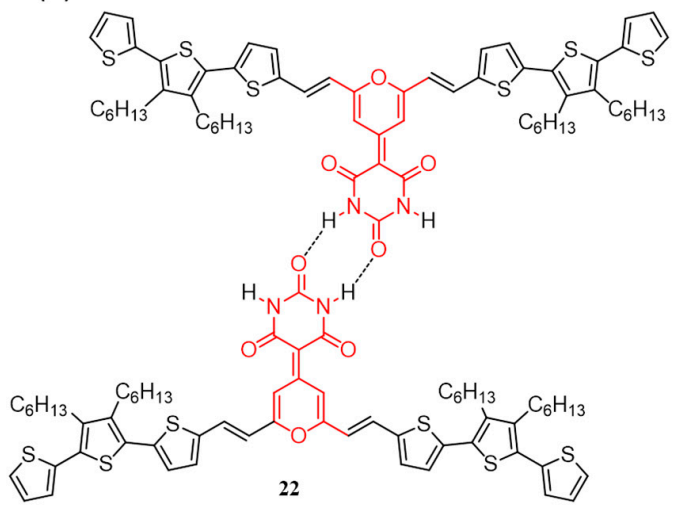

(b)
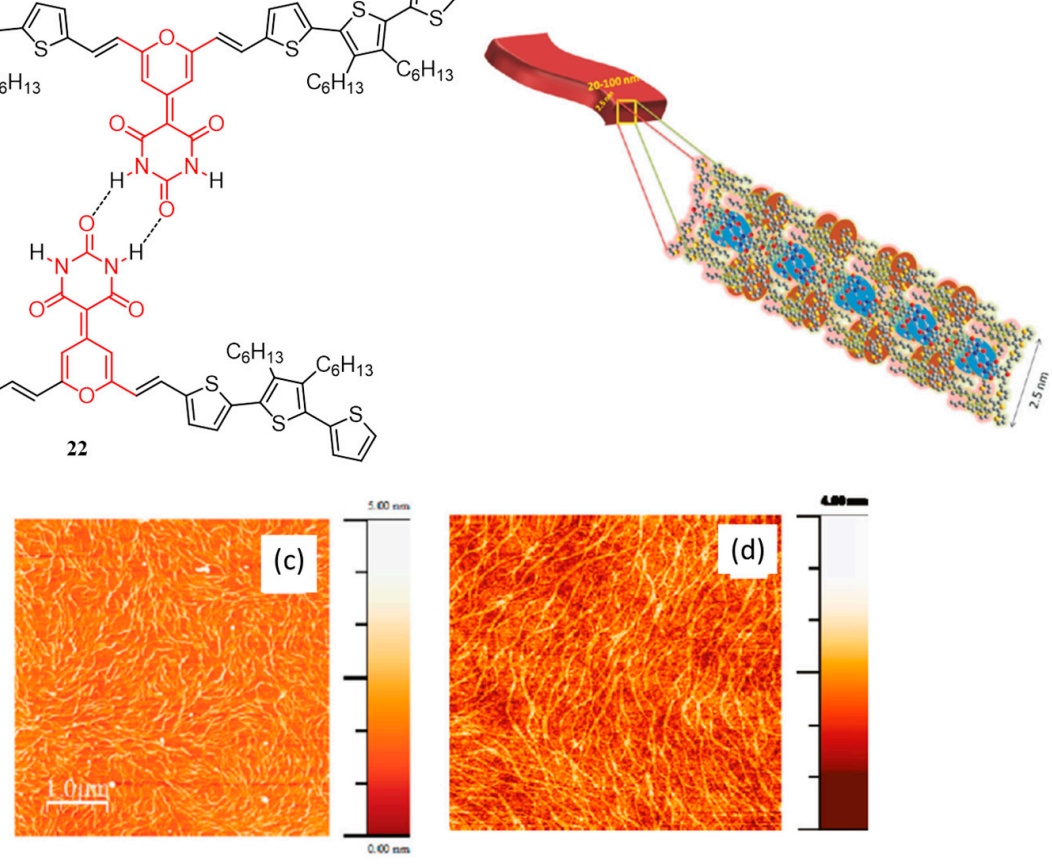

Figure 9. Schematic representation of (a) the intermolecular H-bonding between thiophene oligomers (22) synthesized by Patil et al. [56] and (b) the self-assembly of 22 into nanoribbons. AFM topography image of 22 in the (c) absence and (d) presence of $\mathrm{PC}_{61} \mathrm{BM}$ spin-cast from chlorobenzene solution. Adapted with permission from Ref. [56] Copyright 2011 American Chemical Society. 
The same group has synthesized another D-A-D type pi-conjugated oligomer (23, Figure 10a) with an aim to improve the solar cell efficiency [57]. As mentioned above, 22 consists of an acidic $\mathrm{N}-\mathrm{H}$ proton and electronegative $\mathrm{C}=\mathrm{O}$ that assist in self-assembling via hydrogen bonding. On the other hand, the hydrogen bonding is disrupted in the case of 23 by the introduction of a methyl group. Though $\mathbf{2 2}$ formed nanoribbons as mentioned above, films of $\mathbf{2 3}$ (pristine and blend) were homogeneous without any phase segregation (Figure 10b,c). Importantly, the photovoltaic device made from 23 gave an efficiency of $1.8 \%$. The poor performance of 22 was attributed to the formation of nanoribbons which resulted in phase segregation with $\mathrm{PC}_{61} \mathrm{BM}$. These results imply that prevention of H-bonding helped in developing better interdigitating networks which in turn enhanced the PCE. The reduced connection between the cathode and the active layer, due to an insulating layer formation by the reaction of acidic amide proton with calcium in the device was another reason for the poor performance of 22 .

(a)
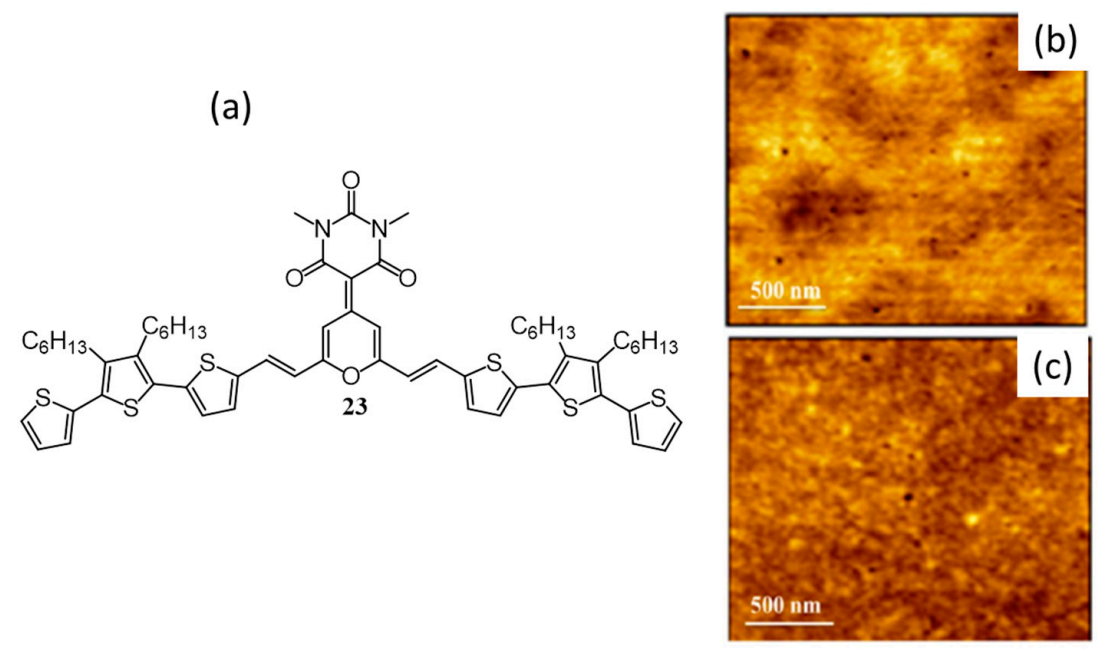

Figure 10. (a) Chemical structure of 23 synthesized by Patil et al. [57]. AFM images of 23 (b) without and (c) with $\mathrm{PC}_{61} \mathrm{BM}$. Adapted with permission from Ref. [57] Copyright 2013 American Chemical Society.

Another example to establish the fact that amide groups exhibiting strong H-bonding negatively affecting the solar cell efficiency was reported by Kim et al. They made six dithienosilole-based donors (24-29) consisting of different end groups (esters and amides) and alkyl side chains (n-octyl, n-decyl, and 2-ethylhexyl chains) as shown in Figure 11a [58]. Detailed studies showed that the optical properties of the molecules were affected by the alkyl side-chains as well as the end-functional groups. The absorption maximum of the thin films of the molecules was shifted bathochromically by $50-80 \mathrm{~nm}$, due to the planarization of the conjugated backbone except in the case of 29 which showed $7 \mathrm{~nm}$ blue-shift. The effect of temperature on the charge carrier mobility properties of the molecules was studied at temperatures between 80 and $280 \mathrm{~K}$ using field-effect transistor device architecture. It revealed an increasing mobility trend in the order $25>24>28>27>26>29$. It was found that the $\mathrm{H}$-bonding results a decrease in the planarity of the conjugated backbone, as a result, more energy was required for charge transport in amides when compared to esters. This poor charge transport property was well reflected in photovoltaic performance too; 29 exhibited extremely low efficiency $(0.21 \%)$ among all, while 24 performed best and had a PCE of $4.31 \%$. The $\mathrm{PC}_{61} \mathrm{BM}$ blend with esters (especially 24 and 25 ) yielded good $\mathrm{BHJ}$ morphology consisting of small domain of 20-30 nm (RMS roughness of $2.7 \mathrm{~nm}$ ). This contributed to the efficient separation of the excitons and facilitated the charge transport, leading to high PCEs. On the other hand, blends of 27 and 28 with $\mathrm{PC}_{61} \mathrm{BM}$ showed less distinct features in the morphology with much lower roughness values $(\sim 0.5 \mathrm{~nm})$ due to the enhanced miscibility. Blend film of 29 lacks a clear interface, which resulted in the poor performance of the device. AFM images of all the blend films are shown in Figure 11b. 
(a)

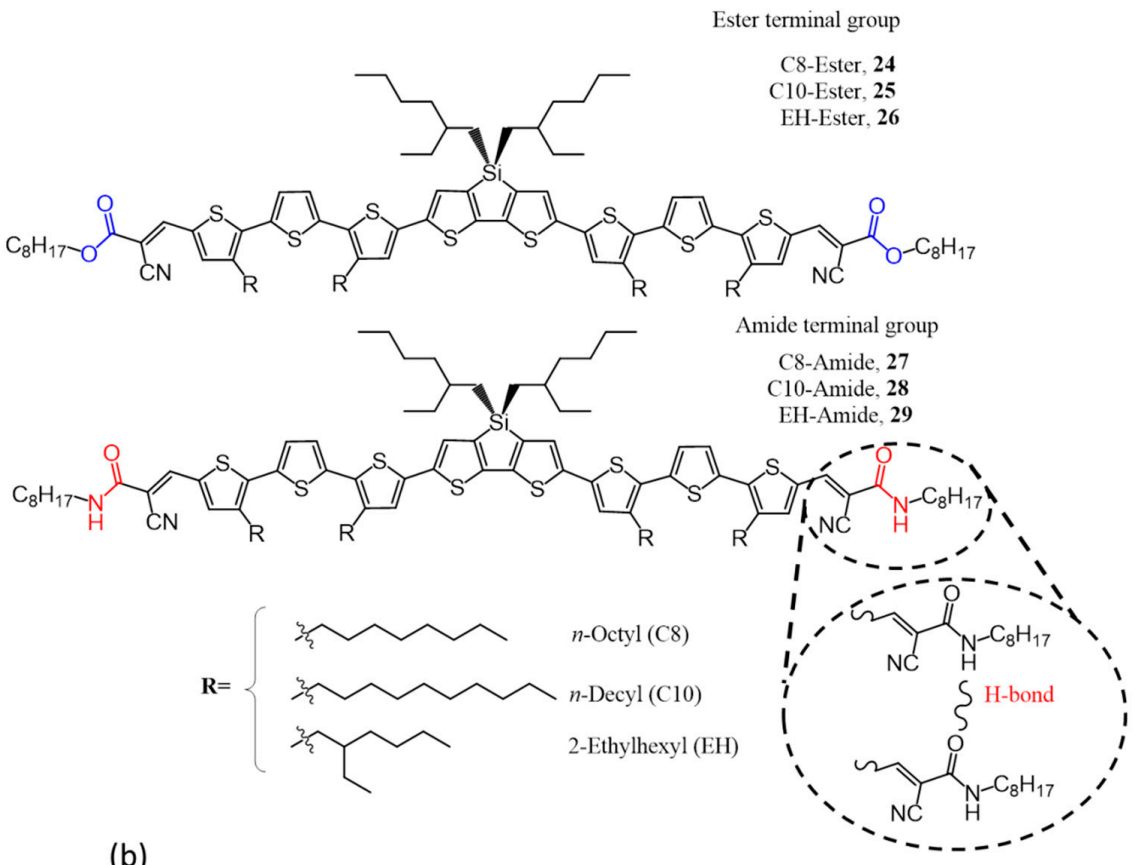

(b)

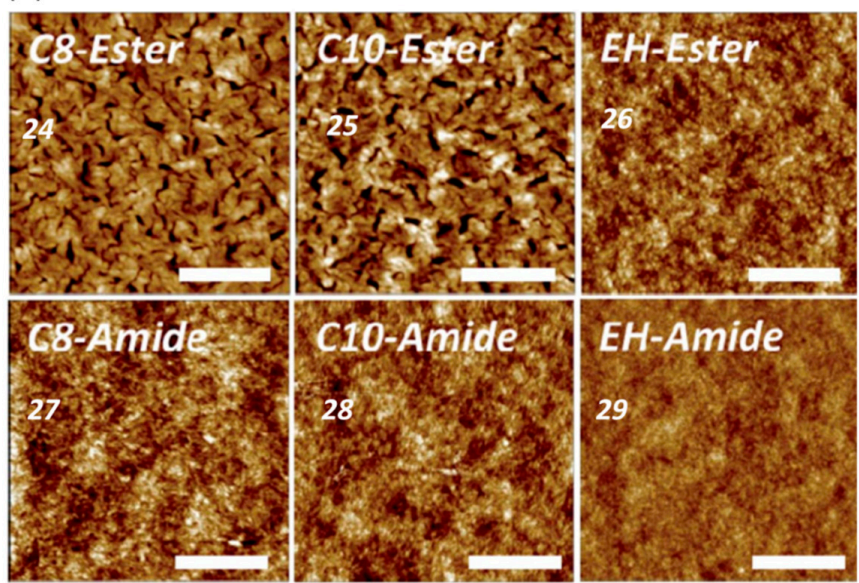

Figure 11. (a) Chemical structures of 24-29 synthesized by Kim et al. [58]. (b) AFM height images of the optimized active layer consisting of small molecule donors and $\mathrm{PC}_{61} \mathrm{BM}$; the scale bar is $1 \mu \mathrm{m}$. The abbreviations of the authors are the following: 24: C8-Ester, 25: C10-Ester, 26: EH-Ester, 27: C8-Amide, 28: C10-Amide and 29: EH-Amide. Adapted with permission from Ref. [58] Copyright 2013 The Royal Society of Chemistry.

Molecules possessing free imide groups also have an adverse effect on the photovoltaic performance due to the formation of strong intermolecular hydrogen bonding as demonstrated by Roncali and co-workers [59]. Two donors $\mathbf{3 0}$ and $\mathbf{3 1}$ with a D-A-D structure involving isoindigo (IsI) as a central acceptor block and benzofuran (30) and dithienopyrrole (31) as a side donor unit were synthesized (Figure 12). The molecule 31 has a free imide group in the center and therefore, able to form intermolecular hydrogen bond while such an interaction is absent in the case of $\mathbf{3 0}$ as the nitrogen atom is alkylated. BHJ devices were prepared by spin-casting active films from a chlorobenzene solution of donor $/ \mathrm{PC}_{61} \mathrm{BM}(1: 2 w / w)$. 31 performed least $(0.01 \%)$ as the hydrogen bonding locks the molecules into an unfavorable organization. However, planar heterojunction devices yielded PCE of $0.19 \%$ which decreased upon thermal annealing. On the other hand, 30 yielded a PCE of $0.15 \%$ which increased on annealing at $110{ }^{\circ} \mathrm{C}$ to $0.65 \%$. 


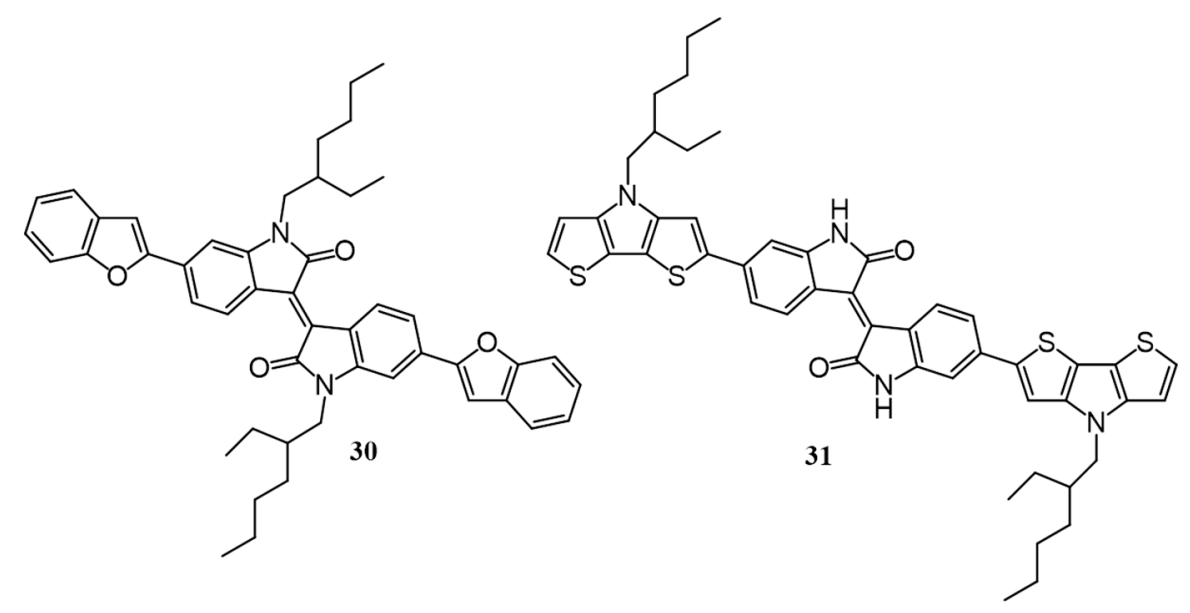

Figure 12. Chemical structure of 30 and 31 synthesized by Roncali et al. [59].

In 2014, Wong et al. reported the synthesis of two oligomers, one with ester (32) and the other with amide (33) end groups [60]. They synthesized a fullerene derivative with amide functionality (34) for comparison and also to investigate the utilization of hydrogen bonding self-assembly as a tool to control the morphology. The chemical structures of the oligomers and the fullerene derivative are shown in Figure 13a. UV-visible absorption studies revealed that the absorption maximum of 32 is more red-shifted than 33 . This was attributed to the presence of better electron withdrawing property of the ester group as compared to the amide. An amide hydrogen bonding in the case of 33, disrupting the close pi-pi stacking between the planar conjugated back bone of the oligomer was also contributed to this effect. The absence of pi-pi stacking in $\mathbf{3 3}$ was supported by gracing incidence wide angle $\mathrm{X}$-ray scattering studies. The AFM images of the oligomers revealed that 33 were able to form a fibrous structure which is beneficial for charge transport in BHJ, Figure 13c. However, devices fabricated using 33 performed poor, mainly due to unfavorable morphology induced by inter-molecular hydrogen bonding. Hole mobility calculated by space charge limited current (SCLC) method for $\mathbf{3 2}$ and $\mathbf{3 3}$ was found to be $6.3 \times 10^{-6}$ and $1.1 \times 10^{-6} \mathrm{~cm}^{2} \cdot \mathrm{V}^{-1} \cdot \mathrm{s}^{-1}$, respectively. BHJ devices fabricated with $\mathrm{PC}_{71} \mathrm{BM}$ and 32 (1:2) gave an efficiency of $1.15 \%$, whereas, $\mathrm{PC}_{71} \mathrm{BM}$ and 33 (1:4) gave an efficiency of $0.40 \%$. Stronger aggregation and large-scale phase separation were seen with $\mathbf{3 4}$ as the acceptor resulting in much lower efficiencies.

Pi-pi stacking is one of the most important interactions utilized for making ordered chromophore assemblies for optoelectronic applications. Effective pi-stacking is necessary for the efficient charge transport in organic materials and hence it plays a crucial role in photovoltaic device performances too. In the following section, we describe a few systems used in BHJ devices, which self-assemble mainly through pi-pi stacking.

Discotic liquid crystalline organic molecules exhibit intermolecular pi-pi stacking and mesoscopic long-range ordering. As a result, they show unique and interesting optoelectronic properties and can be used for advanced device applications. MacKenzie and co-workers have used a hexaphenyl-substituted hexabenzocoronene (35) [61] based discotic liquid crystalline molecule in combination with $N, N^{\prime}$-bis(1-ethylpropyl)-3,4,9,10-perylenebis(dicarboximide) (36) [62]. The blended thin films of these molecules consist of vertically segregated perylene and hexabenzocoronene with the remarkably high interfacial surface area [63]. This is the first example of the use of self-assembling small molecule in organic photovoltaics. Figure 14a shows the chemical structure of the molecules and Figure 14b shows a simplified scheme of the pi-pi stacked assembly of 35 . The liquid crystalline ordering of $\mathbf{3 5}$ has micro-scale domain structures confirmed by polarized optical microscopy. Studies revealed the efficient photoinduced charge transfer between hexabenzocoronene and perylene. Due to this phenomenon, the blend film of $\mathbf{3 5 / 3 6}$ (40:60) showed photovoltaic response with external quantum efficiency $>34 \%$ near $490 \mathrm{~nm}$. The photovoltaic device under a light beam of $490 \mathrm{~nm}$ illumination at $0.47 \mathrm{~mW} \cdot \mathrm{cm}^{-2}$ gave a PCE of $2.0 \%$. 
(a)

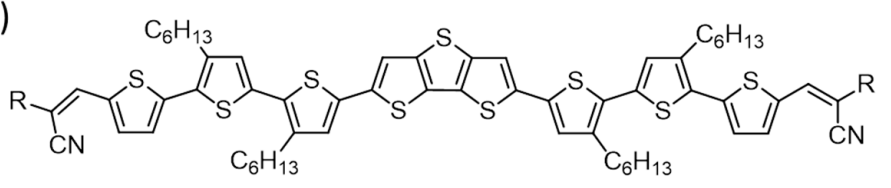

$32: \mathrm{R}=\mathrm{COOC}_{8} \mathrm{H}_{17}$

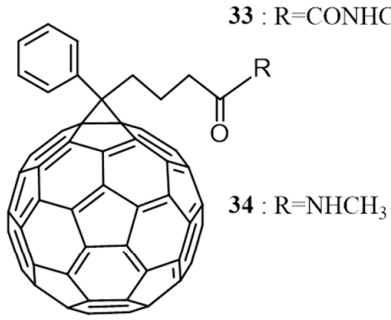

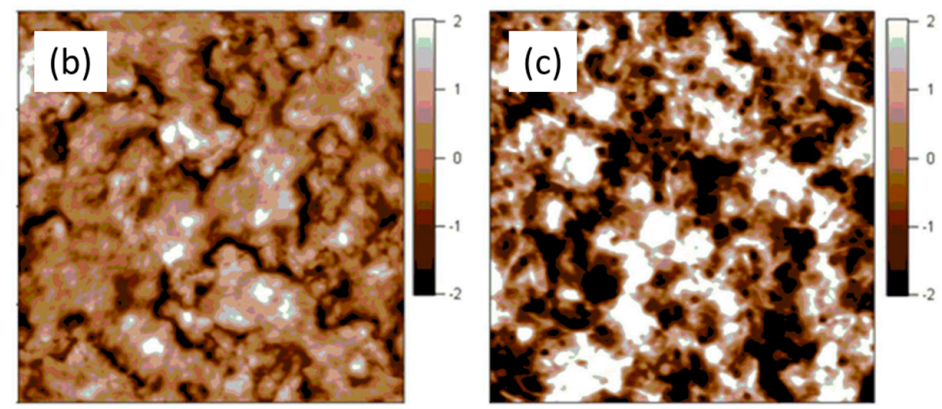

Figure 13. (a) The structure of the oligomers 32-34 synthesized by Wong et al. [60]. AFM height images of spin coated films from $10 \mathrm{mg} \cdot \mathrm{mL}^{-1}$ chloroform solution of (b) 32 and (c) 33 . Adapted with permission from Ref. [60] Copyright 2014 Nature Publishing Group.

(a)

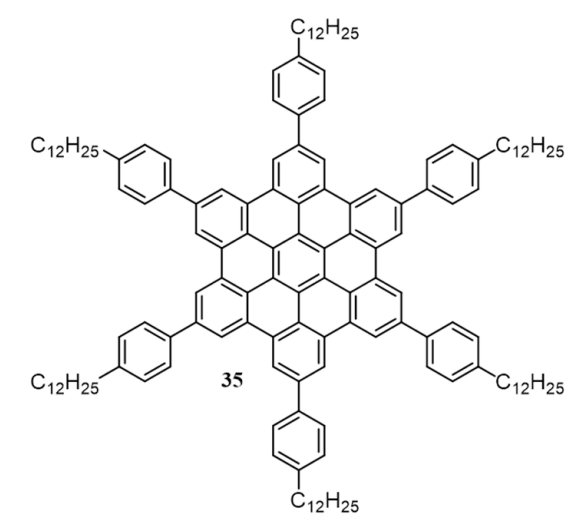

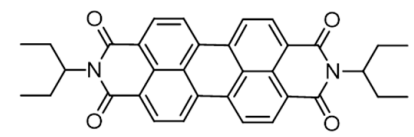

(b)

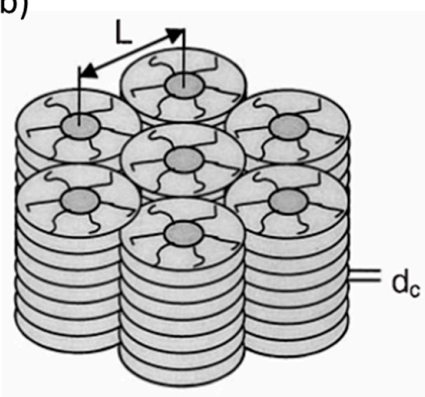

36

Figure 14. Chemical structures of 35 and 36 synthesized by Müllen et al. [61] and Schön et al. [62] respectively; (b) A simplified representation of the pi-pi stacking of the discotic molecules, where, $\mathrm{L}$ is the intercolumnar distance and $\mathrm{d}_{\mathrm{c}}$ is the co-facial distance. Adapted with permission from Ref. [63] Copyright 2001 The American Association for the Advancement of Science.

Facchetti et al. studied how subtle pi-core substituent variations affect photovoltaic responses of functional chromophoric systems [64]. In 2010, they have reported the synthesis of two new squaraine dyes, substituted at the pyrrolic nitrogen with $n$-hexyl (37) or $n$-hexenyl (38) chains (Figure 15). 
The dyes exhibited a remarkable difference in optoelectronic properties due to the variation in packing as evident from the crystal structure. The crystal of $\mathbf{3 8}$ exhibits shorter interplanar and the interstack distance between cores ( 3.138 and $7.343 \AA$, respectively) in comparison to 37 (3.417 and $7.809 \AA$, respectively). The crystal packing of 38 also features edge-pi interaction between the terminal hexenyl double bond and phenyl rings (2.85-2.90 $\AA$ ), while no such interaction was present in 37. Upon fabrication of BHJ solar cells using conventional architecture, 38 exhibited a maximum PCE of $2.05 \%$, while 37 had a maximum PCE of $1.47 \%$. This was attributed to the presence of more compact and denser nanofibrils of $\mathbf{3 8}$ due to the non-covalent alkenyl-phenyl interaction.
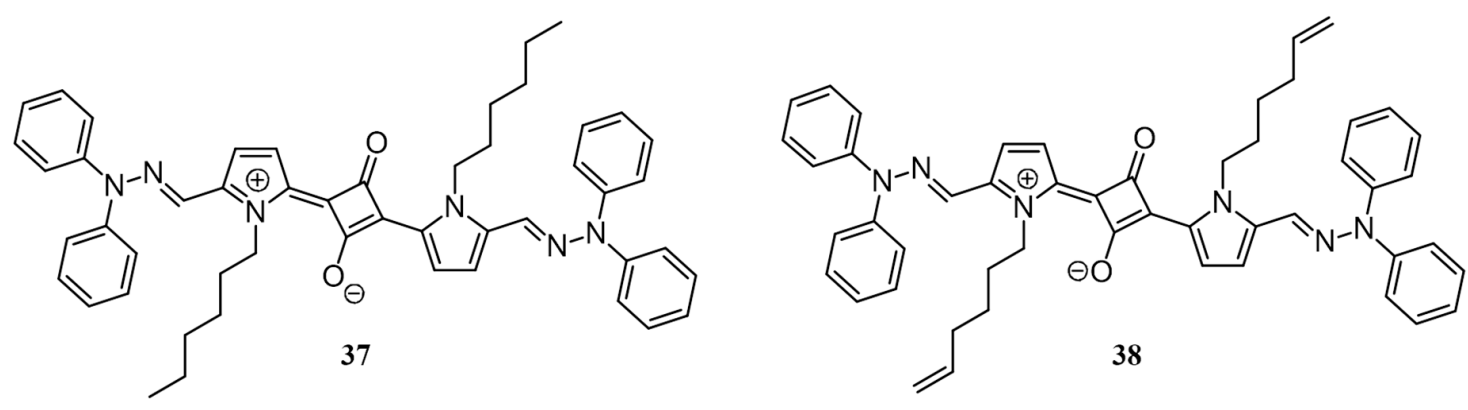

Figure 15. Chemical structures of 37 and 38 synthesized by Facchetti et al. [64].

The incorporation of pi-stacking moieties as end groups would facilitate small molecules/oligomers to stack efficiently, leading to the enhancement in charge carrier mobility properties. In 2011, Fréchet and coworkers explored this idea by preparing seven small molecules consisting of diketopyrrolopyrrole (DPP) as the electron-deficient core [65]. DPP is known to provide solution-processability and film-state molecular ordering. The molecules were end-functionalized with various acceptors such as triphenylamine (39), BDT (40), and pyrene (41). Further, the effect of end-group symmetry was studied by preparing 42 , where the regio-connectivity between pyrene and the chromophoric core was changed. To study the effect of alkyl chains on molecular packing and solar cell efficiency, the DPP unit of $\mathbf{4 2}$ was incorporated with 2-hexyldecyl (43), 2-butyloctyl (44), and 2-ethylhexyl (45). All the chemical structures of the oligomers are shown in Figure 16a. The blend film of 43 with $\mathrm{PC}_{71} \mathrm{BM}$ gave the highest photocurrent efficiency of $4.1 \%$, whereas, lower efficiency was obtained for $39(1.3 \%), 40(1.7 \%), 41(0.7 \%), 42(2.7 \%)$ and $44(3.0 \%)$. The molecule 45 had poor solubility for processing it into a device and hence its photovoltaic properties were not investigated. To understand the reason for the variation in photovoltaic performances of the molecules, the active layer morphology for all derivatives were studied by AFM (Figure 16b-g). The presence of relatively crystalline domains with sizes of $\sim 10-30 \mathrm{~nm}$ was assumed for the better performances of $\mathbf{4 3}$ and $\mathbf{4 4}$.

Thienoisoindigo and isoindigo based copolymers have been known to exhibit balanced ambipolar charge transport properties with both electron and hole mobilities exceeding $0.1 \mathrm{~cm}^{2} \cdot \mathrm{V}^{-1} \cdot \mathrm{s}^{-1}$ [66]. Considering this aspect, Mori and co-workers have synthesized and investigated the photovoltaic performance of two molecules consisting of thienoisoindigo core end-capped with benzothiophene (46), and benzofuran (47), and another molecule with isoindigo core end capped with benzothiophene (48; Figure 17) [67]. The electronic structures of the molecules were studied by density functional theory (DFT) calculations. It revealed that the optimized molecular structures of $\mathbf{4 6}$ and $\mathbf{4 7}$ are almost flat, while 48 is non-planar because of the twist between benzothiophene and isoindigo units $\left(23.9^{\circ}\right)$ as well as the bent of isoindigo unit $\left(11.3^{\circ}\right)$. As a result, the intermolecular pi-pi stacking was stronger in 46 and 47 resulting in higher crystallization temperature $\left(260-270{ }^{\circ} \mathrm{C}\right)$ than that of $48\left(220^{\circ} \mathrm{C}\right)$. In accordance with these observations, the charge-carrier mobilities of 46 and 47 are two-three order of magnitude higher $\left(4.0 \times 10^{-7}\right.$ and $2.1 \times 10^{-6} \mathrm{~cm}^{2} \cdot \mathrm{V}^{-1} \cdot \mathrm{s}^{-1}$, respectively) than that of 48 $\left(1.9 \times 10^{-9} \mathrm{~cm}^{2} \cdot \mathrm{V}^{-1} \cdot \mathrm{s}^{-1}\right)$ as measured by SCLC method. BHJ devices of 46 and 47 with $\mathrm{PC}_{71} \mathrm{BM}$ showed good photovoltaic device efficiencies of $2.4 \%$ and $1.5 \%$, respectively. On the other hand, devices made of $\mathbf{4 8}$ under identical conditions did not work. The planar structure of the thienoisoindigo unit, 
therefore, has an obvious effect on the molecular packing properties and the thin-film morphology. This unit also decreases the steric interference caused by the benzothiophene and benzofuran unit thereby improving the photovoltaic properties.

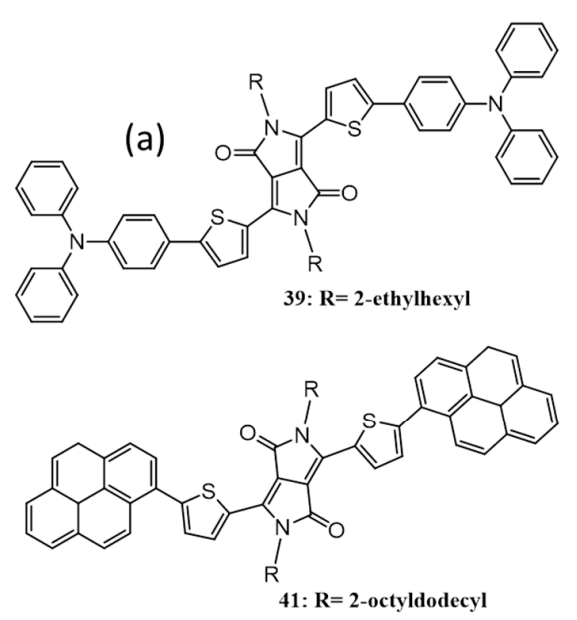

(b)
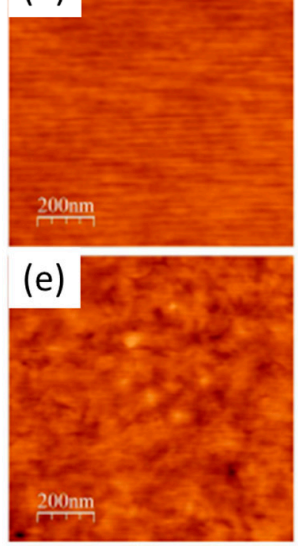

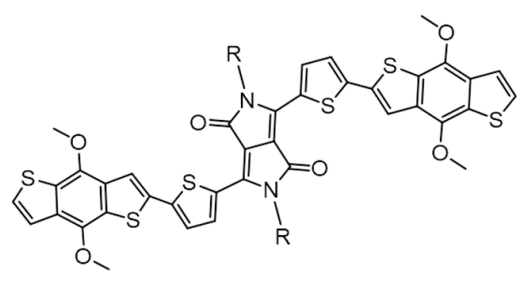

40: $R=$ 2-ethylhexyl

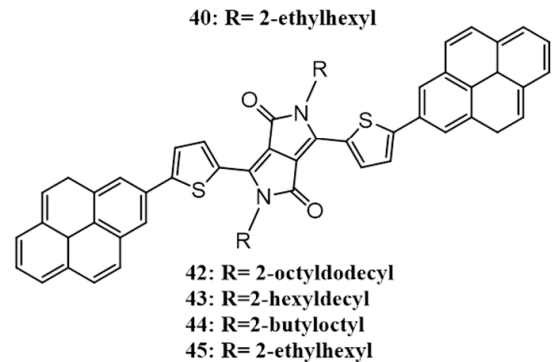

45: $R=2$-ethylhexyl
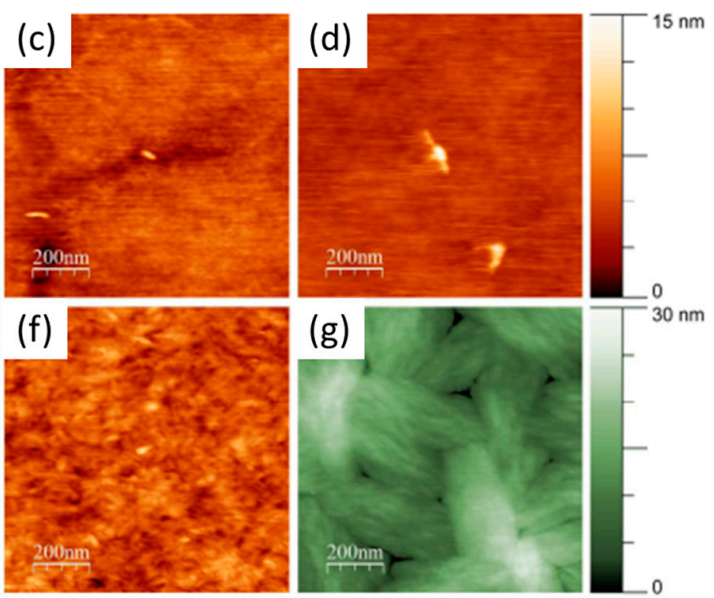

Figure 16. (a) Chemical structures of 39-45 synthesized by Fréchet et al. [65]. Tapping-mode AFM images of the blends of (b) 39; (c) 40; (d) 41; (e) 42; (f) 43; (g) 44 with $\mathrm{PC}_{71} \mathrm{BM}$. Adapted with permission from Ref. [65] Copyright 2011 WILEY-VCH Verlag GmbH \& Co., KGaA, Weinheim.

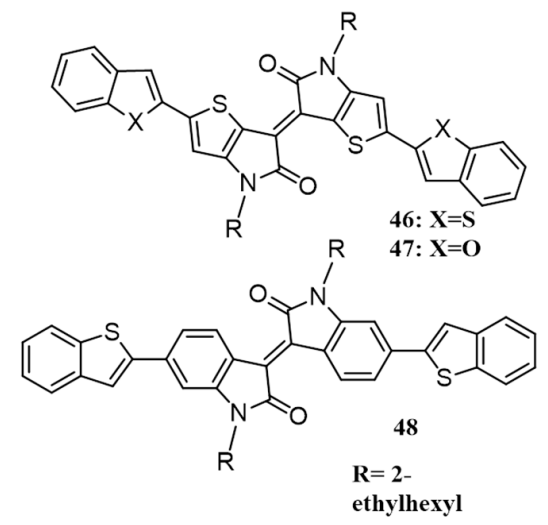

Figure 17. The chemical structures of $\mathbf{4 6}-\mathbf{4 8}$ synthesized by Mori et al. [67]. 
Due to the low-lying LUMO and high electron mobilities, perylenediimide (PDI) derivatives have been extensively used as an acceptor in OSCs for more than a decade [68,69]. However, PDIs give low PCE values because of the poor BHJ morphology. They have a strong tendency to stack through the extended pi-surfaces and resulting in large crystallites and macrophase separation in the bulk active layer. Moreover, PDI derivatives easily form excimers which act as traps for electrons thus reducing the overall efficiency. In order to get rid of these issues, twisted PDI dimers have been used by connecting the imide position through a hydrazine linker or by functionalizing the "bay positions". Incorporation of bulky "swallow tail" PDI side chains at the imide position was also found to introduce twisting in the molecular packing [70-72]. Although adopting twisted PDIs have led to very high efficiencies, these too suffer from certain limitations. Completely preventing pi-pi stacking is not a possible solution to inhibit excimer formation since an absence of continuous pathway can lead to charge recombination. In this context, Wasielewski et al. in 2013 introduced a new method to inhibit the excimer formation by substituting suitably at $\mathrm{C} 2, \mathrm{C} 5, \mathrm{C} 8$, and $\mathrm{C} 11$ positions of PDI [73]. This arranges the molecules in a slip-stacked manner thereby inhibiting excimer formation without rupturing the pi-stacking interactions. This novel idea was then used to develop BHJ solar cells for which they synthesized three PDI derivatives 49, 50 and 51 with hexyl, phenethyl and phenyl side chains, respectively as acceptors and $\mathbf{5 2}$ as the donor polymer (Figure 18) [74]. Upon fabrication of the inverted solar cell, the blend of $51: 52$ gave the highest efficiency of $3.64 \%$, while blends of 49 and 50 with 52 gave an efficiency of $0.65 \%$ and $1.20 \%$, respectively. From the AFM analysis of the active layer, it was clear that the improved efficiency in the case of $\mathbf{5 1}$ was mainly due to moderate crystallinity and formation of micrometer-sized crystallites, while $\mathbf{4 9}$ forms the roughest and $\mathbf{5 0}$ forms the smoothest films.

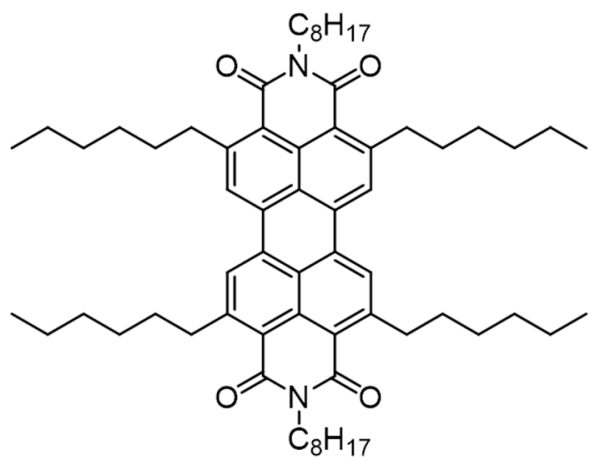

49

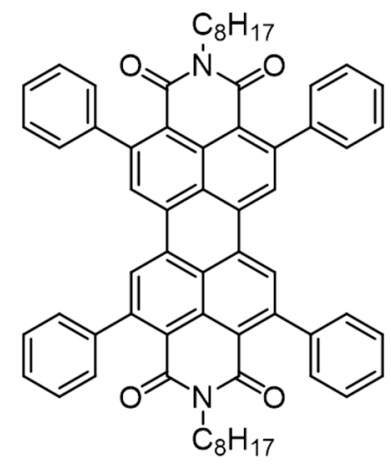

51

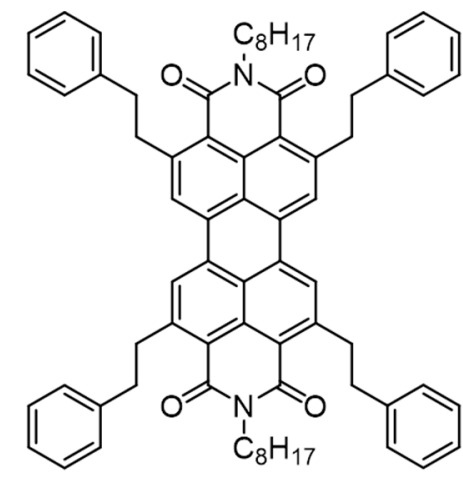

50

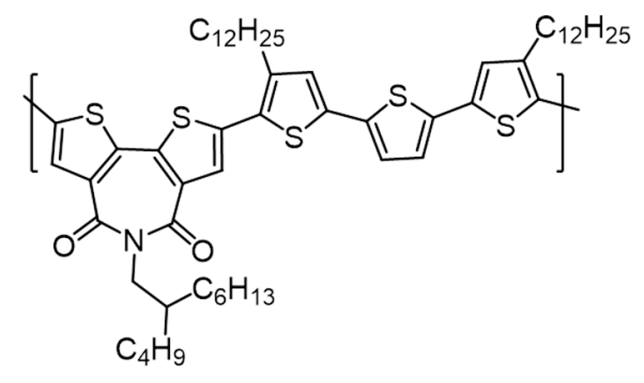

52

Figure 18. The chemical structures of 49-52 synthesized by Wasielewski et al. [74].

In 2015, our group reported the optical, electronic and photovoltaic properties of thiophene oligomers end-functionalized with oxazolone (53) and isoxazolone (54) derivatives (Figure 19a) [75]. We have illustrated that small structural changes significantly affect the molecular and supramolecular 
properties of the oligomers. More importantly, it also affects the $\mathrm{p} / \mathrm{n}$ polarity of the molecules in a bulk-heterojunction device architecture. Comparison of the highest occupied molecular orbital (HOMO) and lowest unoccupied molecular orbital (LUMO) levels of 53 and 54 with that of $\mathrm{PC}_{61} \mathrm{BM}$ and 18 (P3HT) revealed that, in principle, both of them can act as donors to $\mathrm{PC}_{61} \mathrm{BM}$ and acceptors to 18. However, $\mathbf{5 3}$ acted as a p-type material (PCE of $0.75 \%$ with $1: 1 w / w \mathrm{PC}_{61} \mathrm{BM}$ ), whereas, $\mathbf{5 4}$ behaved more like an n-type material (PCE of $0.19 \%$ with $1: 1 w / w 18$ ) in BHJ solar cells with an inverted configuration. This observation could be explained by considering the molecular (energy levels) and supramolecular (film state packing) properties of the molecules. The shallower HOMO and LUMO of 53 (compared to 54) made it better electron donor to $\mathrm{PC}_{61} \mathrm{BM}$, whereas, deeper HOMO and LUMO of 54 are helpful for accepting electrons from 18 (Figure 19b). Depicted by DFT, XRD, thermogravimetry analysis (TGA) and UV-vis absorption studies, $\mathbf{5 3}$ has a coplanar structure, whereas, $\mathbf{5 4}$ consists of an out-of-plane isoxazolone acceptor. As a result, the former forms highly ordered, stable aggregates through strong pi-pi stacking and latter exhibit weaker pi-pi stacking. Supramolecular organization of 53 and $\mathbf{5 4}$ in the self-assembled state is schematically depicted in Figure 19c. Detailed absorption studies proved that the self-assembly of 53 was intact upon the addition of $\mathbf{1 8}$ or $\mathrm{PC}_{61} \mathrm{BM}$ (Figure 19d). In the case of 54, the addition of $\mathrm{PC}_{61} \mathrm{BM}$ destroys the assembly resulting in a hypsochromic shift of the absorption maximum (Figure $19 \mathrm{e}$ ). The $\mathrm{p} / \mathrm{n}$ polarity of the oligomers was also confirmed by flash-photolysis time-resolved microwave conductivity analysis.

(a)

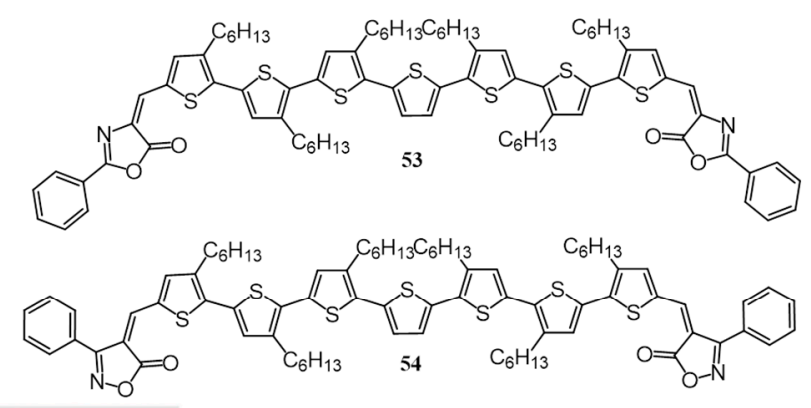

(b)
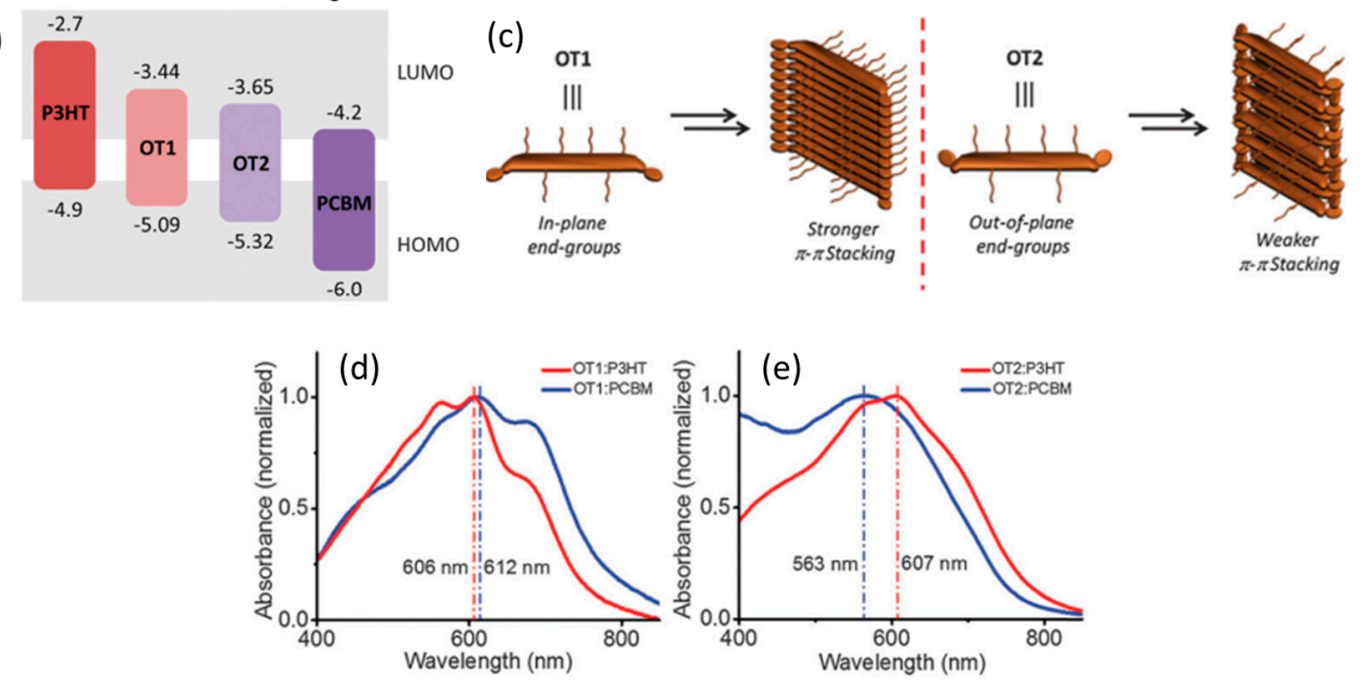

Figure 19. (a) The chemical structure of oligomers 53 and 54 as synthesized by Nair et al. [75]. (b) Scheme showing the comparison of the HOMO-LUMO levels of the oligomers with that of $\mathbf{1 8}$ and $\mathrm{PC}_{61} \mathrm{BM}$ (c) Simplified schematic representation of the supramolecular organization of 53 and $\mathbf{5 4}$ in the self-assembled state. Normalized absorption spectra of (d) 53 and (e) 54 blend films (1:1 w/w) with 18 or $\mathrm{PC}_{61} \mathrm{BM}$ spin-cast from chlorobenzene solution. Abbreviated by authors as following - 53: OT1 and 54: OT2. 
Several "star-shaped" donors with complex architectures (C-3 symmetric or tripodal) capable of forming self-assembled structures have been reported for photovoltaic applications with efficiencies surpassing $4 \%[76,77]$. Stupp and co-workers have foreseen that the increased pi-pi stacking interactions in disc-like molecules would facilitate the formation of self-assembled fibers when appended with solubilizing alkyl side chains [78]. Very recently, they have designed and synthesized tripodal donor molecules, 55 (with 2-ethylhexyl) and $\mathbf{5 6}$ (with dodecyl), where electron-donating triphenylamine functions as the donor core and DPP units flanked by thiophene groups chosen as the chromophoric "arms" (Figure 20a). The films of the active layer were first investigated by AFM and 2D-GIXRD. 55 forms featureless films (Figure 20b) while $\mathbf{5 6}$ forms short nanowires when casting from chloroform solvent (Figure 20c). The self-assembly of $\mathbf{5 6}$ was further enhanced when casting from chlorobenzene while no enhancement in morphology was seen for 55 (Figure 20d). GIXRD results showed that $\mathbf{5 6}$ have a tendency to self-assemble with cofacial stacking to a greater extent than $\mathbf{5 5}$, which was well supported by the classical molecular dynamics simulation studies. AFM analysis showed that $\mathbf{5 6}$ forms small nanowires in chloroform, but forms featureless films after blending with $\mathrm{PC}_{71} \mathrm{BM}$. This was attributed to two reasons; $\mathrm{PC}_{71} \mathrm{BM}$ disrupt the stacking of the donor and the use of highly volatile solvent chloroform did not provide the molecules enough time to stack efficiently. A combination of m-cresol and DIO promotes assembly of 56 into a well-dispersed network of nanowires, while the use of this solvent combination has increased the roughness in the case of 55 . Solar cells were fabricated containing 55 and 56 using optimized weight ratios of donor/PC ${ }_{71} \mathrm{BM}$ of 1:3 and 1:2, respectively. Without any solvent additives, devices of $\mathbf{5 5}$ show higher performance than those of $\mathbf{5 6}$, with PCEs of $2.41 \%$ and $1.29 \%$, respectively. With the addition of DIO, a significant improvement in the PCE (4.19\%) was observed for 56, whereas, only marginal increase was observed for 55 (2.75\%) under identical conditions. The performance of the molecules was further improved by the addition of $1.0 \mathrm{vol} \%$ of m-cresol as a solvent additive, which mainly functions as a dispersant. The fully optimized devices have a PCE of $4.39 \%$ for $\mathbf{5 6}$ and $2.91 \%$ for $\mathbf{5 5}$. The authors concluded that the use of linear alkyl chains rather than branched ones boosts supramolecular self-assembly in tripodal systems via pi-pi stacking, thereby bestowing a 50\% improvement in device performance. In other words, the supramolecular assembly of $\mathbf{5 6}$ with linear alkyl chains creates ordered aggregates, while steric effects due to branched alkyl chain prevent 55 from stacking, thus forming amorphous domains with more structural defects that contribute to trap-mediated recombination.

The synergistic effects of hydrogen bonding and pi-pi stacking have been utilized in organic molecules for solar cell applications. In 2009, research groups of Würthner and Thelakkat made a nanostructured donor-acceptor interface of an n-type organogelator (57) with a p-type polymer (58) by combining hydrogen bonding and pi-pi stacking interactions, Figure 21a [79-81]. The nanostructures were prepared via two routes (Figure 21b); the first method (route A) involves the preparation of the organogel of 57 followed by removal of the solvent. The pores and grooves of the resulting xerogel were subsequently filled by the polymer, 58 . The second method (route B) is a single-step process consisting of the blending of 57 and 58 yielding a three-dimensional network of the organogel of former embedded into an amorphous matrix of latter. In route B, blends of 57/58 were taken in three different ratios of 3:1, 1:1, and 1:3. The composition 3:1 delivered the highest current and power conversion values. The film morphology obtained via both routes was examined by SEM (Figure 21c-f), which showed the superstructure of 57-xerogel obtained via route A is highly entangled and aggregated. However, in route B, the amorphous polymer 58 occupies the vacancies in the xerogel of the blend film. The presence of polymer also prevents the formation of thicker gel strands resulting in high donor-acceptor interface. Films prepared by both methods were smoothened by doctor blading the surface using the polymer in chlorobenzene solution. To understand the importance of gelated network structure on charge separation and transport, devices were made using a non-gelating derivative of 57, $N$-(1-nonyldecyl)- $N^{\prime}$-(1-pentylhexyl)-perylene-3,4,9,10-tetracarboxylic bisimide and measured its photovoltaic properties in combination with 58 . This device gave an efficiency of $0.003 \%$, while the xerogel sample gave the highest PCE of $0.04 \%$ via route B. 


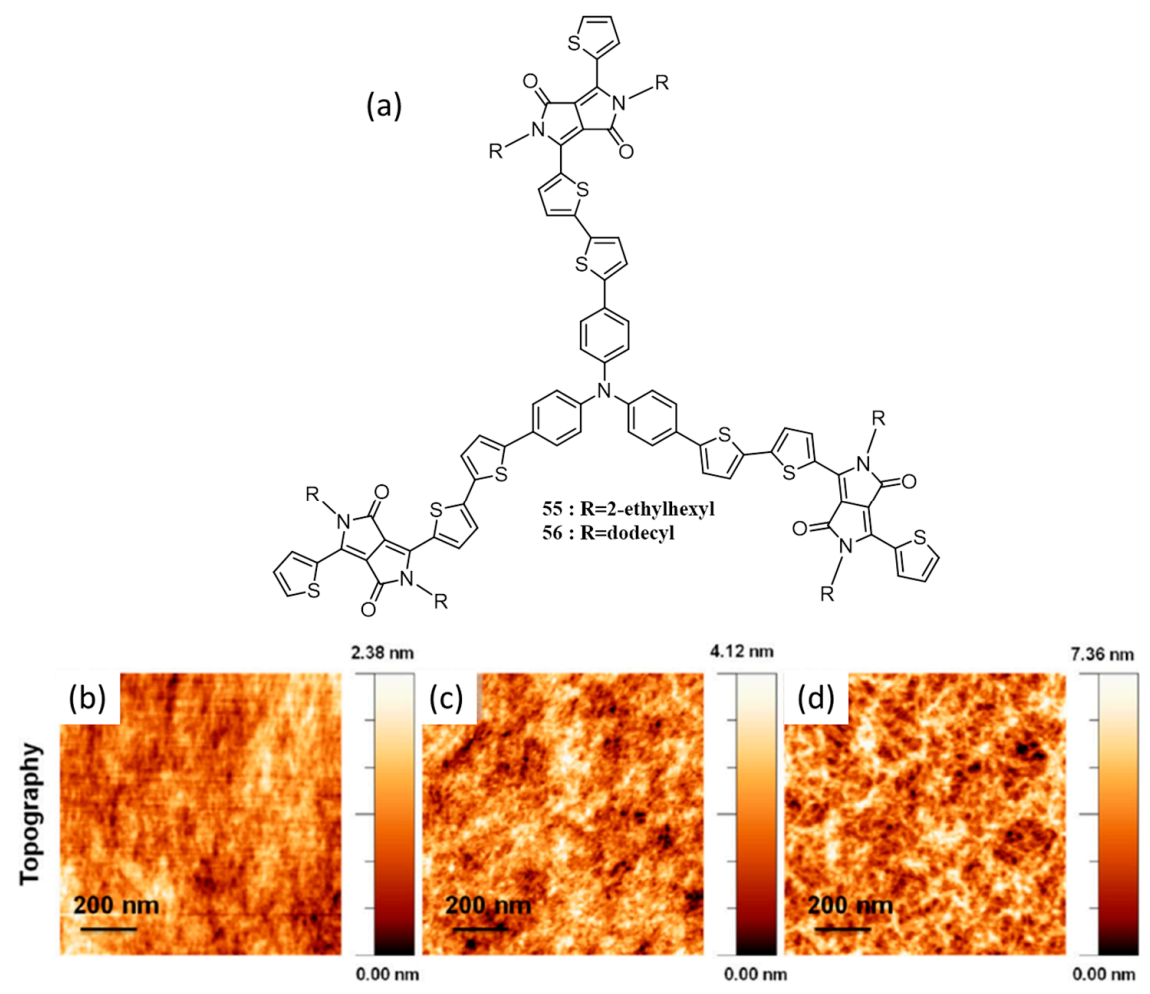

Figure 20. (a) The chemical structures of 55 and 56 synthesized by Stupp et al. [78]. AFM topography images of (b) 55 cast from chloroform; (c) 56 cast from chloroform; and (d) 56 cast from chlorobenzene. Adapted with permission from Ref. [78] Copyright 2016 American Chemical Society.

(a)
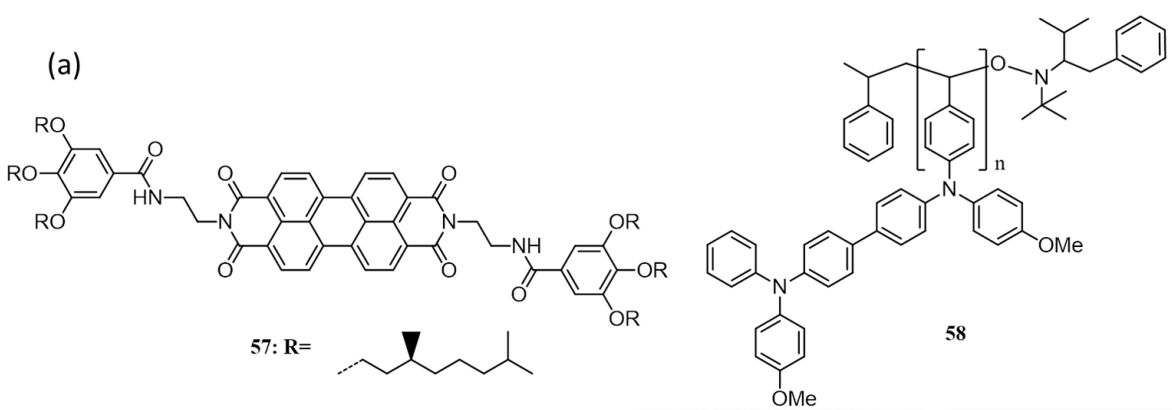

(b)
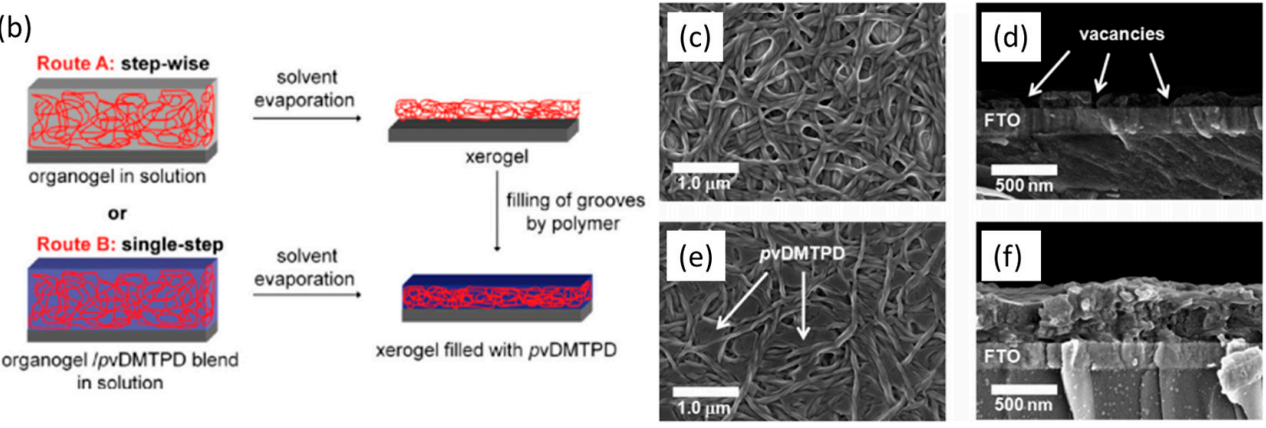

Figure 21. (a) Chemical structures of 57 and 58 synthesized by Würthner et al. [79] and Thelakkat et al. [80] (b) Schematic representation of the blending of organogel and polymer via route A and route B. SEM images of (c) 57-xerogel via route A and (d) corresponding cross section; (e) Surface image of 57-xerogel/58 blend (3:1) via route B and (f) corresponding cross-section. Abbreviated by authors as 58: poly(vinyl-dimethoxytetraphenylbenzidine) (pvDMTPD). Adapted with permission from Ref. [81] Copyright 2009 American Chemical Society. 
Hairpin molecules have the ability to form one-dimensional (1D) nanowires through pi-pi stacking and hydrogen bonding. These wires, with a grooved exterior, are known to provide high interfacial contact between donor and acceptor components [82]. Stupp et al. have synthesized a hairpin shaped gelator by connecting 1,2-cyclohexyldiamine having hydrogen bonding groups to a sexithiophene (59) self-assemble into 1D nanowires, Figure 22 [83]. The packing of the molecules will result in grooved nanostructures with void space, where small molecules like $\mathrm{PC}_{61} \mathrm{BM}$ get incorporated easily. At concentrations $>0.5 \mathrm{wt} \%$, the interpenetrated nanowires lead to the formation of gels in solvents such as toluene and chlorocyclohexane. Photovoltaic devices of 59 and $\mathrm{PC}_{61} \mathrm{BM}$ (40:60) in chlorobenzene gave the highest efficiency of $0.22 \%$ upon annealing at $80^{\circ} \mathrm{C}$, which decreased a little at $90{ }^{\circ} \mathrm{C}$ and drastically at $100{ }^{\circ} \mathrm{C}$. Differential scanning calorimetry and optical polarizing microscope analysis suggested that the nanostructures melt at $109{ }^{\circ} \mathrm{C}$ and do not reassemble upon cooling. This irreversible change of $\mathbf{5 9}$ in higher temperature is attributed to the drop in efficiency. They later changed the acceptor to $\mathrm{PC}_{71} \mathrm{BM}$, obtained an efficiency of $0.48 \%$ at $90{ }^{\circ} \mathrm{C}$. The role of self-assembly in this system was studied by fabricating devices with dihexylsexithiophene (60). This linear molecule consists of the same oligothiophene moiety but devoid of hydrogen bonding units. The PCE of the devices without annealing was $0.32 \%$, which was similar to the $59 / \mathrm{PC}_{71} \mathrm{BM}$ devices. Upon annealing at $80{ }^{\circ} \mathrm{C}$, the efficiency increased to $0.39 \%$ but further increase in temperatures drastically decreased the efficiency as in the case of $\mathbf{5 9}$. However, the mean PCE of $\mathbf{5 9}$ was $0.42 \%$, whereas, the mean PCE of $\mathbf{6 0}$ was $0.36 \%$. Welch's unpaired $t$-test at the $1 \%$ significance level proved the difference in mean between 59 and $\mathbf{6 0}$ was statistically significant. This work signifies the importance of grooved structure, which promotes receptor-ligand type configurations in bulk heterojunctions and improves device efficiency.

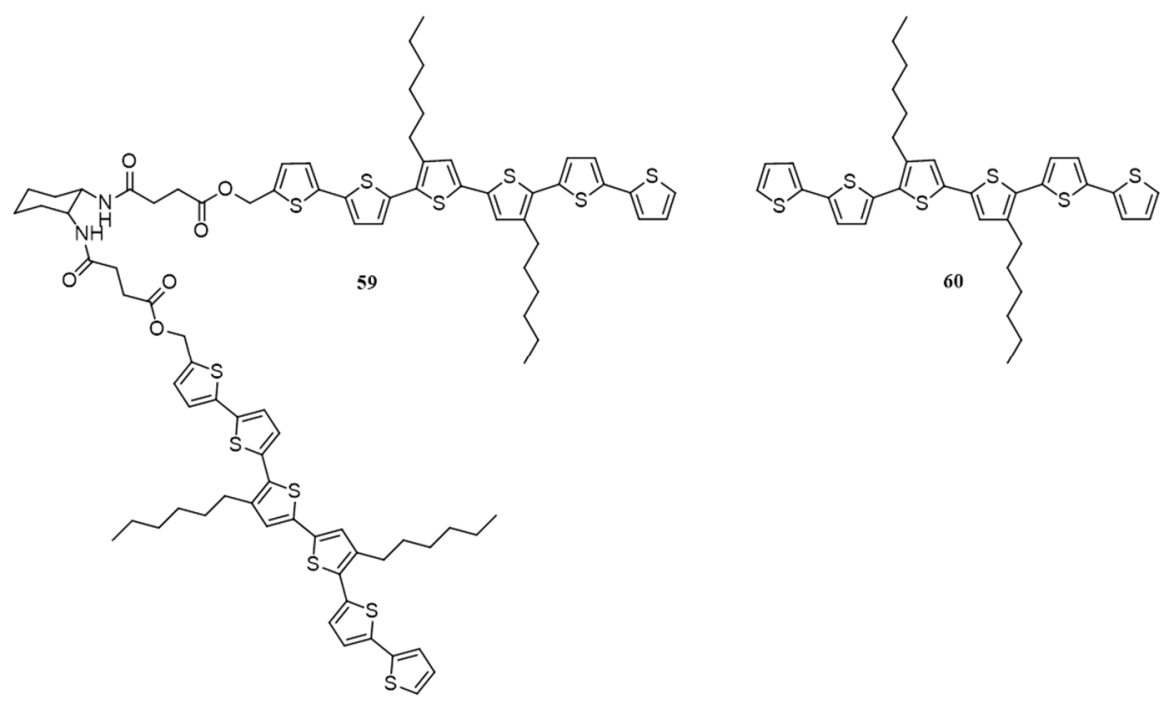

Figure 22. Chemical structures of 59 and $\mathbf{6 0}$ synthesized by Stupp et al. [83].

The same group has reported another hairpin-shaped molecule consisting of trans-1,2-diamidocyclohexane as core and DPP as the arm (61) having a chemical structure given in Figure 23 [84]. Self-assembled nanowires were prepared through a step-wise cooling process with minimal stirring of solutions. The fabricated devices of the nanowires with $\mathrm{PC}_{71} \mathrm{BM}(1: 1 \mathrm{wt} \%)$ as acceptor showed an optimized efficiency up to $0.53 \%$, which was significantly higher than those of devices prepared by simple mixing of donor and acceptor molecules. For comparison purposes, the authors have made cells using a linear molecule that contains the same arm of the hairpin molecule (62), which gave an efficiency of only $0.24 \%$. Therefore, synergistic action of hydrogen bonds and pi-pi stacking in donor molecules that created long nanowires by self-assembly results in devices that are more efficient than those built with analogous donor molecules containing only the conjugated structure. 


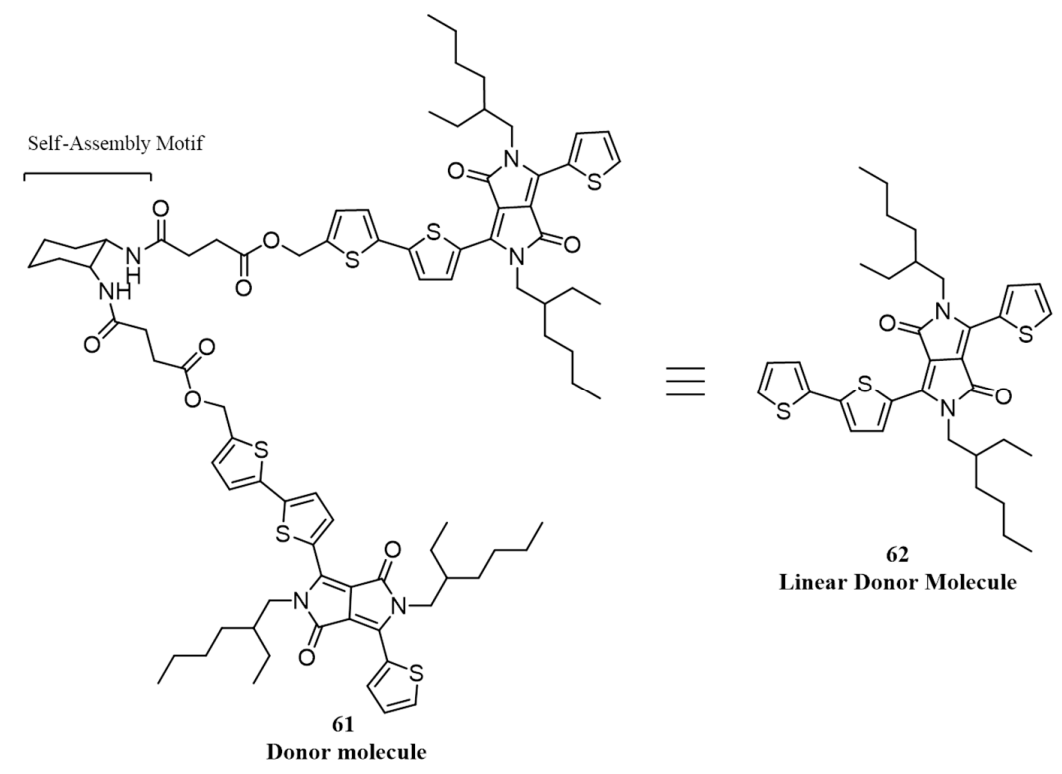

Figure 23. Chemical structures of $\mathbf{6 1}$ and $\mathbf{6 2}$ synthesized by Stupp et al. [84].

Dicarboxylic acid is an excellent end-functional group for enhancing intermolecular connectivity and crystallinity in solution-processable conjugated small molecules. As a proof of concept, quarterthiophenes end-functionalized with diester (63) and diacid (64) groups were synthesized by Lam and co-workers (Figure 24) and studied their photovoltaic properties [85]. The idea of using an acid end group is that it may result in strong hydrogen bonding which may assist pi-pi stacking between the oligomers. Consequently, the formation of a pseudo-polymer may happen, which was expected to improve the charge transport among the chains and enhance the efficiency of diacid in comparison with diester. In the film state absorption studies, an extended red-shift absorption in the visible region was observed in $\mathbf{6 4}$ with reference to $\mathbf{6 3}$, which is an indication of hydrogen bond induced pi-pi stacking in the molecule. The enhanced pi-pi stacking was also evident in the thermogravimetric analysis studies as 64 exhibited higher thermal transition temperatures than that of 63 . Solar cells were fabricated using 63 and $\mathbf{6 4}$ as donors and $\mathrm{PC}_{61} \mathrm{BM}$ as acceptor. 63 exhibited an efficiency of $0.39 \%$ for films fabricated from chlorobenzene and $0.42 \%$ for films from $o$-dichlorobenzene. For 64 , a solvent mixture of THF and DMF was used as the molecule has poor solubility in chlorinated solvents, and the PCE was $0.91 \%$.
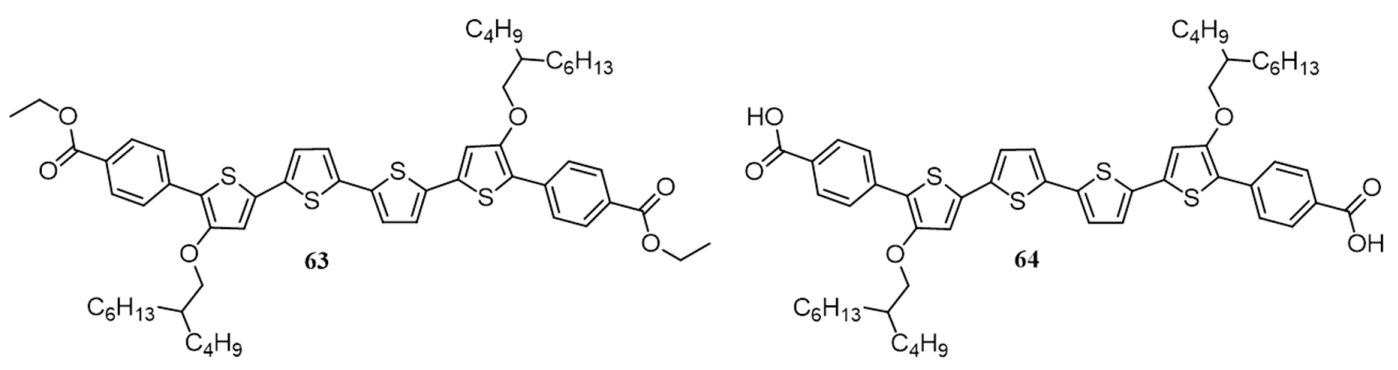

Figure 24. Chemical structures of the quarterthiophene core with diester (63) and diacid (64) end-groups, synthesized by Lam et al. [85].

Dipole-dipole interaction is another supramolecular force successfully used for developing BHJ based organic solar cells. According to the Bassler model, increased energetic disorder associated with dipole moments is detrimental to charge hopping and hence molecules with minimum or zero dipole moments are considered promising for optoelectronic applications [86,87]. However, certain reports suggest that the self-assembled centrosymmetric dimer formation of highly dipolar D-A systems 
eliminate molecular dipole moments at the supramolecular levels [88]. To illustrate the use of highly dipolar D-A substituted pi-systems in BHJ solar cells, Würthner and co-workers have synthesized six D-A dyes, 65-71 (Figure 25a) [89]. Among them, 66, 69 and 70 possess large ground state dipole moment $\left(\mu_{\mathrm{g}} ; 12-13 \mathrm{D}\right)$ and show small changes of the dipole moment $(\Delta \mu)$ upon optical excitation, whereas, 65, 67, 68 and 71 exhibits distinctly lower $\mu_{\mathrm{g}}$ and higher $\Delta \mu$ values. BHJ photovoltaic devices were fabricated with a device structure of ITO/PEDOT:PSS $(40 \mathrm{~nm}) /$ dye:PC ${ }_{61} \mathrm{BM} / \mathrm{Al}(120 \mathrm{~nm})$. Most of the cells showed low efficiency, but devices prepared from 67 and 68 exhibited higher $J_{S C}$ and PCEs of $2.3 \%$ and $3.0 \%$, respectively. Cells were later optimized using 68 , where clear improvements were seen upon replacing $\mathrm{PC}_{61} \mathrm{BM}$ with $\mathrm{PC}_{71} \mathrm{BM}$. Replacement of hole-transporting layer, PEDOT:PSS by $\mathrm{MoO}_{3}$ has further improved the efficiency to $4.5 \%$ and $5.1 \%$ under standard and reduced lighting conditions, respectively.

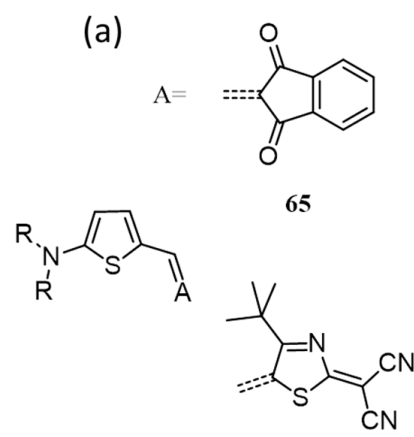

69

(b)

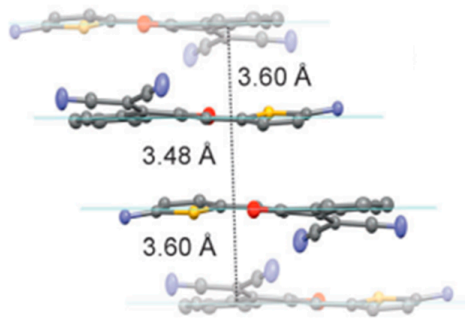

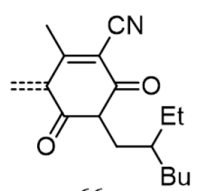

66<smiles>C=C(OCC)C(C#N)=C1N=C(c2ccccc2)S1</smiles>

70<smiles>C=C1C(=O)c2ccccc2C1=C(C#N)C#N</smiles>

67,68

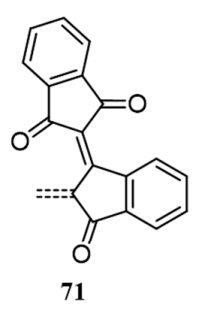

(c)

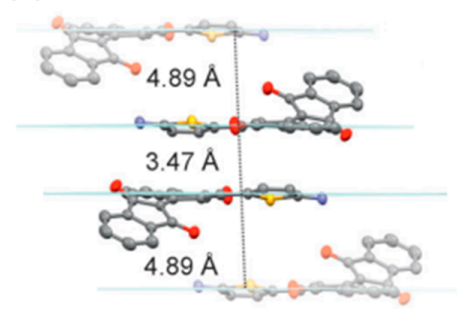

Figure 25. (a) Molecular structures of the investigated D-A dyes (65-71), synthesized by Würthner et al. [89].The substituents are $\mathrm{R}=n \mathrm{Bu}$ and $\mathrm{R}^{\prime}=\mathrm{Et}$ for 68 and $\mathrm{R}=\mathrm{R}^{\prime}=n \mathrm{Bu}$ for all other dyes. Adapted with permission from Ref. [89] Copyright 2011 WILEY-VCH Verlag GmbH \& Co. KGaA, Weinheim.

In 2012, Heeger, Bazan and co-workers synthesized four D'-A-D-A-D' type isomorphic small molecules for investigation of dipole moment effect and conformational stability on the self-assembly and photovoltaic performance [90]. All the four molecules are isomeric to each other, and the only difference in the structures is the position of the nitrogen atom. Three of them are based on symmetrical and unsymmetrical regiochemistries of the acceptor, $[1,2,5]$ thiadiazolo[3,4-c]pyridine (PT; 72-74) [91-93]. 75 has 2,1,3-benzothiadiazole (BT) acceptor as the core (Figure 26). Though the structures of these molecules are quite similar but they exhibited a significant difference in PCE mainly attributed to the difference in the molecular packing. The symmetrical molecules $\mathbf{7 2}$ and $\mathbf{7 3}$ gave best efficiencies (with $0.25 \mathrm{v} / \mathrm{v}$ DIO), $6.70 \%$ and $5.56 \%$, respectively, while unsymmetrical molecule showed lower efficiency (3.16\%). The depletion in the efficiency of $\mathbf{7 4}$ can be attributed to the packing frustration that resulted from the unsymmetrical geometry. With the increase in the $v \%$ of DIO, the efficiency goes down for all the four molecules. The molecules $\mathbf{7 2}$ and $\mathbf{7 3}$ possess strongest Bragg's reflections with scattering wave vector at $\approx 3$ and $\approx 18 \mathrm{~nm}^{-1}$ which attributes to crystalline domains 
and pi-pi stacking, respectively. For both, an amorphous scattering was observed at $\approx 13 \mathrm{~nm}^{-1}$. For 74, a broad peak was extended from 12 to $20 \mathrm{~nm}^{-1}$, which reflects its large degree of disorder. 75 exhibits lowest degree of order and HRTEM showed a lack of phase separation within the films, which resulted in low performance $(0.19 \%)$. It was concluded that the net dipole moment resulted in the difference of self-assembly in PT and BT based molecules. In BT containing molecule, local dipole moment distribution frustrates the self-assembly process. On the other hand, in the case of the PT-based molecule, the pyridyl $N$ atom imparts extra stability by minimizing the variation in net dipole moment and thereby enhancing the morphology of the active layer.
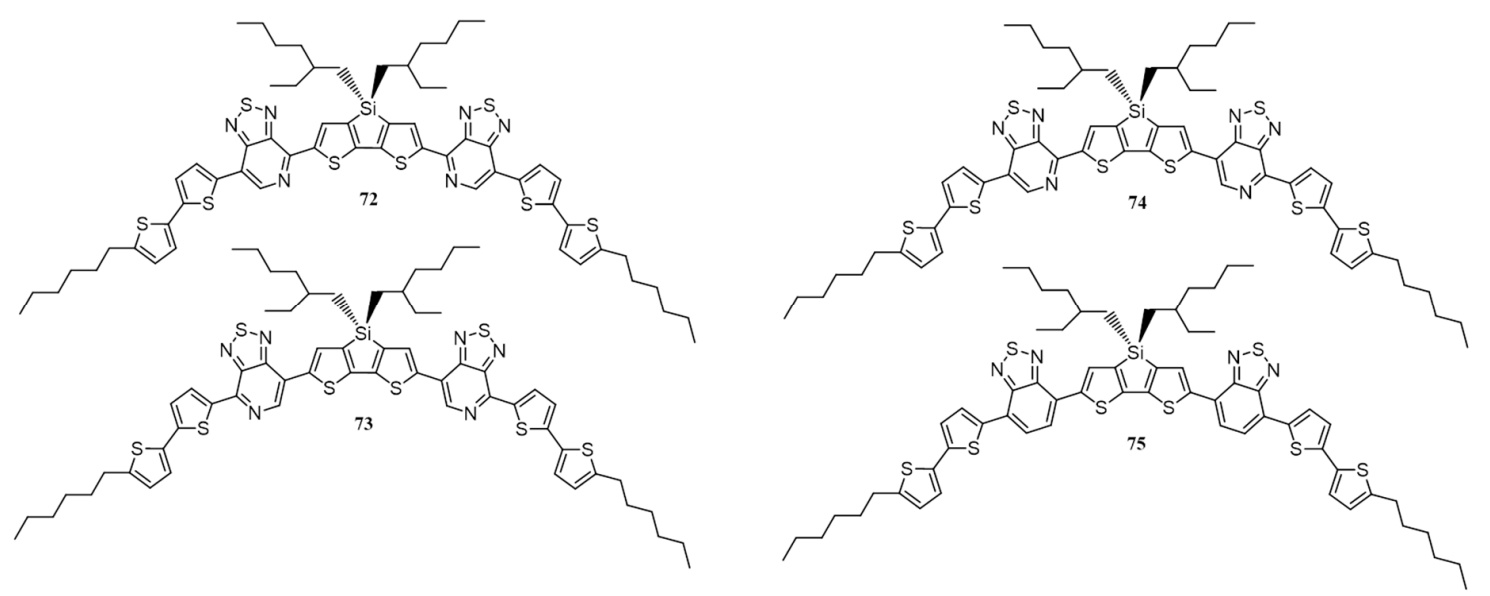

Figure 26. Molecular structures of compounds 72-75 synthesized by Heeger, Bazan et al. [91-93].

\section{Polymers}

Polymers are macromolecules composed of a large number of repeating units. In general, the organic polymers are insulating in nature due to the absence of free charge carriers. However, in 1977 Heeger, MacDiarmid and Shirakawa have changed the view on polymers as they could make polyacetylene conductive just like a metal through doping [94]. It was later understood that a key feature of a polymer that will be conductive is the presence of a linear series of overlapping $p_{z}$ orbitals with $\mathrm{sp}^{2}$ or $\mathrm{sp}$ hybridization (conjugated double or triple bonds), creating a chain of delocalized electrons. Consequently, the charge carriers are free to move along the long conjugated backbone, and hence they exhibit very interesting electronic properties. However, the electron delocalization locks in a planar conformation between monomers have often lead to rod-like behavior and liquid crystallinity in some polymers. This phenomenon drastically alters their behavior, often decreasing solubility and increasing kinetically trapped metastable structures. In self-assembling polymers, interpolymer charge transport is more difficult and normally limited by charge hopping from one polymer to the adjacent polymer. Therefore, these challenges needed to be solved by introducing supramolecular interactions within the polymers, thereby minimizing the death of charge carriers via charge hopping within them. Supramolecular interactions have been utilized in several non-conjugated polymers and conjugated polymers for developing BHJ solar cells. Typical examples in this category are discussed in the following section.

Construction of supramolecular side-chain polymers via association of proton acceptor (H-acceptor) polymers with low-bandgap proton donor (H-donor) dyes is a strategy adopted by many leading research groups for developing materials for photovoltaic applications. In 2009, Lin et al. prepared a number of such polymers by mixing pyridyl pendant containing $\mathrm{H}$-acceptor polymers $(\mathbf{7 6}, \mathbf{7 7})$ with low-bandgap H-donor dyes bearing terminal cyanoacrylic acids (78-81) in a molar ratio of 1:1 (Figure 27) [95]. The preparation of the supramolecular polymer complexes involves the dissolution of the dyes and polymers in THF, evaporation of the excess solvent and finally drying in vacuum at $60{ }^{\circ} \mathrm{C}$. The complexation of the dyes and the polymers through $\mathrm{H}$-bonding occurred during the 
solvent evaporation process. The hydrogen bonding in supramolecular side-chain polymers was confirmed by Fourier transform infrared spectroscopy (FTIR). Bulk-heterojunction solar devices were fabricated using the $\mathrm{H}$-bonded polymer complexes as donor and $\mathrm{PC}_{61} \mathrm{BM}$ as an acceptor in the wt ratio of 1:1. The highest efficiency $(0.50 \%)$ was obtained for the active layer composed of $76 / 80: \mathrm{PC}_{61} \mathrm{BM}$. The authors have also demonstrated the importance of $\mathrm{H}$-bonding by making a device consisting of a physically blended active layer of $\mathbf{7 6}$ and a non-hydrogen bonding methyl ester derivative of $\mathbf{7 8}$, which showed a lower efficiency of $0.16 \%$.
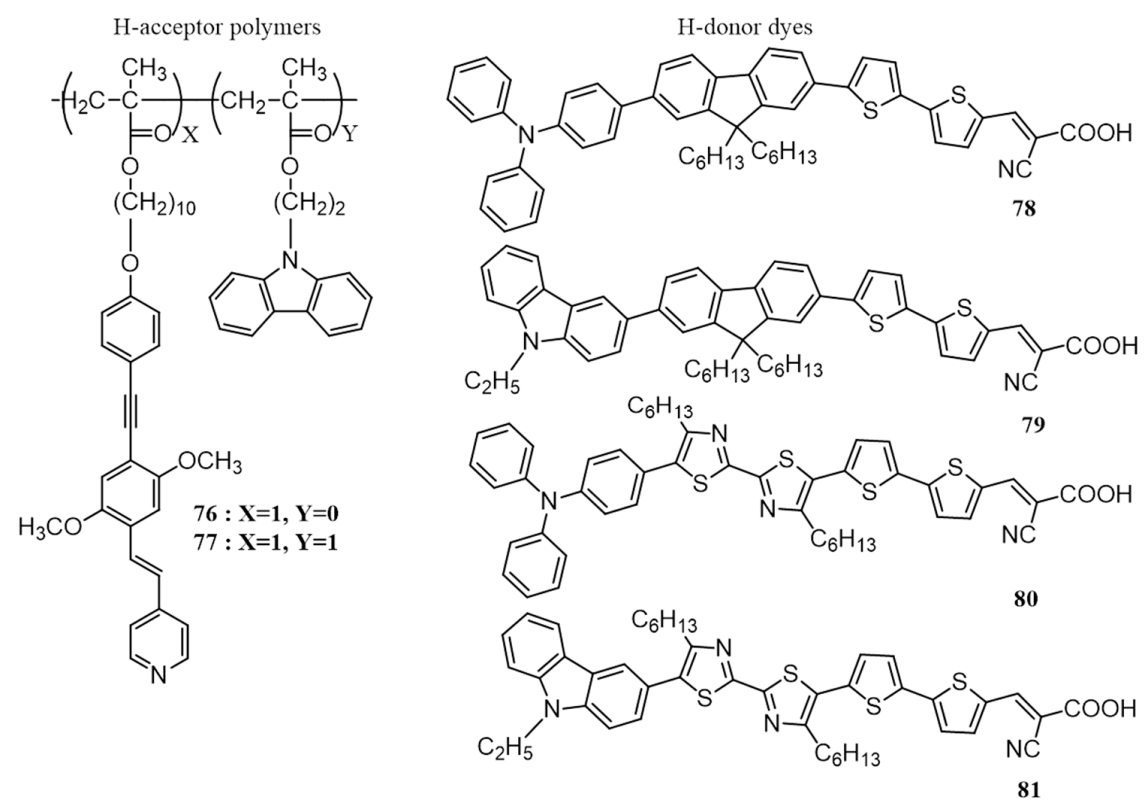

Figure 27. Chemical structures of the polymers $(\mathbf{7 6 , 7 7 )}$ and low-bandgap molecules $(\mathbf{7 8 - 8 1})$ synthesized by Lin et al. [95].

The same group reported a similar work in 2010, in which a series of H-bonded cross-linking polymers were prepared by complexing with fluorene based $\mathrm{H}$-acceptor polymer and carbazole based $\mathrm{H}$-donor dyes. The H-donors composed of 3,6- and 2,7-functionalized electron-donating carbazole cores flanked by symmetrical thiophene linkers and cyanoacrylic acid as the end group (83-86) are shown in Figure 28. The H-acceptor polymer consists of side-chain carrying pyridyl pendants (82) [96]. DFT calculations have predicted that the carbazole units of $\mathrm{H}$-donor are co-planar with the pi-spacer (conjugated thiophenes) and cyanoacrylic acids in the dyes. The supramolecular polymer networks were confirmed by FTIR. The complexes have a broad range of absorption in the visible range between 350 and $600 \mathrm{~nm}$. As in the previous case, BHJ photovoltaic devices were fabricated using H-bonded polymers as donors and $\mathrm{PC}_{61} \mathrm{BM}$ as the acceptor. The highest efficiency was obtained for $82 / 84(0.31 \%)$ which is attributed to broader absorption and increased photoinduced charge transfer as exhibited by the highest photoluminescence quenching. $\mathrm{BHJ}$ devices were also made by blending $\mathrm{PC}_{61} \mathrm{BM}$ with 82,84 and 85 , and the PCEs obtained were $0.02 \%, 0.15 \%$ and $0.11 \%$, respectively. These values are significantly lower than those of H-bonded polymer networks of $82 / 84(0.31 \%)$ and $\mathbf{8 2} / 85(0.24 \%)$. Therefore, supramolecular $\mathrm{H}$-interaction has proven to be a good method to enhance the PCE.

An approach to control the molecular stacking through the intermolecular H-bonds induced by solvents was demonstrated by Chen et al. They have synthesized a regioregular poly\{[3-(60-bromohexyl)thiophene]-co-[3-(6'-(1-imidazole)hexyl)thiophene]\} (87; Figure 29a) for building supramolecular nanoscale domains in polymer solar cells [97]. Studies proved that the polymer forms stable H-bonding with methanol. The self-assembly properties of the polymer were also explored in the presence of $\mathbf{8 8}$ (Figure 29b). In chlorobenzene, no higher order aggregates were observed, indicating that the compounds were molecularly dissolved and no interaction occurs 
between them. However, when $2 \% v / v$ methanol was added, the absorption intensity enhances with a red-shift in the absorption maximum due to stronger pi-pi stacking. The AFM height images of blend films show fiber-like textures (Figure 29b), suggesting that aggregates are present in this composition. Polymer solar cells that were cast from $\mathrm{CB} / \mathrm{MeOH}(49: 1)$ gave an efficiency of $1.65 \%$, which on annealing improved to $3.16 \%$. The authors concluded that the hydrogen bonds involved in the system provide a delicate balance between self-assembly of $\mathbf{8 8}$ and crystallization of $\mathbf{8 7}$ resulting in the desired morphology and better efficiency.

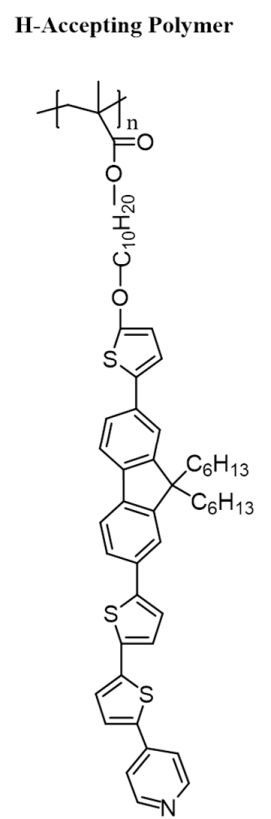

82

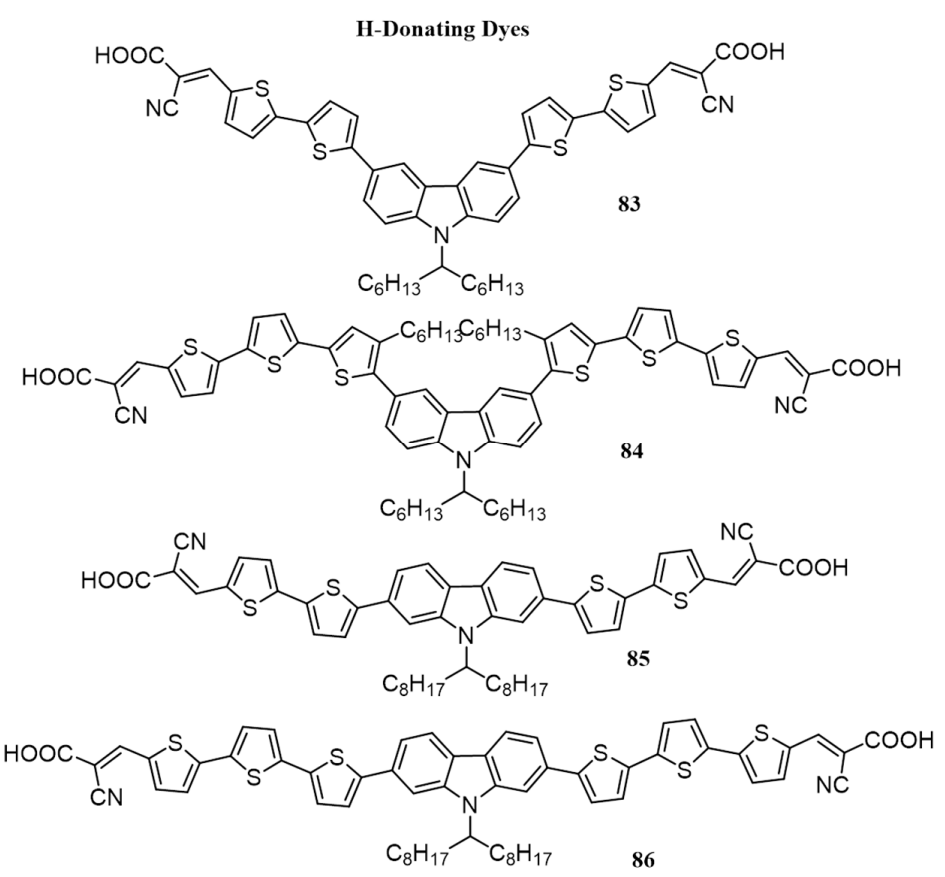

Figure 28. Chemical structures of the H-acceptor side-chain polymer (82) and H-donor dyes (83-86) synthesized by Lin et al. [96].

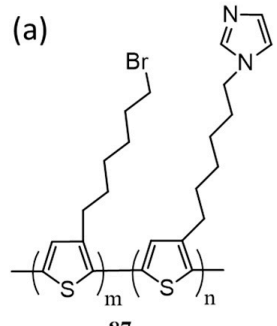

87

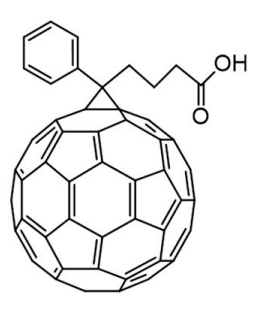

88

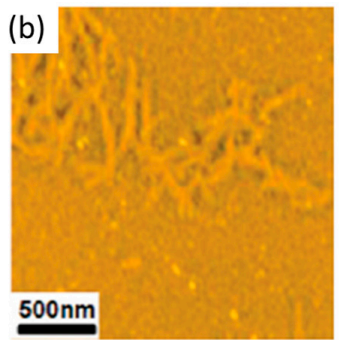

(b)

$500 \mathrm{~nm}$

Figure 29. (a) Chemical structure of $\mathbf{8 7}$ and $\mathbf{8 8}$ synthesized by Chen et al. [97] (b) Tapping-mode AFM topographic image obtained from the surfaces of 87/88 (1:0.8 w/w) films prepared as-spun using $\mathrm{CB} / \mathrm{MeOH}(49: 1)$ as a solvent. Adapted with permission from Ref. [97] Copyright 2012 American Chemical Society.

Recently, block copolymers (BCP) emerge as a promising class of materials or templates for organic solar cells. BCPs consist of two or more covalently bound non-compatible homopolymers. The incompatibility of the blocks leads to morphological segregation in the film state but the large scale segregation will be prevented due to the presence of covalent bonds. This unique behavior of BCPs makes them an ideal candidate for solar cells, and many reviews are available on this topic [98-104]. Rod-coil BCPs of poly(3-hexylthiophene) and polystyrene, poly(2-vinyl pyridine), or polylactide have been studied extensively by many groups [105]. Watkins et al. synthesized block copolymer, (89) comprised of poly(3-hexylthiophene) (18) and poly[3-(2,5,8,11-tetraoxadodecane)thiophene] (P3TODT) 
and studied the cooperative self-assembly with functionalized fullerene derivatives (90 and 91) in BHJ solar cells (Figure 30a) [106]. The cooperative self-assembly happens through H-bond between the fullerene and one segment of the block copolymer. UV-visible absorption and GIXRD data revealed the pi-pi stacking of $\mathbf{1 8}$ inducing crystallinity to the copolymer. AFM images of the thin films of $\mathbf{8 9}$ reveal a periodic nanostructure with some degree of long-range order. To study the effect of $\mathbf{9 0}$ on the crystallinity and molecular packing of 89 , GIXRD experiments were conducted on blend films of varying weight ratios (Figure 30b). It was found that the blend has similar peaks to that of 89 films which were attributed to the ordered 18 microdomains. This suggests that 90 get incorporated in the amorphous domains of P3TODT. Comparison of TEM images was conducted on the blend samples of BCP with 90 and 91 (Figure 30c,d). A clear macrophase separation was seen in the 89/91 film, while the $\mathbf{8 9 / 9 0}$ system exhibits nanostructure morphology due to favorable H-bonding between the polymer and fullerene derivative. Field-effect transistor analysis revealed that the hole mobility of $\mathbf{8 9}$ was slightly lower than $\mathbf{1 8}$. This could be due to the presence of amorphous P3TODT in the copolymer, which reduces the crystalline content compared to homo-18. BHJ cells were made from 89/90 (3:2) exhibited a higher PCE (2.04\%), in comparison to those with the 89/91 (3:2) system (0.95\%). For the 89/91 system, large domains of 91 (50-100 $\mathrm{nm}$ ) were observed, which reduce the donor-acceptor interface available for charge separation and results in low device efficiency.

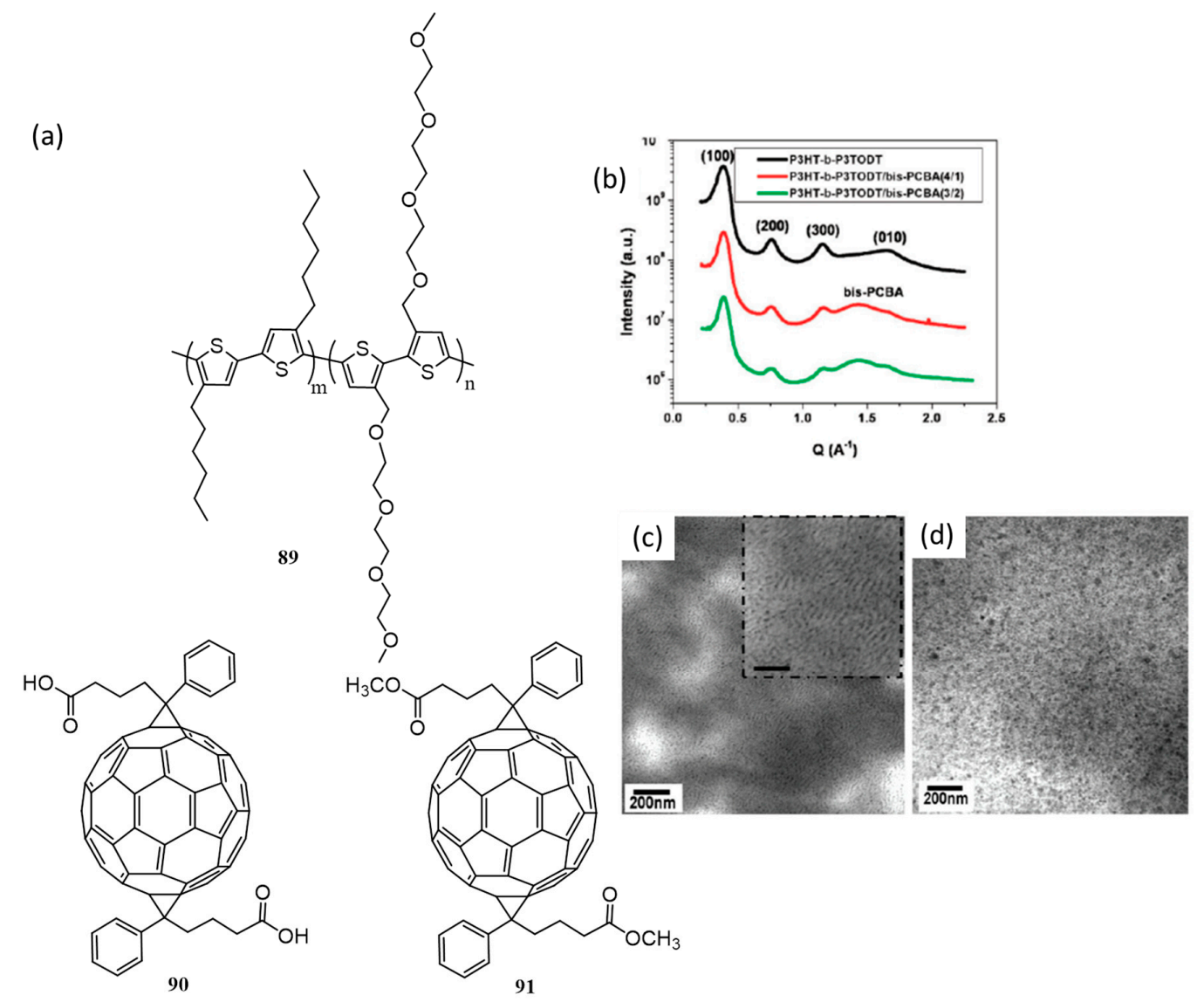

Figure 30. (a) Chemical structures of 89-91 synthesized by Watkins et al. [106]. (b) Overlay of GIXRD out-of-plane diffractograms of 89 and its blends with different ratio of $\mathbf{9 0}$. TEM images of (c) 89/91 (3:2) and (d) 89/90 (3:2), after thermal annealing at $150{ }^{\circ} \mathrm{C}$ for $30 \mathrm{~min}$. Abbreviated by authors as following: 89:P3HT- $b$-P3TODT, 90:bis-PCBA and 91:bis-PCBM. Adapted with permission from Ref. [106] Copyright 2012 American Chemical Society.

$\mathrm{Chu}$, Lin and co-workers have synthesized a low-bandgap polymer (92) consisting of bithiazole, dithieno[3,2-b:2', $\left.3^{\prime}-d\right]$ pyrroles, and pendent melamine derivatives [107]. Using the same method 
described by Lin et al. supramolecular polymers were made with complementary uracil-based conjugated cross-linkers containing carbazole (93) and fluorene (94). The structures of the polymer and the cross linkers are given in Figure 31. The supramolecular polymers (92/93 and 92/94) have enhanced properties in terms of light absorption, bandgap and crystallinity. The PCEs of fabricated devices, where the active layer was composed of supramolecular polymer networks as electron donors and $\mathrm{PC}_{71} \mathrm{BM}$ as an electron acceptor in the ratio $1: 1$ were found to be $0.97 \%$ and $0.68 \%$, respectively. In contrast, a blend of polymer 92 with $\mathrm{PC}_{71} \mathrm{BM}$ yielded an efficiency of $0.52 \%$. The PCE of $\mathbf{9 2} / \mathbf{9 3}$ was further improved to $1.56 \%$ by changing the polymer $/ \mathrm{PC}_{71} \mathrm{BM}$ ratio to $1: 2 w / w$.

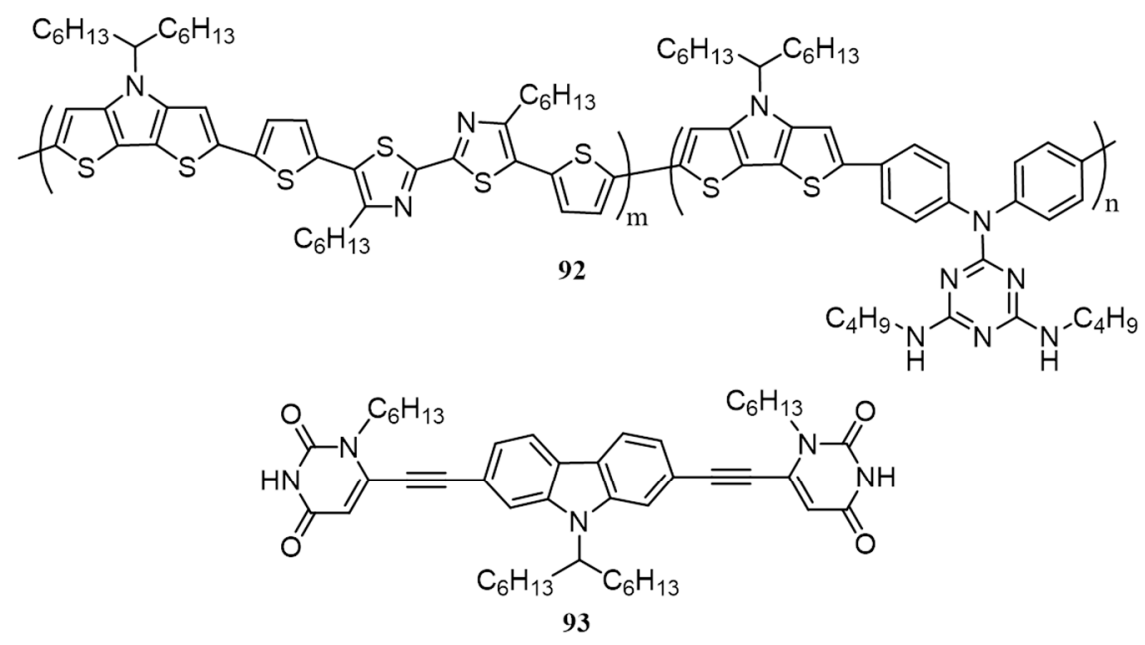

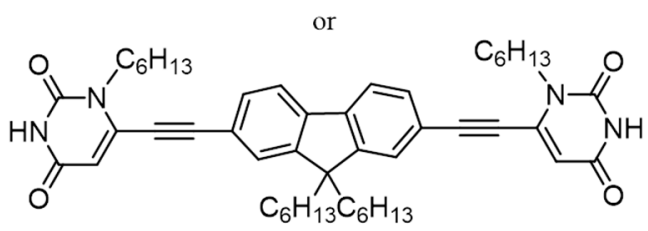

94

Figure 31. Chemical structure of the conjugated main-chain polymer (92) and complementary uracil-based conjugated cross-linkers (93 and 94$)$, synthesized by Lin et al. [107].

In another work utilizing the 'three point' complementary H-bonding, Qin et al. in 2013, synthesized 1-n-hexylisoorotic acid functionalized BCP (95) and 2,6-diaminopyridine tethered $\mathrm{PC}_{61} \mathrm{BM}$ analog (96; Figure 32) [108]. In order to study the complementary H-bonding between 95 and 96, fluorescence titration experiments were carried out. Quenching of $26 \%$ in fluorescence intensity of $\mathbf{9 5}$ was observed, whereas, less than 7\% decrease was seen for $\mathbf{1 8}$ under identical conditions. The Stern-Volmer constants obtained from quenching studies proved the presence of a strong binding between 95 and 96 in chlorobenzene at room temperature. The strength of the 'three-point' hydrogen bonding was further confirmed by ${ }^{1} \mathrm{H}$ NMR titration experiments between 96 and 97 (97 is a model compound) in $\mathrm{CDCl}_{3}$. The devices were fabricated with conventional structures by varying the weight ratios of polymer to the fullerene derivatives. It was observed that the composition of

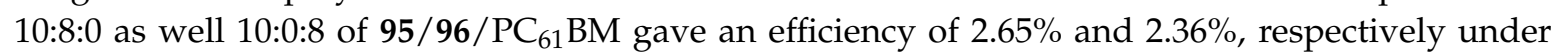
optimized conditions. It was obvious that the devices of 10:8:0 performed well due to the 'three-point' complementary interactions present in the donor/acceptor moieties.

Verduzco et al. have extensively studied the use of BCPs for photovoltaic applications [109-114]. Very recently, they reported the photovoltaic properties of a supramolecular BCP consisting of

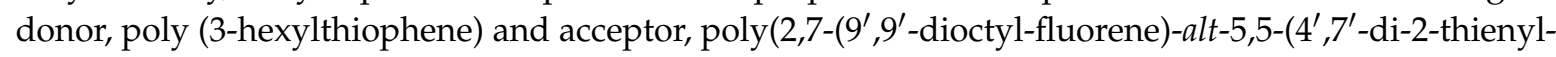
$2^{\prime}, 1^{\prime}, 3^{\prime}$-benzothiadiazole)) conjugated polymers connected through self-associating ureido-pyrimidinone hydrogen bonding units (Figure 33) [115]. Mixing of $\mathbf{9 8}$ and $\mathbf{1 0 0}$ containing hydroxyl groups 
form non-associating conjugated polymer blends while mixing of 99 and 101 containing ureido-pyrimidinone end group resulted in supramolecular BCP. BHJ cells were prepared using conventional device architecture and compared the performance of supramolecular BCP with that of the non-associating conjugated polymer blends under two different annealing conditions: 100 and $155{ }^{\circ} \mathrm{C}$. The non-associative blends exhibited a decrease in PCE at higher annealing temperature (from $0.62 \%$ to $0.43 \%$ ) while the supramolecular BCP exhibited an enhancement in performance (from $0.45 \%$ at $100{ }^{\circ} \mathrm{C}$ to $0.77 \%$ at $155{ }^{\circ} \mathrm{C}$ ). Morphological analysis proved that the supramolecular association increased the miscibility and long-range ordering of P3HT crystallites at elevated temperatures which resulted in performance superior to non-associating conjugated polymer blends. The enhancement was also attributed to the inhibition of large scale macroscopic phase separation in supramolecular BCP.

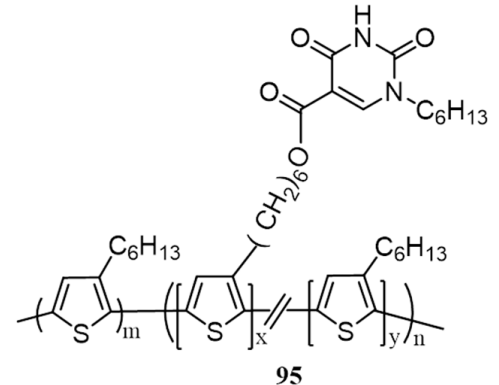

$\mathrm{m} / \mathrm{n}=6 / 1, \mathrm{x} / \mathrm{y}=1 / 1$

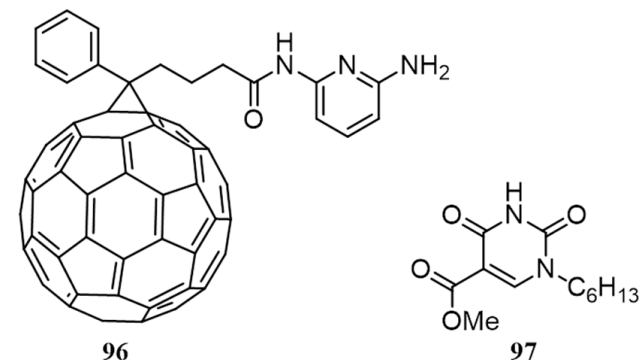

96

97

Figure 32. Chemical structures of the functionalized block copolymer (95), 2,6-diaminopyridine tethered fullerene derivative (96) and the model compound (97) synthesized by Qin et al. [108].

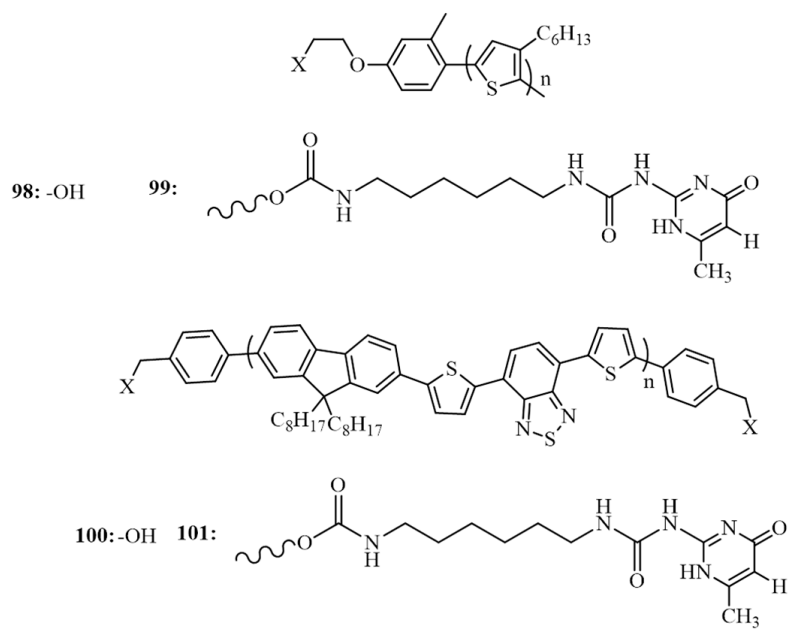

Figure 33. Chemical structures of 98-101 synthesized by Verduzco et al. [115].

Poly(p-phenylenevinylene) (PPV) is an attractive class of conjugated polymer for advanced device applications due to their interesting optical and electronic properties. Reports suggest that PPVs are good candidates for BHJ solar cells. Tan and co-workers in 2008 synthesized PPV derivatives consisting of triphenylamine moieties capable of 3D pi-pi stacking as side chains (102 and 103; Figure 34) [116]. For comparison, PPV without triphenylamine (104) was also synthesized. The BHJ solar cells in combination with fullerene $\left(\mathrm{PC}_{61} \mathrm{BM}\right)$ have been fabricated and characterized. The $\mathrm{PCE}$ of $103 / \mathrm{PC}_{61} \mathrm{BM}$ $(0.45 \%)$ was higher in comparison with that of $102 / \mathrm{PC}_{61} \mathrm{BM}(0.27 \%)$, while 104 gave an efficiency of $0.09 \%$. The results indicated that improved efficiency for $\mathbf{1 0 2}$ and $\mathbf{1 0 3}$ was due to the extended conjugated side chains of triphenylamine moieties by 3D pi-pi stacking, which was also reflected in the improvement in the hole-transporting properties of these polymers. 


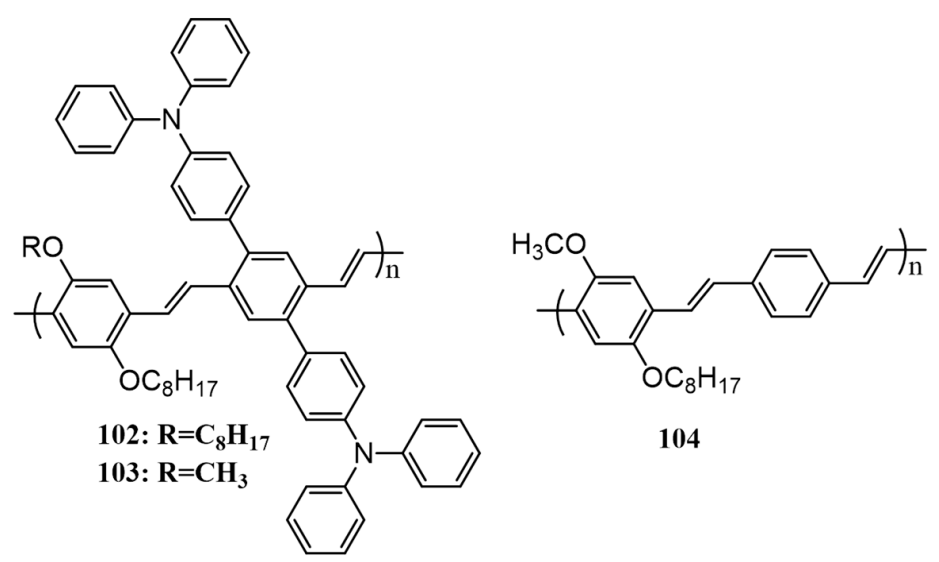

Figure 34. Chemical structure of the PPV derivatives (102-104) synthesized by Tan et al. [116].

Quinacridone, commonly known as red-violet pigment is used for making organic thin film transistors with high mobility [117]. This planar molecule exhibit high crystallizability and excellent self-assembly properties. A novel poly[quinacridone-quaterthiophene] (105) containing quinacridone and quaterthiophene derivatives was synthesized by Moon et al. in 2008 (Figure 35a) [118]. It was expected that the compound would show efficient self-assembly and charge carrier mobility due to the presence of quinacridone core. Film state X-ray diffraction measurements were done to analyze the ordering structure of 105 . A d-spacing of $23.2 \AA(\lambda=2 \mathrm{~d} \sin \theta)$, indicates that 105 formed the conventional edge-on pi-stacking on the substrate while the pi-pi stacking distance was found to be $3.5 \AA$. The photovoltaic device of the polymer with $\mathrm{PC}_{71} \mathrm{BM}(1: 2)$ gave an efficiency of $2.3 \%$ and $2.0 \%$ in the presence and absence of poly[(9,9-bis(30-( $N, N$-dimethylamino)propyl)-2,7-fluorene)-alt-2,7-(9,9-dioctylfluorene)] (PFN), respectively. PFN is used to enhance the interfacial adhesion and electron transport properties between the active layer and cathode.

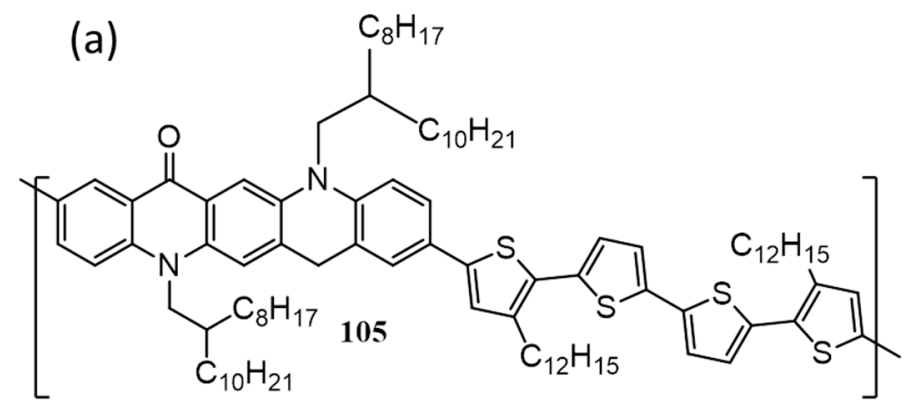
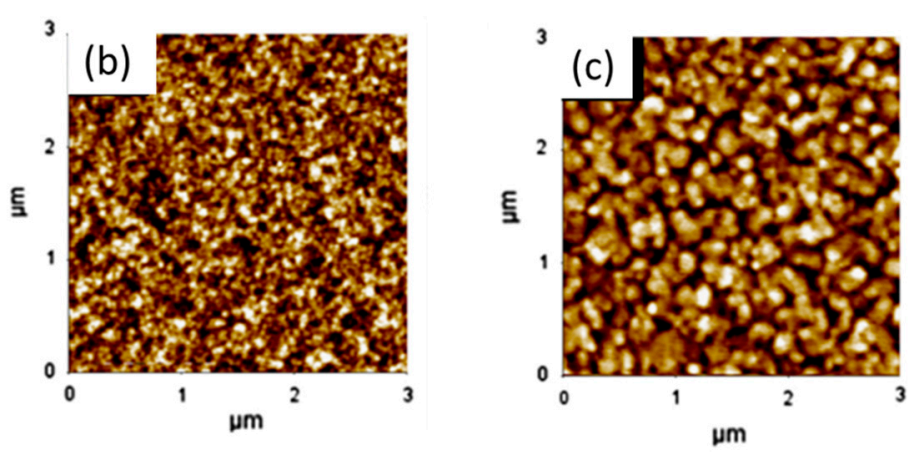

Figure 35. (a) Chemical structure of the polymer (105) synthesized by Moon et al. [118]. Topographic AFM images of (b) 105/PC ${ }_{71} \mathrm{BM} 1: 1\left(3 \times 3 \mu \mathrm{m}^{2}\right)$ and (c) 105/PC 71 BM 1:2 $\left(3 \times 3 \mu \mathrm{m}^{2}\right)$. Adapted with permission from Ref. [118] 2013 Elsevier. 
Interestingly, when the donor/acceptor weight ratio was changed to 1:1, the efficiency was dropped to $1.1 \%$ without PFN and $1.8 \%$ with PFN. In order to understand the difference in performance by varying the ratio of the active layer, hole mobility was measured using SCLC method. The hole mobility of $105 / \mathrm{PC}_{71} \mathrm{BM}$ film of 1:1 ratio was estimated to be $4.70 \times 10^{-3} \mathrm{~cm}^{2} \cdot \mathrm{V}^{-1} \cdot \mathrm{s}^{-1}$, while that of 1:2 ratio was $3.85 \times 10^{-3} \mathrm{~cm}^{2} \cdot \mathrm{V}^{-1} \cdot \mathrm{s}^{-1}$. Since the electron mobility of $\mathrm{PC}_{71} \mathrm{BM}$ was $2 \times 10^{-3} \mathrm{~cm}^{2} \cdot \mathrm{V}^{-1} \cdot \mathrm{s}^{-1}$, a better balance in the hole and electron transport happen only in 1:2 blended films. Apart from this, AFM images of the active layer with 1:1 ratio (Figure 35b) posed good micro-phase separation between polymer and $\mathrm{PC}_{71} \mathrm{BM}$, whereas, the blend film showed self-assembled, large domains when the ratio was 1:2 (Figure 35c). The former morphology is good for a better charge carrier generation yielding higher efficiency.

Kim et al. have reported that a low-bandgap polymer, poly[4,8-bis(5-(2-ethylhexyl)thiophen2-yl)benzo[1,2-b:4,5- $\left.b^{\prime}\right]$ dithiophene-alt-3-fluoro thieno [3,4-b] thiophene-2-carboxylate] (106) as the electron donor[119] and poly[[ $N, N^{\prime}$-bis(2-octyl dodecyl)- napthalene-1,4,5,8-bis(dicarboximide)-2,6diyl]-alt-5,5'-(2,2'-bithiophene)] (107) as the acceptor[120] for BHJ solar cells [121]. The structures of the polymers are shown in Figure 36. Both donor and acceptor have large pi-plane to facilitate better stacking. From contact angle experiments, it was observed that the polymers have very similar surface tensions of 26.1 and $25.5 \mathrm{mN} \cdot \mathrm{m}^{-1}$, respectively. Therefore, it was assumed that the polymer blends have the potential for forming well-intermixed morphology with suppressed phase separation as it possesses extremely low interfacial tension of $0.25 \mathrm{mN} \cdot \mathrm{m}^{-1}$ between the domains of 106 and 107 . In order to understand the real potential, photovoltaic cells were fabricated with blends of donor/acceptor polymers (1.3:1). Cells with inverted architecture gave an efficiency of $4.60 \%$ with DIO (1.25 vol \%), and 3.41\% without DIO. For gaining a deeper understanding of the effect of DIO, charge-carrier mobilities of the blends were measured. A ten-fold increase in the electron mobility was observed for devices with DIO than that of devices without DIO. As a result, the ratio between the hole and electron mobilities in the former device were more balanced, which reduces the charge recombination thus yielding better photovoltaic performance. The direct evidence for the effect of DIO on the morphology of the polymer solar cells was obtained from 2D-GIXRD scattering analysis as shown in Figure 36b-e. The film of 107 showed strong (100), (200), and (300) peaks with pronounced reflections in both in-plane and out-of-plane directions, whereas, 106 showed only first order reflections. Upon blending of 106/107 in the absence of DIO, the disappearance of higher order peaks of 107 was observed. However, a remarkable recovery of the crystalline features of $\mathbf{1 0 7}$ along with a prominent pi-pi stacking peak with face-on geometry was observed in the presence of DIO. Highly ordered face-on stacks of the polymers treated with DIO led to the better charge transport from the active layer to the corresponding electrodes, eventually resulted in higher PCE in comparison to blends without DIO.

As in the case of PDIs, naphthalenediimide (NDI) based systems also have a strong tendency to aggregate in specific organic solvents. BHJ active layers comprised of naphthalene derivatives often contain large aggregates resulting in poor efficiency. Neher et al. were able to successfully suppress this preaggregate formation at the early stages of film formation by using highly polarizable aromatic solvents such as $p$-xylene, chloronaphthalene and tetralin [121]. Prior to fabrication of solar cell the optical properties of the polymers were studied in different solvents (toluene, $p$-xylene, chlorobenzene, chloroform, dichlorobenzene, trichlorobenzene, tetralin and chloronapthalene). A high degree of preaggregation was observed in toluene and $p$-xylene, while aggregation was weaker or even absent in tetralin and chloronapthalene. The authors fabricated BHJ solar cells consisting of poly(3-hexylthiophene) (18) as donor and NDI copolymers $(\mathbf{1 0 8 , 1 0 9 )}$ as acceptors (Figure 37). In the case of 108, highest PCE (1.4\%) was obtained for a mixture of $p$-xylene and chloronaphthalene (1:1), while $\mathbf{1 0 9}$ gave the highest efficiency $(1.1 \%)$ when fabricated from tetralin. 


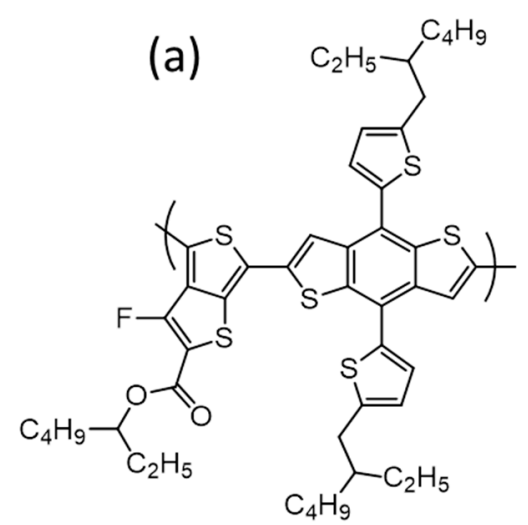

106
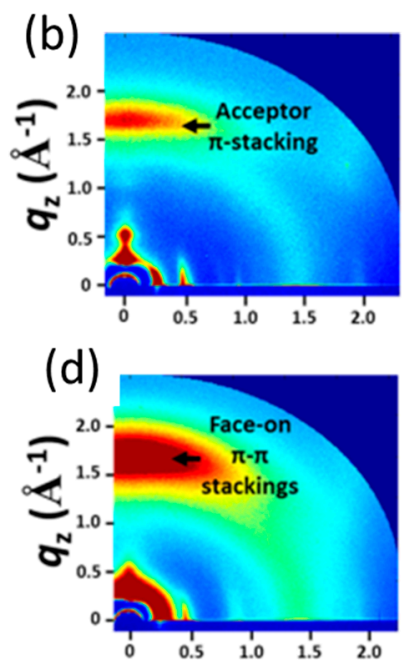

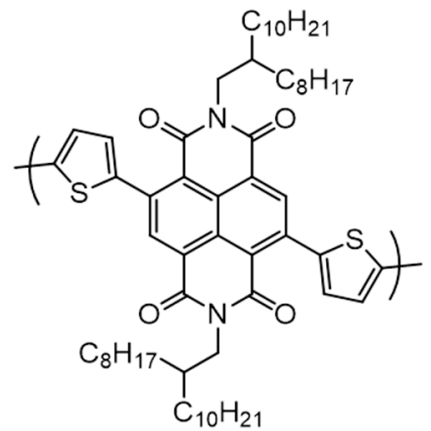

107

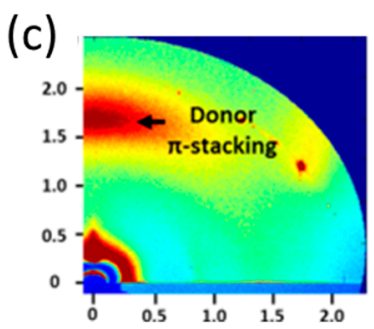

(e)

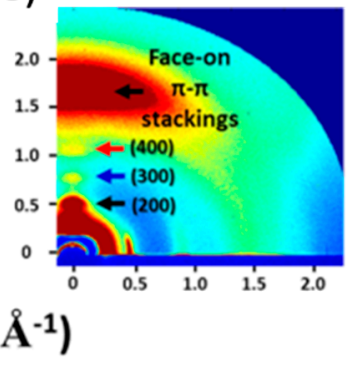

Figure 36. (a) Chemical structure of polymers (106 and 107) synthesized by Kim et al. [121]. 2D-GIXRD images of (b) 107; (c) 106, 106/107 blend (1.3:1) films (d) without DIO; and (e) with DIO. Adapted with permission from Ref. [121] Copyright 2014 American Chemical Society.

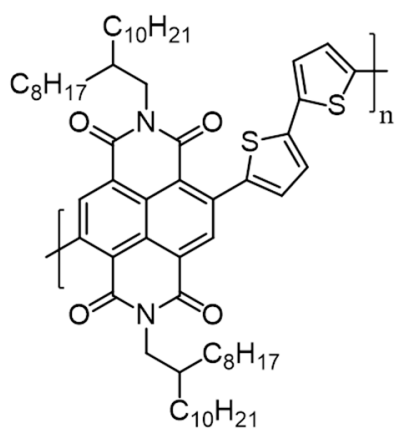

108

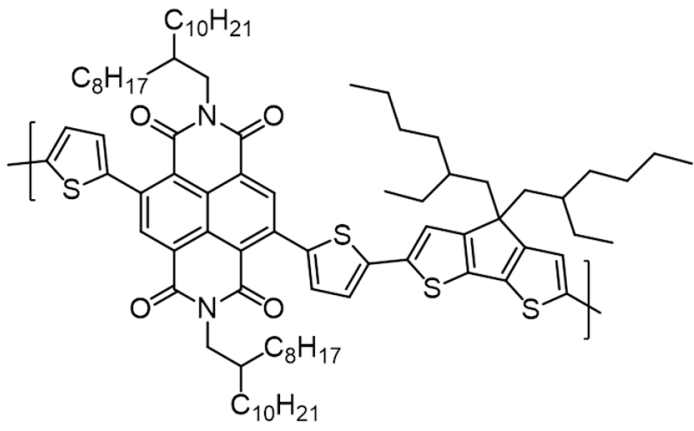

109

Figure 37. Chemical structure of copolymer acceptors (108 and 109) synthesized by Neher et al. [121].

\section{Conclusions}

Use of various supramolecular interactions is a proven way of making functional nanostructures with desired morphological features. In recent years, scientists have been using these weak non-covalent interactions for making organic solar cell devices with good stability. In this review, 
we have briefly discussed all works where supramolecular interactions were used effectively for making photovoltaic devices. Table 1 summaries the various photovoltaic parameters of the organic small molecules and polymers discussed in this review along with the corresponding references. These reports clearly suggest that supramolecular interactions and self-assembly are an impressive tool in tuning and tailoring the nanoscale domains of the active layer of organic solar cells. Both hydrogen bonding and pi-pi stacking improve the film quality and electronic communication between the chromophores. However, excessive aggregation of the chromophores through these interactions results in large scale domains, leading to poor exciton dissociation. Moreover, due to the increase in the surface roughness of the film, the charge carrier collection efficiency at the electrode interface also decreases, yielding poor power conversion efficiencies. No universal methods have been developed to address this issue and the control of the size of the nanostructures still remains a concern. However, rational selection of solvents, solvent additives and post-fabrication temperature treatments was found to be useful in certain cases. Limiting pi-stacking through the use of covalently fixed twisted dimers and bulky side chains are effective in non-fullerene acceptors. Another major issue is the lack of control over the direction of the self-assembly in systems for OPV applications. Chromophore packing perpendicular to the substrate/electrode surface is absolutely necessary for good efficiency. In summary, although supramolecular materials based technologies are ready for industrial applications, the use of supramolecular interactions in organic solar cells for commercial use needs more time as it is still in its infancy stage.

Table 1. Photovoltaic parameters of the BHJ solar cells discussed in this review.

\begin{tabular}{|c|c|c|c|c|c|c|c|}
\hline SI No & Device Structure & $\begin{array}{c}J \mathrm{SC} \\
\left(\mathrm{mA} \cdot \mathrm{cm}^{-2}\right)\end{array}$ & $V_{\text {OC }}(\mathrm{V})$ & FF & $\eta(\%)$ & $\begin{array}{l}\text { Light Intensity } \\
\left(\mathrm{mW} \cdot \mathrm{cm}^{-2}\right)\end{array}$ & Ref. \\
\hline 1. & ITO/PEDOT:PSS/1:PC 61 BM(1:2.8)/Al & 0.32 & 0.82 & 0.39 & 0.10 & 88 & [48] \\
\hline 2. & ITO/PEDOT:PSS/6:PC 61 BM(1:1)/ZnO/Al & 5.10 & 0.96 & 0.49 & 2.40 & 100 & [51] \\
\hline 4. & ITO/PEDOT:PSS/12:PC 61 BM(1:1)/Ca/Al & 7.00 & 0.79 & 0.54 & 3.01 & 100 & [53] \\
\hline 5. & ITO/PEDOT:PSS /17:PC 61 BM(1:1)/Ca/Al & 7.74 & 0.83 & 0.46 & 2.98 & 100 & [54] \\
\hline 6. & ITO/PEDOT:PSS/P3HT:PC 61 BM(1:4)/Al & - & - & - & 1.77 & 100 & [55] \\
\hline 7. & ITO/PEDOT:PSS/22:PC 61 BM(1:1)/Al & 0.84 & 0.47 & 0.46 & 0.18 & 100 & [56] \\
\hline 10. & ITO/PEDOT:PSS/31:PC 61 BM(1:2)/Al & 1 & 0.6 & 0.38 & 0.26 & 100 & [59] \\
\hline 11. & ITO/PEDOT:PSS/32:PC 61 BM(1:1)/ZnO/Al & 3.90 & 0.64 & 0.47 & 1.15 & 100 & {$[60]$} \\
\hline 12. & $\mathrm{ITO} / 35: 36(40: 60) / \mathrm{Al}$ & 0.03 & 0.69 & 0.40 & 1.95 & 0.47 & [63] \\
\hline 13. & ITO/PEDOT:PSS/38:PC ${ }_{71} \mathrm{BM}(1: 3) / \mathrm{LiF} / \mathrm{Al}$ & 9.32 & 0.57 & 0.37 & 2.05 & 100 & {$[64]$} \\
\hline 14. & ITO/PEDOT:PSS/43:PC 71 BM(2:1)/Al & 8.3 & 0.76 & 0.58 & 4.1 & 100 & [65] \\
\hline 15. & ITO/PEDOT:PSS / 46:PC 71 BM(3:2)/LiF/Al & 7.26 & 0.67 & 0.49 & 2.4 & 100 & [67] \\
\hline 16. & 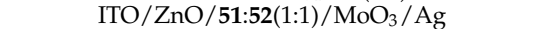 & 6.56 & 1.02 & 0.54 & 3.67 & 100 & [74] \\
\hline 22. & ITO/PEDOT:PSS/64:PC ${ }_{61} \mathrm{BM}(1: 1) / \mathrm{Al}$ & 2.86 & 0.71 & 0.45 & 0.91 & 100 & [85] \\
\hline 23. & $\mathrm{ITO} / \mathrm{MoO}_{3} / 68: \mathrm{PC}_{71} \mathrm{BM}(45: 55) / \mathrm{Ba} / \mathrm{Ag}$ & 10.5 & 0.99 & 0.49 & 5.10 & 23 & [89] \\
\hline 24. & $\mathrm{ITO} / \mathrm{MoO}_{x} / 72: \mathrm{PC}_{70} \mathrm{BM}(70: 30) / \mathrm{Al}$ & 0.78 & 14.4 & 0.59 & 6.70 & 100 & [90] \\
\hline 25. & ITO/PEDOT:PSS/76/80:PC ${ }_{61} \mathrm{BM}(1: 1) / \mathrm{Ca} / \mathrm{Al}$ & 3.17 & 0.47 & 0.34 & 0.50 & 100 & [95] \\
\hline 26. & ITO/PEDOT:PSS/82/84:PC 61 BM(1:1)Ca/Al & 1.90 & 0.55 & 0.29 & 0.31 & 100 & [96] \\
\hline 27. & ITO/PEDOT:PSS/87:88(1:0.8)/LiF/Al & 9.11 & 0.67 & 0.51 & 3.16 & 100 & [97] \\
\hline 28. & ITO/PEDOT:PSS/89/90(3:2)/LiF/Al & 6.32 & 0.58 & 0.55 & 2.04 & 100 & [106] \\
\hline 29. & ITO/PEDOT:PSS/92/93:PC $71 \mathrm{BM}(1: 2) / \mathrm{Ca} / \mathrm{Al}$ & 7.16 & 0.60 & 0.36 & 1.56 & 100 & [107] \\
\hline 30. & $\mathrm{ITO} / \mathrm{MoO}_{3} / \mathbf{9 5}: 96(10: 8) / \mathrm{Al}$ & 8.59 & 0.59 & 0.52 & 2.65 & 100 & {$[108]$} \\
\hline 31. & ITO/PEDOT:PSS/99:101(1:1)/Al & 3.18 & 0.96 & 0.25 & 0.77 & 100 & {$[115$} \\
\hline 32. & ITO/PEDOT:PSS/103:PC ${ }_{61} \mathrm{BM}(1: 1) / \mathrm{LiF} / \mathrm{Al}$ & 1.20 & 0.89 & 0.38 & 0.45 & 90 & [116] \\
\hline 33. & ITO/PEDOT:PSS/105:PC 71 BM(1:2)/Al & 7.90 & 0.59 & 0.49 & 2.3 & 100 & {$[118$} \\
\hline 34. & ITO/PEDOT:PSS/106:107(1.3:1)/LiF/Al & 10.61 & 0.82 & 0.53 & 4.60 & 100 & [120] \\
\hline 35. & ITO/PEDOT:PSS/18:108(1:0.75)/Sm/Al & 3.77 & 0.56 & 0.65 & 1.4 & 100 & {$[121]$} \\
\hline
\end{tabular}

Acknowledgments: Vijayakumar C. Nair thank Department of Science \& Technology (DST) Ramanujan Fellowship (SR/S2/RJN-133/2012) and Council of Scientific \& Industrial Research (CSIR) network project NWP-54 (TAPSUN) for financial support. Tanwistha Ghosh and Jayanthy S. Panicker are grateful to University Grants Commission (UGC) for the Senior Research Fellowship.

Conflicts of Interest: The authors declare no conflict of interest. 


\section{References}

1. Cheng, Y.-B. Print Flexible Solar Cells. Nature 2016, 539, 488-489. [CrossRef] [PubMed]

2. Nazeeruddin, M.K. Twenty-Five Years of Low-Cost Solar Cells. Nature 2016, 538, 463-464. [CrossRef] [PubMed]

3. Banerji, N. Organic Photovoltaics: Pushing the Knowledge of Interfaces. Nat. Mater. 2017. [CrossRef] [PubMed]

4. Major, J.D.; Treharne, R.E.; Phillips, L.J.; Durose, K. A Low-Cost Non-Toxic Post-Growth Activation Step for CdTe Solar Cells. Nature 2014, 511, 334-337. [CrossRef] [PubMed]

5. Battaglia, C.; Cuevas, A.; De Wolf, S. High-Efficiency Crystalline Silicon Solar Cells: Status and Perspectives. Energy Environ. Sci. 2016, 9, 1552-1576. [CrossRef]

6. Poplawsky, J.D.; Guo, W.; Paudel, N.; Ng, A.; More, K.; Leonard, D.; Yan, Y. Structural and Compositional Dependence of the $\mathrm{CdTe}_{x} \mathrm{Se}_{1-x}$ Alloy Layer Photoactivity in CdTe-Based Solar Cells. Nat. Commun. 2016, 7, 12537. [CrossRef] [PubMed]

7. Darling, S.B.; You, F. The Case for Organic Photovoltaics. RSC Adv. 2013, 3, 17633-17648. [CrossRef]

8. Service, R.F. Outlook Brightens for Plastic Solar Cells. Science 2011, 332, 293. [CrossRef] [PubMed]

9. Kaltenbrunner, M.; White, M.S.; Głowacki, E.D.; Sekitani, T.; Someya, T.; Sariciftci, N.S.; Bauer, S. Ultrathin and Lightweight Organic Solar Cells with High Flexibility. Nat. Commun. 2012, 3, 770. [CrossRef] [PubMed]

10. Angmo, D.; Larsen-olsen, T.T.; Krebs, F.C. Roll-to-Roll Fabrication of Polymer Solar Cells As the Performance in Terms of Power Conversion Efficiency and Operational. Mater. Today 2012, 15, 36-49.

11. Wu, J.-S.; Cheng, S.-W.; Cheng, Y.-J.; Hsu, C.-S. Donor-Acceptor Conjugated Polymers Based on Multifused Ladder-Type Arenes for Organic Solar Cells. Chem. Soc. Rev. 2014, 44, 1113-1154. [CrossRef] [PubMed]

12. Youn, H.; Park, H.J.; Guo, L.J. Organic Photovoltaic Cells: From Performance Improvement to Manufacturing Processes. Small 2015, 11, 2228-2246. [CrossRef] [PubMed]

13. Brabec, C.; Scherf, U.; Dyakonov, V. Organic Photovoltaics: Materials, Device Physics, and Manufacturing Technologies, 2nd ed.; Willey: New York, NY, USA, 2014.

14. Liu, D.; Zhu, Q.; Gu, C.; Wang, J.; Qiu, M.; Chen, W.; Bao, X.; Sun, M.; Yang, R. High-Performance Photovoltaic Polymers Employing Symmetry-Breaking Building Blocks. Adv. Mater. 2016, 28, 8490-8498. [CrossRef] [PubMed]

15. Bin, H.; Gao, L.; Zhang, Z.; Yang, Y.; Zhang, Y.; Zhang, C.; Chen, S.; Xue, L.; Yang, C.; Xiao, M.; et al. 11.4\% Efficiency Non-Fullerene Polymer Solar Cells with Trialkylsilyl Substituted 2D-Conjugated Polymer as Donor. Nat. Commun. 2016, 7, 13651. [CrossRef] [PubMed]

16. Deng, D.; Zhang, Y.; Zhang, J.; Wang, Z.; Zhu, L.; Fang, J.; Xia, B.; Wang, Z.; Lu, K.; Ma, W.; et al. Fluorination-Enabled Optimal Morphology Leads to over 11\% Efficiency for Inverted Small-Molecule Organic Solar Cells. Nat. Commun. 2016, 7, 13740. [CrossRef] [PubMed]

17. Holliday, S.; Ashraf, R.S.; Wadsworth, A.; Baran, D.; Yousaf, S.A.; Nielsen, C.B.; Tan, C.; Dimitrov, S.D.; Shang, Z.; Gasparini, N.; et al. High-Efficiency and Air-Stable P3HT-Based Polymer Solar Cells with a New Non-Fullerene Acceptor. Nat. Commun. 2016, 7, 11585. [CrossRef] [PubMed]

18. Zhang, A.; Li, C.; Yang, F.; Zhang, J.; Wang, Z.; Wei, Z.; Li, W. An Electron Acceptor with Porphyrin and Perylene Bisimides for Efficient Non-Fullerene Solar Cells. Angew. Chem. Int. Ed. 2017, 56, 2694-2698. [CrossRef] [PubMed]

19. Nielsen, T.D.; Cruickshank, C.; Foged, S.; Thorsen, J.; Krebs, F.C. Solar Energy Materials \& Solar Cells Business, Market and Intellectual Property Analysis of Polymer Solar Cells. Sol. Energy Mater. Sol. Cells 2010, 94, 1553-1571.

20. The future is light: Organic solar film by Heliatek. Available online: http:/ / www.heliatek.com (accessed on 10 January 2017).

21. Konark.com. Available online: http:/ / www.konarka.com (accessed on 10 January 2017).

22. Tang, C.W. Two-Layer Organic Photovoltaic Cell. Appl. Phys. Lett. 1986, 48, 183-185. [CrossRef]

23. Kaur, N.; Singh, M.; Pathak, D.; Wagner, T.; Nunzi, J.M. Organic Materials for Photovoltaic Applications: Review and Mechanism. Synth. Met. 2014, 190, 20-26. [CrossRef]

24. Wohrle, B.D.; Meissner, D. Organic Solar Cells. Adv. Mater. 1991, 3, 129-138. [CrossRef] 
25. Halls, J.J.M.; Pichler, K.; Friend, R.H.; Moratti, S.C.; Holmes, A.B. Exciton Diffusion and Dissociation in a Poly(p-phenylenevinylene)/ $C_{60}$ Heterojunction Photovoltaic Cell. Appl. Phys. Lett. 2012, 68, 3120-3122. [CrossRef]

26. Peumans, P.; Forrest, S.R. Very-High-Efficiency Double-Heterostructure Copper Phthalocyanine $/ \mathrm{C}_{60}$ Photovoltaic Cells. Appl. Phys. Lett. 2001, 79, 126-128. [CrossRef]

27. Xue, J.; Uchida, S.; Rand, B.P.; Forrest, S.R. 4.2\% Efficient Organic Photovoltaic Cells with Low Series Resistances. Appl. Phys. Lett. 2004, 84, 3013-3015. [CrossRef]

28. Xue, J.; Rand, B.P.; Uchida, S.; Forrest, S.R. Mixed Donor-Acceptor Molecular Heterojunctions for Photovoltaic Applications. II. Device Performance. J. Appl. Phys. 2005, 12, 1249031-1249039. [CrossRef]

29. Fitzner, R.; Reinold, E.; Mishra, A.; Mena-osteritz, E.; Ziehlke, H.; Körner, C.; Leo, K.; Riede, M.; Weil, M.; Tsaryova, O.; et al. Dicyanovinyl-Substituted Oligothiophenes: Structure-Property Relationships and Application in Vacuum-Processed Small-Molecule Organic Solar Cells. Adv. Energy Mater. 2011, 21, 897-910. [CrossRef]

30. Lin, C.; Liu, S.; Lee, C.; Hunag, J.; Su, W.; Chiu, T.; Chen, C.; Lee, J. Open-Circuit Voltage and Efficiency Improvement of Subphthalocyanine-Based Organic Photovoltaic Device through Deposition Rate Control. Sol. Energy Mater. Sol. Cells 2012, 103, 69-75. [CrossRef]

31. Sariciftci, N.S.; Smilowitz, L.; Heeger, A.J.; Wudi, F. Photoinduced Electron Transfer from a Conducting Polymer to Buckminsterfullerene. Science 1988, 258, 1474-1476. [CrossRef] [PubMed]

32. Lehn, J.M. Cryptates: Inclusion Complexes of Macropolycyclic Receptor Molecules. Pure Appl. Chem. 1978, 50, 871-892. [CrossRef]

33. Steed, J.W.; Atwood, J.L. Supramolecular Chemistry; John Wiley and Sons Ltd.: London, UK, 2009.

34. Nernst, W. Verteilung eines Stoffes zwischen zwei Lösungsmitteln und zwischen Lösungsmittel und Dampfraum. Z. Phys. Chem. 1891, 8, 110-139. [CrossRef]

35. Jorgensen, W.L.; Pranata, J. Importance of Secondary Interactions in Triply Hydrogen Bonded Complexes: Guanine-Cytosine vs. Uracil-2,6-Diaminopyridine. J. Am. Chem. Soc. 2010, 112, 2008-2010. [CrossRef]

36. Pranata, J.; Wierschke, S.G.; Jorgensen, W.L. OPLS Potential Functions for Nucleotide Bases. Relative Association Constants of Hydrogen-Bonded Base Pairs in Chloroform. J. Am. Chem. Soc. 1991, 113, 2810-2819. [CrossRef]

37. Hunter, C.A.; Sanders, J.K.M. The Nature of Pi-Pi Interactions. J. Am. Chem. Soc. 1990, 112, 5525-5534. [CrossRef]

38. Demeshko, S.; Dechert, S.; Meyer, F. Anion- $\pi$ Interactions in a Carousel Copper(II)-Triazine Complex. J. Am. Chem. Soc. 2004, 126, 4508-4509. [CrossRef] [PubMed]

39. Chen, W.; Nikiforov, M.P.; Darling, S.B. Morphology Characterization in Organic and Hybrid Solar Cells. Energy Environ. Sci. 2012, 5, 8045-8074. [CrossRef]

40. Huang, Y.; Kramer, E.J.; Heeger, A.J.; Bazan, G.C. Bulk Heterojunction Solar Cells: Morphology and Performance Relationships. Chem. Rev. 2014, 114, 7006-7043. [CrossRef] [PubMed]

41. Bassani, D.M.; Jonusauskaite, L.; Lavie-cambot, A.; Mcclenaghan, N.D.; Pozzo, J.; Ray, D.; Vives, G. Harnessing Supramolecular Interactions in Organic Solid-State Devices: Current Status and Future Potential. Coord. Chem. Rev. 2010, 254, 2429-2445. [CrossRef]

42. Troshin, P.A.; Sariciftci, N.S. Supramolecular Chemistry for Organic Photovoltaics; John Wiley \& Sons, Ltd.: London, UK, 2012.

43. Broggi, A.; Tomasi, I.; Bianchi, L.; Marrocchi, A.; Vaccaro, L. Small Molecular Aryl Acetylenes: Chemically Tailoring High-Efficiency Organic Semiconductors for Solar Cells and Field-Effect Transistors. Chempluschem 2014, 79, 486-507. [CrossRef]

44. Haruk, A.M.; Mativetsky, J.M. Supramolecular Approaches to Nanoscale Morphological Control in Organic Solar Cells. Int. J. Mol. Sci. 2015, 16, 13381-13406. [CrossRef] [PubMed]

45. Lin, Y.; Li, Y.; Zhan, X. Small Molecule Semiconductors for High-Efficiency Organic Photovoltaics. Chem. Soc. Rev. 2012, 41, 4245-4272. [CrossRef] [PubMed]

46. Mishra, A.; Bäuerle, P. Small Molecule Organic Semiconductors on the Move: Promises for Future Solar Energy Technology. Angew. Chem. Int. Ed. Engl. 2012, 51, 2020-2067. [CrossRef] [PubMed]

47. Kan, B.; Li, M.; Zhang, Q.; Liu, F.; Wan, X.; Wang, Y.; Ni, W.; Long, G.; Yang, X.; Feng, H.; et al. A Series of Simple Oligomer-like Small Molecules Based on Oligothiophenes for Solution-Processed Solar Cells with High Efficiency. J. Am. Chem. Soc. 2015, 137, 3886-3893. [CrossRef] [PubMed] 
48. El-ghayoury, A.; Schenning, A.P.H.J.; van Hal, P.A.; van Duren, J.K.J.; Janssen, Â.A.J.; Meijer, E.W. Supramolecular Hydrogen-Bonded Oligo( $p$-Phenylene Vinylene) Polymers. Angew. Chem. Int. Ed. 2001, 40, 3660-3663. [CrossRef]

49. Huang, C.; Mcclenaghan, N.D.; Kuhn, A.; Hofstraat, J.W.; Bassani, D.M. Enhanced Photovoltaic Response in Hydrogen-Bonded All-Organic Devices. Org. Lett. 2005, 7, 3409-3412. [CrossRef] [PubMed]

50. Gupta, A.; Ali, A.; Bilic, A.; Gao, M.; Hegedus, K.; Singh, B.; Watkins, S.E.; Wilson, G.J.; Bach, U.; Evans, R.A. Absorption Enhancement of Oligothiophene Dyes through the Use of a Cyanopyridone Acceptor Group in Solution-Processed Organic Solar Cells. Chem. Commun. 2012, 48, 1889-1891. [CrossRef] [PubMed]

51. Kumar, R.J.; Subbiah, J.; Holmes, A.B. Enhancement of Efficiency in Organic Photovoltaic Devices Containing Self-Complementary Hydrogen-Bonding Domains. Beilstein J. Org. Chem. 2013, 9, 1102-1110. [CrossRef] [PubMed]

52. Aytun, T.; Barreda, L.; Ruiz-carretero, A.; Lehrman, J.A.; Stupp, S.I. Improving Solar Cell Efficiency through Hydrogen Bonding: Method for Tuning Active Layer Morphology. Chem. Mater. 2015, 27, 1201-1209. [CrossRef]

53. Yagai, S.; Suzuki, M.; Lin, X.; Gushiken, M.; Noguchi, T.; Karatsu, T.; Kitamura, A.; Saeki, A.; Seki, S.; Kikkawa, Y.; et al. Supramolecular Engineering of Oligothiophene Nanorods without Insulators: Hierarchical Association of Rosettes and Photovoltaic Properties. Chem. Eur. J. 2014, 20, 16128-16137. [CrossRef] [PubMed]

54. Ouchi, H.; Lin, X.; Kizaki, T.; Prabhu, D.D.; Silly, F.; Kajitani, T.; Fukushima, T.; Nakayama, K.; Yagai, S. Hydrogen-Bonded Oligothiophene Rosettes with a Benzodithiophene Terminal Unit: Self-Assembly and Application to Bulk Heterojunction Solar Cells. Chem. Commun. 2016, 52, 7874-7877. [CrossRef] [PubMed]

55. Liu, C.; Li, Y.; Li, C.; Li, W.; Zhou, C.; Liu, H.; Bo, Z.; Li, Y. New Methanofullerenes Containing Amide as Electron Acceptor for Construction Photovoltaic Devices. J. Phys. Chem. C 2009, 113, 21970-21975. [CrossRef]

56. Siram, R.B.K.; Tandy, K.; Horecha, M.; Formanek, P.; Stamm, M.; Gevorgyan, S.; Krebs, F.C.; Kiriy, A.; Meredith, P.; Burn, P.L.; et al. Synthesis and Self-Assembly of Donor-Acceptor-Donor Based Oligothiophenes and Their Optoelectronic Properties. J. Phys. Chem. C 2011, 115, 14369-14376. [CrossRef]

57. Siram, R.B.K.; Stephen, M.; Ali, F.; Patil, S. Investigation of Phase Separation in Bulk Heterojunction Solar Cells via Supramolecular Chemistry. J. Phys. Chem. C 2013, 117, 9129-9136. [CrossRef]

58. Kim, K.; Yu, H.; Kang, H.; Kang, D.J.; Cho, C.; Cho, H.; Oh, J.H.; Kim, B.J. Influence of Intermolecular Interactions of Electron Donating Small Molecules on Their Molecular Packing and Performance in Organic Electronic Devices. J. Mater. Chem. A 2013, 1, 14538-14547. [CrossRef]

59. Yassin, A.; Leriche, P.; Allain, M.; Roncali, J. Donor-acceptor-donor (D-A-D) Molecules Based on Isoindigo as Active Material for Organic Solar Cells. New J. Chem. 2013, 37, 502-507. [CrossRef]

60. Xiao, Z.; Sun, K.; Subbiah, J.; Ji, S.; Jones, D.J.; Wong, W.W.H. Hydrogen Bonding in Bulk Heterojunction Solar Cells: A Case Study. Sci. Rep. 2014, 4, 5701. [CrossRef] [PubMed]

61. Fechtenkötter, A.; Saalwächter, K.; Harbison, M.A.; Müllen, K.; Spiess, H.W. Highly Ordered Columnar Structures from Hexa-Peri-hexabenzocoronenes-Synthesis, X-ray Diffraction, and Solid-State Heteronuclear Multiple-Quantum NMR Investigations. Angew. Chem. Int. Ed. 1999, 38, 3039-3042. [CrossRef]

62. Schön, J.H.; Kloc, C.; Batlogg, B. Perylene: A Promising Organic Field-Effect Transistor Material. Appl. Phys. Lett. 2000, 77, 3776-3778. [CrossRef]

63. Schmidt-mende, L.; Fechtenkotter, A.; Mullen, K.; Moons, E.; Friend, R.H.; MacKenzie, J.D. Self-Organized Discotic Liquid Crystals for High-Efficiency Organic Photovoltaics. Science 2001, 293, 1119-1122. [CrossRef] [PubMed]

64. Bagnis, D.; Beverina, L.; Huang, H.; Silvestri, F.; Yao, Y.; Yan, H.; Pagani, G.A.; Marks, T.J.; Facchetti, A. Marked Alkyl- vs. Alkenyl-Substitutent Effects on Squaraine Dye Solid-State Structure, Carrier Mobility, and Bulk-Heterojunction Solar Cell Efficiency. J. Am. Chem. Soc. 2010, 132, 4074-4075. [CrossRef] [PubMed]

65. Lee, O.P.; Yiu, A.T.; Beaujuge, P.M.; Woo, C.H.; Holcombe, T.W.; Millstone, J.E.; Douglas, J.D.; Chen, M.S.; Fréchet, J.M.J. Efficient Small Molecule Bulk Heterojunction Solar Cells with High Fill Factors via Pyrene-Directed Molecular Self-Assembly. Adv. Mater. 2011, 23, 5359-5363. [CrossRef] [PubMed]

66. Ashraf, R.S.; Kronemeijer, J.; James, I.; Sirringhaus, H.; McCulloch, I. A New Thiophene Substituted Isoindigo Based Copolymer for High Performance Ambipolar Transistors. Chem. Commun. 2012, 48, 3939-3941. [CrossRef] [PubMed] 
67. Odajima, T.; Ashizawa, M.; Konosu, Y.; Matsumoto, H.; Mori, T. Impact of Molecular Planarity on Electronic Devices in Thienoisoindigo-Based Organic Semiconductors. J. Mater. Chem. C 2014, 2, 10455-10467. [CrossRef]

68. Liu, Z.; Wu, Y.; Zhang, Q.; Gao, X. Non-Fullerene Small Molecule Acceptors Based on Perylene Diimides. J. Mater. Chem. A 2016, 4, 17604-17622. [CrossRef]

69. Fernández-lázaro, F.; Zink-Lorre, N.; Sastre-Santos, A. Perylenediimides as Non-Fullerene Acceptors in Bulk-Heterojunction Solar Cells (BHJSCs). J. Mater. Chem. A 2016, 4, 9336-9346. [CrossRef]

70. Rajaram, S.; Shivanna, R.; Kandappa, S.K.; Narayan, K.S. Nonplanar Perylene Diimides as Potential Alternatives to Fullerenes in Organic Solar Cells. J. Phys. Chem. Lett. 2012, 3, 2405-2408. [CrossRef] [PubMed]

71. Jiang, W.; Ye, L.; Li, X.; Xiao, C.; Tan, F.; Zhao, W.; Hou, J.; Wang, Z. Bay-Linked Perylene Bisimides as Promising Non-Fullerene Acceptors for Organic Solar Cells. Chem. Commun. 2014, 50, 1024-1026. [CrossRef] [PubMed]

72. Hartnett, P.E.; Matte, R.H.S.S.; Eastham, N.D.; Jackson, N.E.; Wu, Y.; Chen, L.X.; Ratner, M.A.; Chang, R.P.H.; Hersam, M.C.; Wasielewski, M.R.; et al. Ring-Fusion as a Perylenediimide Dimer Design Concept for High-Performance Non-Fullerene Organic Photovoltaic Acceptors. Chem. Sci. 2016, 7, 3543-3555. [CrossRef]

73. Eaton, S.W.; Shoer, L.E.; Karlen, S.D.; Dyar, S.M.; Margulies, E.A.; Veldkamp, B.S.; Ramanan, C.; Hartzler, D.A.; Savikhin, S.; Marks, T.J.; et al. Singlet Exciton Fission in Polycrystalline Thin Films of a Slip-Stacked Perylenediimide. J. Am. Chem. Soc. 2013, 135, 14701-14712. [CrossRef] [PubMed]

74. Hartnett, P.E.; Timalsina, A.; Matte, H.S.S.R.; Zhou, N.; Guo, X.; Zhao, W.; Facchetti, A.; Chang, R.P.H.; Hersam, M.C.; Wasielewski, M.R.; et al. Slip-Stacked Perylenediimides as an Alternative Strategy for High Efficiency Nonfullerene Acceptors in Organic Photovoltaics. J. Am. Chem. Soc. 2014, 136, 16345-16356. [CrossRef] [PubMed]

75. Ghosh, T.; Gopal, A.; Saeki, A.; Seki, S.; Nair, V.C. p/n-Polarity of Thiophene Oligomers in Photovoltaic Cells: Role of Molecular vs. Supramolecular Properties. Phys. Chem. Chem. Phys. 2015, 17, 10630-10639. [CrossRef] [PubMed]

76. De Bettignies, R.; Nicolas, Y.; Blanchard, P.; Levillain, E.; Nunzi, J.-M.; Roncali, J. Planarized Star-Shaped Oligothiophenes as a New Class of Organic Semiconductors for Heterojunctions Solar Cell. Adv. Mater. 2003, 15, 1939-1943. [CrossRef]

77. Ripaud, E.; Rousseau, T.; Leriche, P.; Roncali, J. Unsymmetrical Triphenylamine-Oligothiophene Hybrid Conjugated Systems as Donor Materials for High-Voltage Solution-Processed Organic Solar Cells. Adv. Energy Mater. 2011, 1, 540-545. [CrossRef]

78. Aytun, T.; Santos, P.J.; Bruns, C.J.; Huang, D.; Koltonow, A.R.; Cruz, M.O.; Stupp, S.I. Self-Assembling Tripodal Small-Molecule Donors for Bulk Heterojunction Solar Cells. J. Phys. Chem. C 2016, 120, 3602-3611. [CrossRef]

79. Wurthner, F.; Bauer, C.; Stepanenko, V.; Yagai, S. A Black Perylene Bisimide Super Gelator with an Unexpected J-Type Absorption Band. Adv. Mater. 2008, 20, 1695-1698. [CrossRef]

80. Lindner, S.M.; Thelakkat, M. Nanostructures of N-Type Organic Semiconductor in a P-Type Matrix via Self-Assembly of Block Copolymers. Macromolecules 2004, 37, 8832-8835. [CrossRef]

81. Wicklein, A.; Ghosh, S.; Sommer, M.; Wurthner, F.; Thelakkat, M. Self-Assembly of Semiconductor Organogelator Nanowires for Photoinduced Charge Separation. ACS Nano 2009, 3, 1107-1114. [CrossRef] [PubMed]

82. Tsai, W.; Tevis, I.D.; Tayi, A.S.; Cui, H.; Stupp, S.I. Semiconducting Nanowires from Hairpin-Shaped Self-Assembling Sexithiophenes. J. Phys. Chem. B 2010, 114, 14778-14786. [CrossRef] [PubMed]

83. Tevis, I.D.; Tsai, W.; Palmer, L.C.; Aytun, T.; Stupp, S.I. Grooved Nanowires from Self-Assembling Hairpin Molecules for Solar Cells. ACS Nano 2012, 6, 2032-2040. [CrossRef] [PubMed]

84. Ruiz-carretero, A.; Aytun, T.; Bruns, C.J.; Newcomb, C.J.; Tsai, W.; Stupp, S.I. Stepwise Self-Assembly to Improve Solar Cell Morphology. J. Mater. Chem. A 2013, 1, 11674-11681. [CrossRef]

85. Lam, K.H.; Foong, T.; Ooi, Z.E.; Zhang, J.; Grimsdale, A.C.; Lam, Y.M. Enhancing the Performance of Solution-Processed Bulk- Heterojunction Solar Cells Using Hydrogen-Bonding-Induced Self-Organization of Small Molecules. ACS Appl. Mater. Interfaces 2013, 5, 13265-13274. [CrossRef] [PubMed] 
86. Kronenberg, N.M.; Deppisch, M.; Würthner, F.; Lademann, H.W.A.; Deing, K.; Meerholz, K. Bulk Heterojunction Organic Solar Cells Based on Merocyanine Colorants. Chem. Commun. 2008, 48, 6489-6491. [CrossRef] [PubMed]

87. Bürckstümmer, H.; Kronenberg, N.M.; Gsanger, M.; Stolte, M.; Meerholz, K.; Würthner, F. Tailored Merocyanine Dyes for Solution-Processed BHJ Solar Cells. J. Mater. Chem. 2010, 20, 240-243. [CrossRef]

88. Würthner, F.; Yao, S. Dipolar Dye Aggregates: A Problem for Nonlinear Optics, but a Chance for Supramolecular Chemistry. Angew. Chem. Int. Ed. 2000, 39, 1978-1981. [CrossRef]

89. Bürckstümmer, H.; Tulyakova, E.V.; Deppisch, M.; Lenze, M.R.; Kronenberg, N.M.; Gsänger, M.; Stolte, M.; Meerholz, K.; Würthner, F. Efficient Solution-Processed Bulk Heterojunction Solar Cells by Antiparallel Supramolecular Arrangement of Dipolar Donor-Acceptor Dyes. Angew. Chem. Int. Ed. 2011, 50, 11628-11632. [CrossRef] [PubMed]

90. Takacs, C.J.; Sun, Y.; Welch, G.C.; Perez, L.A.; Liu, X.; Wen, W.; Bazan, G.C.; Heeger, A.J. Solar Cell Efficiency, Self-Assembly, and Dipole-Dipole Interactions of Isomorphic Narrow-Bandgap Molecules. J. Am. Chem. Soc. 2012, 134, 16597-16606. [CrossRef] [PubMed]

91. Sun, Y.; Welch, G.C.; Leong, W.L.; Takacs, C.J.; Bazan, G.C.; Heeger, A.J. Solution-Processed Small-Molecule Solar Cells with 6.7\% Efficiency. Nat. Mater. 2012, 11, 44-48. [CrossRef] [PubMed]

92. Henson, Z.B.; Welch, G.C.; Poll, T.; Bazan, G.C. Pyridalthiadiazole-Based Narrow Band Gap Chromophores. J. Am. Chem. Soc. 2012, 134, 3766-3779. [CrossRef] [PubMed]

93. Welch, G.C.; Perez, L.A.; Hoven, C.V.; Zhang, Y.; Dang, X.; Sharenko, A.; Toney, M.F.; Kramer, E.J.; Nguyen, D.T.; Bazan, G.C. A Modular Molecular Framework for Utility in Small-Molecule Solution-Processed Organic Photovoltaic Devices. J. Mater. Chem. 2011, 21, 12700-12709. [CrossRef]

94. Shirakawa, H.; Louis, E.J.; Macdiarmid, A.G.; Chiang, C.K.; Heeger, A.J. Synthesis of Electrically Conducting Organic Polymers: Halogen Derivtives of Polyacetylene, $(\mathrm{CH})_{x}$. J. Chem. Soc. Chem. Commun. 1977, 16, 578-580. [CrossRef]

95. Liang, T.; Chiang, I.; Yang, P.; Kekuda, D.; Chu, C.; Lin, H. Supramolecular Assembly of H-Bonded Side-Chain Polymers Containing Conjugated Pyridyl H-Acceptor Pendants and Various Low-Band-Gap H-Donor Dyes Bearing Cyanoacrylic Acid Groups for Organic Solar Cell Applications. J. Polym. Sci. Part A Polym. Chem. 2009, 47, 5998-6013. [CrossRef]

96. Sahu, D.; Padhy, H.; Patra, D.; Kekuda, D.; Chu, C.; Chiang, I.; Lin, H. Synthesis and Application of H-Bonded Cross-Linking Polymers Containing a Conjugated Pyridyl H-Acceptor Side-Chain Polymer and Various Carbazole-Based H-Donor Dyes Bearing Symmetrical Cyanoacrylic Acids for Organic Solar Cells. Polymer 2010, 51, 6182-6192. [CrossRef]

97. Yao, K.; Chen, L.; Li, F.; Wang, P.; Chen, Y. Cooperative Assembly Donor À Acceptor System Induced by Intermolecular Hydrogen Bonds Leading to Oriented Nanomorphology for Optimized Photovoltaic Performance. J. Phys. Chem. C 2012, 116, 714-721. [CrossRef]

98. Nakabayashi, K.; Mori, H. Donor-Acceptor Block Copolymers: Synthesis and Solar Cell Applications. Materials 2014, 7, 3274-3290. [CrossRef]

99. Lee, Y.; Gomez, E.D. Challenges and Opportunities in the Development of Conjugated Block Copolymers for Photovoltaics. Macromolecules 2015, 48, 7385-7395. [CrossRef]

100. Topham, P.D.; Parnell, A.J.; Hiorns, R.C. Block Copolymer Strategies for Solar Cell Technology. J. Polym. Sci. Part B Polym. Phys. 2011, 49, 1131-1156. [CrossRef]

101. Darling, S.B. Block Copolymers for Photovoltaics. Energy Environ. Sci. 2009, 2, 1266-1273. [CrossRef]

102. Lin, Y.; Verduzco, R. Synthesis and Process-Dependent Film Structure of All-Conjugated Copolymers for Organic Photovoltaics; ACS Symposium Series; American Chemical Society: Washington, DC, USA, 2014.

103. Kipp, D.; Verduzco, R.; Ganesan, V. Block Copolymer Compatibilizers for Ternary Blend Polymer Bulk Heterojunction Solar Cells-An Opportunity for Computation Aided Molecular Design. Mol. Syst. Des. Eng. 2016, 1, 353-369. [CrossRef]

104. Janssen, G.; Aguirre, A.; Goovaerts, E.; Vanlaeke, P.; Poortmans, J.; Manca, J. Optimization of Morphology of P3HT/PCBM Films for Organic Solar Cells: Effects of Thermal Treatments and Spin Coating Solvents. Eur. Phys. J. Appl. Phys. 2007, 37, 287-290. [CrossRef]

105. Lin, Y.; Lim, J.A.; Wei, Q.; Mannsfeld, S.C.B.; Briseno, A.L.; Watkins, J.J. Cooperative Assembly of Hydrogen-Bonded Diblock Copolythiophene/Fullerene Blends for Photovoltaic Devices with Well-Defined Morphologies and Enhanced Stability. Chem. Mater. 2012, 24, 622-632. [CrossRef] 
106. Patra, D.; Ramesh, M.; Sahu, D.; Padhy, H.; Chu, C.; Wei, K.; Lin, H. Enhancement of Photovoltaic Properties in Supramolecular Polymer Networks Featuring a Solar Cell Main-Chain Polymer H-Bonded with Conjugated Cross-Linkers. Polymer 2012, 53, 1219-1228. [CrossRef]

107. Li, F.; Yager, K.G.; Dawson, N.M.; Yang, J.; Malloy, K.J.; Qin, Y. Complementary Hydrogen Bonding and Block Copolymer Self-Assembly in Cooperation toward Stable Solar Cells with Tunable Morphologies. Macromolecules 2013, 46, 9021-9031. [CrossRef]

108. Guo, C.; Lin, Y.; Witman, M.D.; Smith, K.A.; Wang, C.; Hexemer, A.; Strzalka, J.; Gomez, E.D.; Verduzco, R. Conjugated Block Copolymer Photovoltaics with near 3\% Efficiency through Microphase Separation. Nano Lett. 2013, 13, 2957-2963. [CrossRef] [PubMed]

109. Kipp, D.; Mok, J.; Strzalka, J.; Darling, S.B.; Ganesan, V.; Verduzco, R. Rational Design of Thermally Stable, Bicontinuous Donor/Acceptor Morphologies with Conjugated Block Copolymer Additives. ACS Macro Lett. 2015, 4, 867-871. [CrossRef]

110. Mok, J.W.; Lin, Y.; Yager, K.G.; Mohite, A.D.; Nie, W.; Darling, S.B.; Lee, Y.; Gomez, E.; Gosztola, D.; Schaller, R.D.; et al. Linking Group Influences Charge Separation and Recombination in All-Conjugated Block Copolymer Photovoltaics. Adv. Funct. Mater. 2015, 25, 5578-5585. [CrossRef]

111. Smith, K.A.; Lin, Y.; Mok, J.W.; Yager, K.G.; Strzalka, J.; Nie, W.; Mohite, A.D.; Verduzco, R. Molecular Origin of Photovoltaic Performance in Donor-Block-Acceptor All-Conjugated Block Copolymers. Macromolecules 2015, 48, 8346-8353. [CrossRef]

112. Guo, C.; Lee, Y.; Lin, Y.; Strzalka, J.; Wang, C.; Hexemer, A.; Jaye, C.; Fischer, D.A.; Verduzco, R.; Wang, Q.; et al. Photovoltaic Performance of Block Copolymer Devices Is Independent of the Crystalline Texture in the Active Layer. Macromolecules 2016, 49, 4599-4608. [CrossRef]

113. Mok, J.W.; Kipp, D.; Hasbun, L.R.; Dolocan, A.; Strzalka, J.; Ganesan, V.; Verduzco, R. Parallel Bulk Heterojunction Photovoltaics Based on All-Conjugated Block Copolymer Additives. J. Mater. Chem. A 2016, 4, 14804-14813. [CrossRef]

114. Lin, Y.; Nie, W.; Tsai, H.; Li, X.; Gupta, G.; Mohite, A.D.; Verduzco, R. Supramolecular Block Copolymer Photovoltaics through Ureido-Pyrimidinone Hydrogen Bonding Interactions. RSC Adv. 2016, 6, 51562-51568. [CrossRef]

115. Shen, P.; Sang, G.; Lu, J.; Zhao, B.; Wan, M.; Zou, Y.; Li, Y.; Tan, S. Effect of 3D Pi-Pi Stacking on Photovoltaic and Electroluminescent Properties in Triphenylamine-Containing Poly( $p$-phenylenevinylene) Derivatives. Macromolecules 2008, 41, 5716-5722. [CrossRef]

116. Yang, X.; Wang, J.; Zhang, X.; Wang, Z.; Wang, Y. STM Study on 2D Molecular Assemblies of Luminescent Quinacridone Derivatives: Structure Fine-Tuned by Introducing Bulky Substitutes and Co-Adsorption with Monofunctional/Bifunctional Acid. Langmuir 2007, 23, 1287-1291. [CrossRef] [PubMed]

117. Jun, H.; Hun, D.; Hee, M.; Won, S.; Young, J.; Yong, J.; Kyung, D. Self-Organization Polymer Consisting of Quinacridone and Quaterthiophene Units: Coplanar Structure between Benzene and Thiophene Linkage. Sol. Energy Mater. Sol. Cells 2013, 117, 285-292.

118. Liao, S.; Jhuo, H.; Cheng, Y.; Chen, S. Fullerene Derivative-Doped Zinc Oxide Nanofilm as the Cathode of Inverted Polymer Solar Cells with Low-Bandgap Polymer (PTB7-Th) for High Performance. Adv. Mater. 2013, 25, 4766-4771. [CrossRef] [PubMed]

119. Mori, D.; Benten, H.; Okada, I.; Ohkita, H.; Ito, S. Low-Bandgap Donor/Acceptor Polymer Blend Solar Cells with Efficiency Exceeding 4\%. Adv. Energy Mater. 2013, 4, 1-6. [CrossRef]

120. Kang, H.; Kim, K.; Choi, J.; Lee, C.; Kim, B.J. High-Performance All-Polymer Solar Cells Based on Face-On Stacked Polymer Blends with Low Interfacial Tension. ACS Macro Lett. 2014, 3, 1009-1014. [CrossRef]

121. Schubert, M.; Dolfen, D.; Frisch, J.; Roland, S.; Steyrleuthner, R.; Stiller, B.; Chen, Z.; Scherf, U.; Koch, N.; Facchetti, A.; et al. Influence of Aggregation on the Performance of All-Polymer Solar Cells Containing Low-Bandgap Naphthalenediimide Copolymers. Adv. Energy Mater. 2012, 2, 369-380. [CrossRef]

(C) 2017 by the authors. Licensee MDPI, Basel, Switzerland. This article is an open access article distributed under the terms and conditions of the Creative Commons Attribution (CC BY) license (http:/ / creativecommons.org/licenses/by/4.0/). 